\title{
ATTACHMENT TO THE THERAPY GROUP AS PREDICTOR OF TREATMENT OUTCOMES IN WOMEN WITH BINGE-EATING DISORDER
}

\author{
by \\ Leah Keating \\ A thesis submitted to \\ the Faculty of Graduate and Postdoctoral Affairs \\ in partial fulfillment of the requirements for the degree of \\ Master of Arts \\ in \\ Psychology \\ Carleton University \\ Ottawa, Canada \\ (C)2012 Leah Keating
}


Library and Archives

Canada

Published Heritage

Branch

395 Wellington Street

Ottawa ON K1A ON4

Canada
Bibliothèque et

Archives Canada

Direction du

Patrimoine de l'édition

395 , rue Wellington

Ottawa ON K1A ON4

Canada
Your file Votre référence

ISBN: 978-0-494-93597-2

Our file Notre référence

ISBN: $978-0-494-93597-2$
NOTICE:

The author has granted a nonexclusive license allowing Library and Archives Canada to reproduce, publish, archive, preserve, conserve, communicate to the public by telecommunication or on the Internet, loan, distrbute and sell theses worldwide, for commercial or noncommercial purposes, in microform, paper, electronic and/or any other formats.

The author retains copyright ownership and moral rights in this thesis. Neither the thesis nor substantial extracts from it may be printed or otherwise reproduced without the author's permission.
AVIS:

L'auteur a accordé une licence non exclusive permettant à la Bibliothèque et Archives Canada de reproduire, publier, archiver, sauvegarder, conserver, transmettre au public par télécommunication ou par l'Internet, prêter, distribuer et vendre des thèses partout dans le monde, à des fins commerciales ou autres, sur support microforme, papier, électronique et/ou autres formats.

L'auteur conserve la propriété du droit d'auteur et des droits moraux qui protege cette thèse. $\mathrm{Ni}$ la thèse ni des extraits substantiels de celle-ci ne doivent être imprimés ou autrement reproduits sans son autorisation.
In compliance with the Canadian Privacy Act some supporting forms may have been removed from this thesis.

While these forms may be included in the document page count, their removal does not represent any loss of content from the thesis.
Conformément à la loi canadienne sur la protection de la vie privée, quelques formulaires secondaires ont été enlevés de cette thèse.

Bien que ces formulaires aient inclus dans la pagination, il n'y aura aucun contenu manquant. 


\title{
GROUP ATTACHMENT
}

\begin{abstract}
Binge-eating disorder is characterized by overeating and loss of control, and negatively impacts physical and mental health. To enhance treatment outcomes for this disorder, this study examines: the psychometric properties of the Social Group Attachment Scale in women with binge-eating disorder, whether attachment to the therapy group can change during treatment, and whether such changes predict improvements in treatment outcomes. Eighty-seven women with binge-eating disorder received 16 sessions of group psychodynamic interpersonal psychotherapy. Two conditions were homogeneously composed of women either higher or lower in pretreatment individual attachment anxiety. The Social Group Attachment Scale showed evidence of convergent validity. Group attachment insecurity decreased significantly during treatment, and reductions in group attachment avoidance predicted reductions in individual attachment insecurity at 12 months posttreatment. These results indicate that women with binge-eating disorder who receive group psychodynamic interpersonal psychotherapy are able to generalize improvements in attachment security to their relationships outside of therapy. Keywords: binge-eating disorder, group attachment, group processes, change in attachment
\end{abstract}


GROUP ATTACHMENT

\section{Acknowledgements}

I would like thank everyone who assisted me in carrying out this project. I would like to thank my supervisor, Dr. Giorgio Tasca, and my co-supervisor, Dr. Mary Gick, for their support and guidance. Their expertise and diligence have made me a better researcher, and it is truly an honour to have had the opportunity to work with such committed supervisors. I am also grateful to my committee members, Dr. Anne Bowker, Dr. Cheryl Harasymchuk, and Dr. Cecilia Taiana, for their feedback. Thank you to the research coordinators at the Centre for Eating Disorders Research, Anne Trinneer and Ann Barber, for their assistance and attention to detail. Thank you to my colleague, Hilary Maxwell, for providing me with so many statistical resources and for being such an exceptional role model. I would like to thank my partner, Nina, for encouraging me to pursue a career in psychology and for her endless support. Thank you to my Uncle Arthur and Aunt Maureen for their positivity and patience, and to my Nana for modeling hard work and dedication. Finally, I am thankful to my parents for modeling integrity and perseverance, and for continuously inspiring me to follow my dreams. 


\section{Table of Contents}

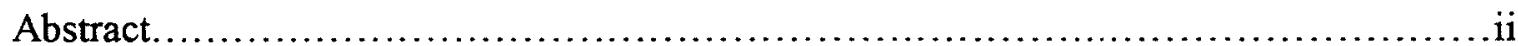

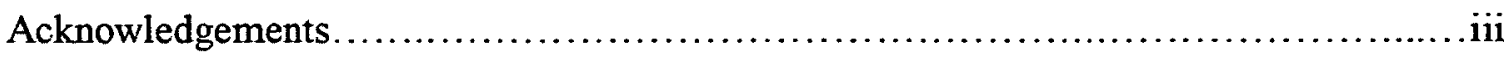

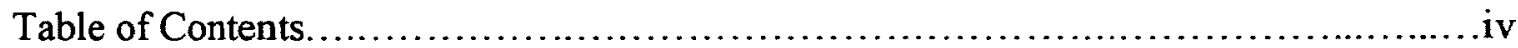

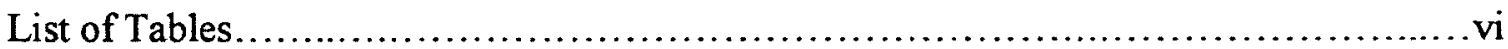

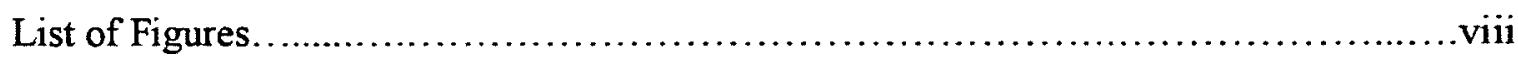

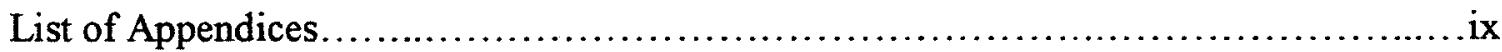

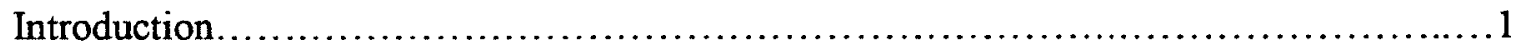

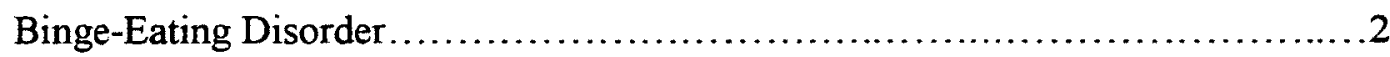

Attachment Theory.................................................. 10

Attachment, Interpersonal Problems, and Eating Disorders......................14

Attachment and Group Processes........................................ 17

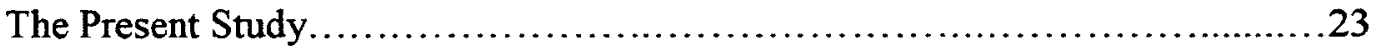

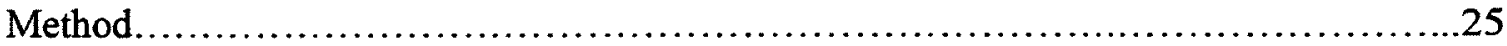

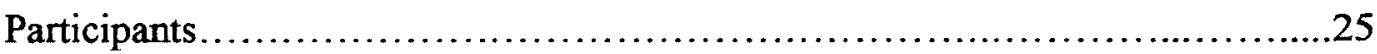

Measures......................................................... 27

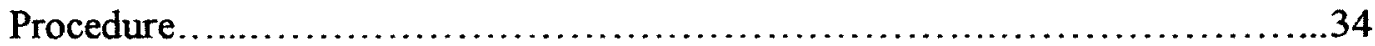

Group Psychodynamic Interpersonal Psychotherapy...........................39

Results................................................................ 41

Data Screening Procedures........................................... 41

Comparison of Attachment Anxiety Conditions...............................49

Hypothesis Test Results...........................................49

Convergent Validity of the Social Group Attachment Scale......................49 


\section{GROUP ATTACHMENT}

Group Attachment Avoidance as a Predictor of Dropout.....................55

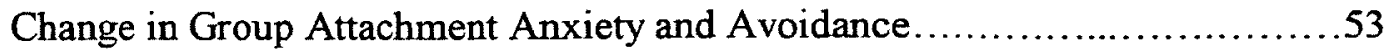

Change in Group Attachment Anxiety and Avoidance as a Predictor of

Treatment Outcomes..................................................... 56

Moderating Effects of Individual Attachment Anxiety........................59

Discussion. ...........................................................

Convergent Validity of the Social Group Attachment Scale...................62

Group Attachment Avoidance as a Predictor of Dropout.......................66

Change in Group Attachment Anxiety and Avoidance .....................67

Change in Group Attachment Anxiety and Avoidance as a Predictor of

Treatment Outcomes........................................................ 70

Moderating Effects of Individual Attachment Anxiety...................... 73

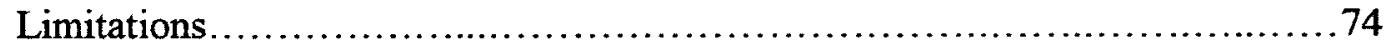

Clinical Implications and Conclusions......................................76

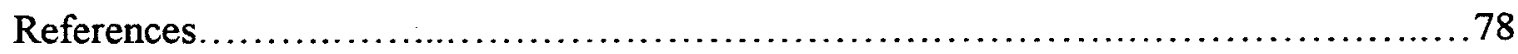

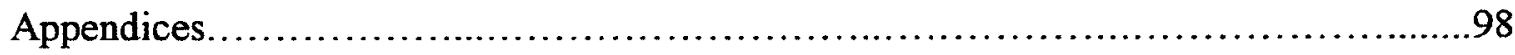


GROUP ATTACHMENT

\section{List of Tables}

Table 1: Pretreatment Demographics by Condition................................26

Table 2: Measures of Internal Consistency for the Attachment Styles Questionnaire......32

Table 3: Number of Cases Missing Data on the Variables Studied....................43

Table 4: Normality Statistics and Outliers for Each Variable in the Study $\ldots \ldots \ldots \ldots \ldots \ldots . . . .46$

Table 5: Comparison of Higher and Lower Attachment Anxiety Conditions on

Attachment.

Table 6: Correlations (and $p$ Values) Used to Assess the Convergent Validity of the

Social Group Attachment Scale.

Table 7: Hierarchical Multiple Regression Analysis Predicting Week 4 Group

Engagement from Pretreatment Individual Attachment and Week 4 Group

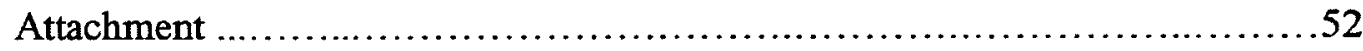

Table 8: Multilevel Models Used to Test Hypotheses 2, 3, 4, and 5.

Table 9: Results of Model Predicting Treatment Dropout from Week 4 Group

Attachment Avoidance and Pretreatment Individual Attachment Avoidance...55

Table 10: Fixed and Random Effects Estimates for Models of Change in Group Attachment Anxiety and Avoidance During Treatment.

Table 11: Fixed and Random Effects Estimates for Models of Change in Treatment

Outcomes Between Pretreatment and 12 Months Posttreatment

Table 12: Fixed and Random Effects for Models Predicting Pretreatment to 12

Months Posttreatment Change in Treatment Outcomes from Change in Group

Attachment .58

Table 13: Fixed and Random Effects for Models Evaluating the Moderating Effect

vi 


\section{GROUP ATTACHMENT}

of Attachment Anxiety Condition on the Relationship Between Change in Group Attachment Anxiety and Change in Treatment Outcomes..............61

Table 14: Fixed and Random Effects for Models Evaluating the Moderating Effect of Individual Attachment Anxiety Condition on the Relationship Between Change in Group Attachment Avoidance and Change in Treatment

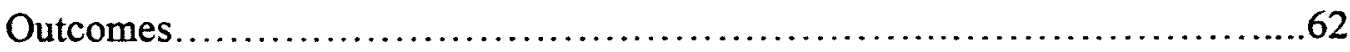


GROUP ATTACHMENT

\section{List of Figures}

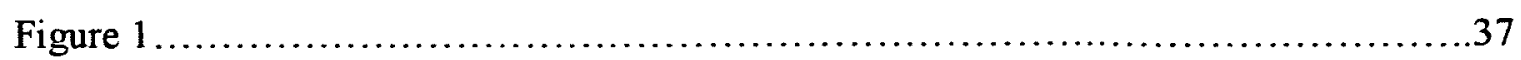


GROUP ATTACHMENT

List of Appendices

Appendix A: DSM-IV-TR Diagnostic Criteria for Binge-Eating Disorder. .98

Appendix B: Measures ........................................................

Appendix C: Proration Decisions............................................ 111

Appendix D: Explication of Multiple Imputation................................113

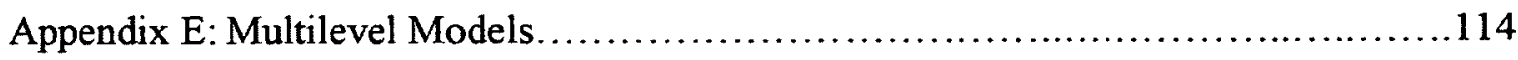

Appendix F: Explication of Multilevel Modeling.................................118

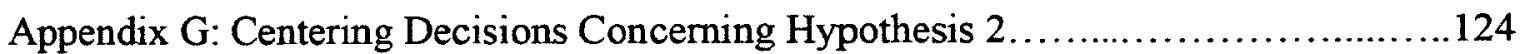


Attachment to the Therapy Group as a Predictor of Treatment Outcomes in Women with Binge-Eating Disorder

Individuals with binge-eating disorder engage in episodes of eating extremely large amounts of food with a subjective sense of loss of control (i.e., a binge), and these episodes are accompanied by significant distress (American Psychiatric Association [APA], 2000). Research has indicated that psychotherapy is moderately effective in alleviating the symptoms of binge-eating disorder. In a recent meta-analysis, receiving psychotherapy substantially increased the odds of participants achieving abstinence from binge eating, as evidenced by the odds ratio of 6.83 (Vocks et al., 2010). As discussed below, findings support the effectiveness of cognitive-behavioural therapy, interpersonal therapies, dialectical behaviour therapy, and group psychodynamic interpersonal psychotherapy for the treatment of binge-eating disorder (Tasca, Ritchie et al., 2006; Tasca et al., 2012; Telch, Agras, \& Linehan, 2001; Wilfley et al., 2002; Wilson et al., 2007). However, posttreatment rates of abstinence from binge eating are inconsistent, ranging from $25 \%$ to $89 \%$, and tend to decrease at follow-up assessments (de Zwaan et al., 2005; Eldredge et al., 1997; Tasca, Ritchie, et al.; Tasca et al.; Telch et al.; Vocks et al.; Wilfley et al.). Additionally, effect sizes for the influence of psychotherapy on reductions in depressive symptoms in individuals with binge-eating disorder tend to be small (Vocks et al.).

To enhance treatment outcomes for individuals with binge-eating disorder, researchers have examined participant characteristics such as attachment anxiety and group processes that predict reductions in target symptoms. As discussed below, the 
relationship between attachment anxiety and number of days binged in women with binge-eating disorder depended on treatment modality (Tasca, Ritchie et al., 2006). Further, in women who attended group psychodynamic interpersonal psychotherapy, attachment anxiety moderated the relationship between growth in group therapy alliance and number of days binged such that growth in group therapy alliance predicted improved binge eating at posttreatment for those higher in attachment anxiety but not for those lower in attachment anxiety (Tasca et al., 2012). Moreover, growth in engagement with the therapy group partially mediated the relationship between attachment anxiety and reductions in number of days binged (Tasca, Balfour, Ritchie, \& Bissada, 2006), and pretreatment attachment anxiety was associated with growth in the therapeutic alliance for participants who received group psychodynamic interpersonal psychotherapy but not group cognitive-behavioural therapy (Tasca, Balfour, Ritchie, \& Bissada, 2007b).

Attachment to the therapy group (Smith, Murphy, \& Coats, 1999) is a newer concept that may also predict treatment outcomes for individuals with binge-eating disorder. I assessed the role of this construct in women who attended group psychodynamic interpersonal psychotherapy for binge-eating disorder. Understanding patients' attachment to their therapy groups may enhance treatment outcomes for these individuals.

\section{Binge-Eating Disorder}

Binge eating in individuals with binge-eating disorder is frequently accompanied by rapid eating, eating when not physically hungry, eating until feeling uncomfortably full, and feelings of embarrassment and disappointment concerning the quantity of food 
that one has eaten (APA, 2000). For an individual to meet criteria for binge-eating disorder, episodes of binge eating must occur on average at least 2 days per week, every week for the past 6 months (APA, 2000; see Appendix A).

Prevalence of binge-eating disorder. Binge-eating disorder is the most common eating disorder (APA, 2000; Hudson, Hiripi, Pope, \& Kessler, 2007). In a sample of 1,501 Canadian women aged 20 to 40 years who were questioned about their eating behaviours in the past 28 days, $3.8 \%$ of participants met criteria for binge-eating disorder based on criteria in the Diagnostic and Statistical Manual of Mental Disorders (DSM-IV$T R$; APA, 2000) and using the Eating Disorder Examination Interview (Fairburn \& Beglin, 1994; Gauvin, Steiger, \& Brodeur, 2009). Research has indicated similar prevalence rates in the United States. A nationally representative survey of 2,980 American respondents indicated that $3.5 \%$ of women met criteria for binge-eating disorder over a 3-month period based on criteria in the World Health Organization Composite International Diagnostic Interview, a face-to-face household interview of the prevalence of mental disorders (Hudson et al.; Kessler \& Merikangas, 2004). However, the prevalence of binge-eating disorder was $6.6 \%$ in a study that used a self-report measure (Grucza, Przybeck, \& Cloninger, 2007). While Favaro, Ferrara, and Santonastaso (2003) reported a lifetime prevalence of $0.6 \%$ for binge-eating disorder in women aged 18 to 25 , research has indicated that the mean age of onset for binge-eating disorder is approximately 25 years and that the prevalence of binge-eating disorder increases from late adolescence and peaks in individuals aged 46 to 55 (Hudson et al:; Johnson, Spitzer, \& Williams, 2001). Research has indicated that binge-eating disorder is 
significantly more common in women than men. Reichborn-Kjennerud, Bulik, Sullivan, Tambs, and Harris (2004) found that the prevalence was $3.8 \%$ in men and $5.2 \%$ in women, and Hudson and colleagues found that the prevalence was $2.0 \%$ in men and $3.5 \%$ in women. However, Grucza and colleagues (2007) did not find significant gender differences in the prevalence of binge-eating disorder.

Psychological correlates of binge-eating disorder. Compared to individuals who do not binge eat, those who engage in binge eating tend to experience lower mentalhealth related quality of life, anxiety disorders, major depressive disorder, alcohol dependence, suicide attempts, poor social functioning, and lower self-esteem (Bulik, Sullivan, \& Kendler, 2002; Grucza et al., 2007; Hudson et al., 2007; Johnson et al., 2001). Telch and Stice (1998) found that $59 \%$ of individuals with binge-eating disorder had a lifetime history of an Axis I disorder and that $49 \%$ had a lifetime history of depression. These high comorbidity rates suggest that binge eating regulates mood in individuals prone to experiencing negative affect (Bulik et al.).

Medical correlates of binge-eating disorder. Binge eating has been associated with lower health-related quality of life, disability, and gastrointestinal and respiratory problems (Bulik et al., 2002; Grenon et al., 2010; Johnson et al., 2001). Negative affect may partially account for these health problems. Compared to participants without psychiatric disorders, women with binge-eating disorder reported more visits to physicians in the past 3 months and were more likely to describe their health as poor, but this relationship was no longer significant after controlling for anxiety and affective disorders (Johnson et al.). Similarly, depressive symptoms predicted lower health-related 
quality of life in women with binge-eating disorder, controlling for age and body mass index (BMI; $\mathrm{kg} / \mathrm{m}^{2}$; Grenon et al.). Binge-eating disorder is also associated with obesity, defined as having a BMI above 30 (Wang, McPherson, Marsh, Gortmaker, \& Brown, 2011). Obesity rates were significantly higher for participants with binge-eating disorder (69.5\%) than for those without binge-eating disorder (29.5\%; Grucza et al., 2007), and half of women with binge-eating disorder had an obesity-related medical condition (Grenon et al.). Obesity has been associated with health problems such as type II diabetes, cardiovascular diseases, asthma, and cancer (Guh et al., 2009; Renehan, Tyson, Egger, Heller, \& Zwahlen, 2009).

Economic correlates of binge-eating disorder. The economic burden of bingeeating disorder and obesity is also substantial. Grenon and colleagues (2010) found that annual health care costs incurred by women seeking treatment for binge-eating disorder were $36.45 \%$ higher than the costs of age-matched norms for women, and that depressive symptoms in these women were positively associated with use of medications (other than antidepressants) controlling for age and BMI. Obesity accounted for $0.7 \%$ to $2.8 \%$ of countries' total health care expenditures, and the medical costs of obese individuals were $30 \%$ greater than those of individuals with a BMI under 25 (Withrow \& Alter, 2011). Given the negative correlates of binge-eating disorder, further research on the treatment of binge-eating disorder is warranted.

Treatments for binge-eating disorder. Research has indicated that several treatments are moderately effective in alleviating the symptoms of binge-eating disorder. Mindfulness-based therapies such as a meditation-based intervention and dialectical 
behaviour therapy (focused on teaching affective regulation skills) have evidenced efficacy in reducing binge frequency but have yielded mixed results regarding reductions in depressive symptoms (Kristeller \& Hallett, 1999; Telch et al., 2001). Group cognitivebehavioural therapy (focused on behavioural strategies, cognitive skills, and relapse prevention) is also efficacious in the treatment of binge-eating disorder. In one randomized control trial, 12-week group cognitive-behavioural therapy demonstrated efficacy in reducing number of days binged, and in those who were unable to obtain clinically significant improvement (operationalized as abstinence from binge eating in the past 4 weeks), receiving 12 more weeks of group cognitive-behavioural therapy significantly enhanced rates of improvement (Eldredge et al., 1997). While both group cognitive-behavioural therapy and group interpersonal therapy (focused on grief, role disputes and transitions, and interpersonal deficits) have shown efficacy in reducing eating pathology and depressive symptoms in individuals with binge-eating disorder (Wilfley et al., 2002), the two treatment modalities do not appear to target different patient groups. That is, after attending group cognitive-behavioural therapy, those who did not obtain clinically significant improvements did not experience further improvements after being subsequently allocated to group interpersonal therapy (Agras et al., 1995).

Psychodynamic therapies (focused on the influence of interpersonal distress on negative affect and subsequently on binge eating) may be particularly helpful for patients who are higher in attachment anxiety. Tasca, Ritchie and colleagues (2006) randomized women with binge-eating disorder to a control condition, group cognitive-behavioural 
therapy, or group psychodynamic interpersonal psychotherapy (focused on selfreflection, affective expression, and interpersonal exploration). The two treatment conditions performed equally well. Compared to participants in the control condition, those who received group cognitive-behavioural therapy or group psychodynamic interpersonal psychotherapy experienced significantly greater improvements in number of days binged, depressive symptoms, interpersonal problems, and hunger. Further, participants who received group psychodynamic interpersonal psychotherapy experienced significantly greater increases in self-esteem than participants who received group cognitive-behavioural therapy and who were in the control group (Tasca, Ritchie et al., 2006). These improvements were maintained at 12 months follow-up. While the two treatments did not differ in their effects on most outcome variables, there was a significant aptitude by treatment interaction. For participants who completed group psychodynamic interpersonal psychotherapy, higher attachment anxiety predicted greater improvements in number of days binged between pre- and posttreatment. For participants who completed group cognitive-behavioural therapy, lower attachment anxiety predicted greater improvements in number of days binged between pre- and posttreatment (Tasca, Ritchie et al.). These results are consistent with the recommendation for research on client characteristics that predict treatment outcomes (Castonguay, Eldredge, \& Agras, 1995). Research has supported the effectiveness of other psychodynamic treatments for binge-eating disorder, as participants who received group-analytic psychotherapy experienced significant improvements in frequency of binge episodes and interpersonal communication, and these improvements were maintained at 12 months follow-up 
(Ciano, Rocco, Angarano, Biasin, \& Balestrieri, 2002).

\section{Negative affect and interpersonal problems as predictors of binge eating.}

While several treatments appear to be effective for binge-eating disorder, further research is needed on factors that contribute to the etiology and maintenance of the disorder, and on client characteristics that predict and facilitate treatment outcomes (Castonguay et al., 1995). Interpersonal problems that lead to negative affect may be one such factor.

Research has indicated that negative social interactions predict deteriorations in mood in patients with bulimia nervosa (Steiger, Gauvin, Jabalpurwala, Séguin, \& Stotland, 1999) and according to the affect regulation model, negative affect precedes binge eating, which in turn temporarily reduces negative affect (Deaver, Miltenberger, Smyth, Meidinger, \& Crosby, 2003). Research has indicated that negative affect is a frequent antecedent to binge eating, that negative affect decreases during binge episodes, and that relief from negative affect is a frequent consequence of binge eating (Deaver et al.; Stickney, Miltenberger, \& Wolff, 1999). Further, negative affect tends to be more severe before, during, and after binge episodes than in similar time periods for regular meals, indicating that individuals binge eat when they experience negative affect and eat regular meals when they feel neutral (Deaver et al.), and that negative reinforcement maintains binge eating (Stickney et al.).

According to the interpersonal model of binge eating, negative affect results from interpersonal disturbances and leads individuals to binge eat (Wilfley et al., 1993). Similarly, Heatherton and Baumeister (1991) postulated that individuals who engage in binge eating are sensitive to others' demands and that when they are unable to meet such 
demands, they become preoccupied with negative views of the self as inadequate and with others' perceptions of the self. Individuals may binge eat to escape from the negative affect that accompanies such aversive self-awareness, thereby focusing their attention on food and avoiding more distressing issues (Heatherton \& Baumeister, 1991). Research by Ansell, Grilo, and White (2012) provides support for this model. Negative affect significantly mediated the relationship between interpersonal problems and binge eating, loss of control over binge eating, and eating disorder pathology in women from a community sample. Negative affect also mediated the relationship between low affiliation (greater coldness) and binge eating and eating disorder pathology (Ansell et al., 2012). Moreover, participants with binge-eating disorder rated interpersonal factors, mood, and cognitions as significantly more influential than physiological factors in influencing binge eating (Arnow, Kenardy, \& Agras, 1992).

Insecure attachment (described below), through its influence on emotional reactivity, hypersensitivity, and self-distancing (Wei, Vogel, Ku, \& Zakalik, 2005), is one factor that may cause interpersonal distress in individuals with binge-eating disorder. Research has indicated that attachment insecurity is associated with interpersonal distress, affective underregulation, and dysregulation; and that differences in interpersonal patterns can be attributed to differences in the expression of and responsiveness to affect (Bartholomew \& Horowitz, 1991; Fuendeling, 1998; Kobak \& Screery, 1998). Wei and colleagues (2005) found that attachment insecurity was associated with negative mood and interpersonal problems, and that these relationships were mediated by emotional reactivity and the tendency to isolate oneself from others in 
the presence of intense emotions. Therefore attachment theory, with its emphasis on interpersonal functioning and affect regulation (Mallinckrodt, 2000; Mikulincer, 1998), provides a conceptual framework from which to study the treatment of binge-eating disorder and its related psychopathology.

\section{Attachment Theory}

According to attachment theory, humans evolved to develop affectional bonds that motivate infants to seek proximity to caregivers and maintain attachment figures' availability, and subsequently to avoid danger (Hazan \& Shaver, 1987; Kobak, 1999; Lopez, 1995). The nature of these bonds results from the quality of the interaction between the infant's proximity-seeking behaviours and the caregiver's responsiveness, and shapes the individual's life course through its influence on the individual's internal working models (Bretherton \& Munholland, 1999; Hazan \& Shaver, 1987; Lopez, 1995). Internal working models are schemas or implicit memory scripts about one's self-worth and about attachment figures' availability that result from experiences with caregivers (Kobak, 1999; Lopez, 1995), and that some believe operate outside of conscious awareness (e.g. Maier, Bernier, Pekrun, Zimmermann, \& Grossman, 2004). They influence strategies for regulating distress and emotions in situations that trigger attachment behaviours (Cassidy, 1994; Kobak, 1999; Kobak \& Screery, 1998; Lopez, 1995). Internal working models are based on strategies that were adaptive in early development and influence social experiences later in life (Bretherton \& Munholland, 1999); that is, they transfer to new relationships, are resistant to change, and bias appraisals of the availability of one's current attachment figures (Kobak, 1999). These 
models influence individuals' attachment styles, which place individuals along a continuum of affect regulation (Slade, 1999) and which can be characterized as secure or insecure.

Securely attached infants tend to have caregivers who respond consistently to their needs, signals, and emotional cues (Hazan \& Shaver, 1987; Kobak, 1999). They perceive their caregivers as accessible and responsive, and as sources of protection and comfort when threats arise (Weinfield, Sroufe, Egeland, \& Carlson, 1999). Subsequently, they are comfortable exploring and attempting to master their environments (Weinfield et al.). These individuals tend to experience emotions as useful and to express them actively, openly, and directly, as they have learned that caregivers will respond sensitively to them (Cassidy, 1994). As adults, securely attached individuals acknowledge and express negative affect coherently and flexibly (Slade, 1999). They have internal working models of themselves as worthy and of others as dependable and responsive (Lopez, 1995). Relative to individuals with insecure (i.e., anxious or avoidant) attachment styles (described below), those with secure attachment styles tend to become close to others easily, and are comfortable with depending on others and with others depending on them (Hazan \& Shaver, 1987).

When an infant's negative emotions fail to restore his or her access to an attachment figure, more dysfunctional patterns occur (Kobak, 1999). Nonresponsive or insensitive caregiving can lead the infant to expect inconsistent responsiveness or rejection from caregivers, and subsequently to develop anxious or avoidant attachment styles (Kobak, 1999). Caregivers who respond inconsistently to infants' distress or who 
intrusively force attention on the infant tend to have anxiously attached infants who cry frequently, explore little, and appear anxious (Hazan \& Shaver, 1987). Anxiously attached infants are not easily comforted when they face perceived environmental threats, and therefore are reluctant to explore and strive for mastery over their environments (Weinfield et al., 1999). To increase proximity to caregivers, these infants tend to engage in behaviour that is angry and resistant or passive (Kobak, 1999). They lack confidence in their caregivers' availability and are fearful that their caregivers will be unresponsive (Weinfield et al.). These individuals' sense of competence and desire to explore are contingent on attachment figures' approval. Anxiously attached individuals' dependency on others compromises their ability to self-regulate affect, resulting in increased vulnerability to stress and emotional instability (Lopez, 1995). Their sensitivity to attachment-related memories results in heightened emotionality, which has been proposed as a means of eliciting attention from inconsistent caregivers (Cassidy, 1994). Anxiously attached adults are hypervigilant to distress (Magai, 1999); they underregulate affect, cognitions, and memories related to attachment, and subsequently their affective structures become overwhelmed (Slade, 1999). They tend to have internal working models of themselves as fearful and unstable, and of others as potentially accessible but as unreliable (Lopez, 1995). These individuals have hyperactivated attachment strategies. That is, they make intense efforts to obtain and maintain proximity to attachment figures through compulsive proximity- and protection seeking (Mikulincer \& Shaver, 2005). They are hypersensitive to cues of abandonment or rejection, they ruminate on personal shortcomings and threats to their relationships, and they desire intense closeness (Hazan 
\& Shaver, 1897; Mikulincer \& Shaver, 2005). They view themselves as worthless and unable to control outcomes in relationships, and these perceptions exacerbate their preoccupations with relationships and abandonment (Rom \& Mikulincer, 2003).

Infants with caregivers who consistently reject their attempts to acquire support, protection, and physical closeness frequently develop avoidant attachment styles, and avoid their caregivers to reduce conflict or separation (Hazan \& Shaver, 1987; Kobak, 1999; Lopez, 1995). These infants minimize negative affect to avoid investing in the attachment relationship, as they view attempts to elicit caregivers' support as increasing their risk of being rejected (Cassidy, 1994). As adults, they overregulate and suppress affect, cognitions, and memories that are related to attachment (Slade, 1999). They have internal working models of the self as unwanted and alone and of others as untrustworthy (Lopez, 1995). Adults with avoidant attachment styles have deactivated attachment strategies, meaning that they have inhibited proximity-seeking urges and behaviours (Mikulincer \& Shaver, 2005). They discount triggers of the attachment system, maintain distance from others, avoid intimacy, strive for self-reliance, are uncomfortable with closeness, and suppress distressing memories and cognitions (Hazan \& Shaver, 1987; Mikulincer \& Shaver, 2005). Adults with avoidant attachment styles find it difficult to trust, depend on, and become emotionally close to others (Hazan \& Shaver, 1987). They hold negative representations of others as untrustworthy and inaccessible, and these representations exacerbate their desire for autonomy and emotional distance (Rom \& Mikulincer, 2003).

In a cross-cultural study, van IJzendoorn and Kroonenberg (1988) found that $65 \%$ 
of individuals had secure attachment styles, $14 \%$ had anxious attachment styles, and $21 \%$ had avoidant attachment styles. While anxious attachment styles were more prevalent in Israel and Japan and avoidant attachment styles were more prevalent in Western European countries, intracultural variation in attachment classifications was 1.44 times the cross-cultural variation (van IJzendoorn \& Kroonenberg, 1988). Research has indicated that attachment styles are stable across the lifetime. Waters and colleagues (2000) conducted a 20-year longitudinal study and found that the stability of attachment between ages 12 months and 20 years was $72 \%$.

\section{Attachment, Interpersonal Problems, and Eating Disorders}

Research has indicated that attachment insecurity and interpersonal problems are implicated in the etiology and treatment of eating disorders, and specifically of bingeeating disorder. Patients with eating disorders tend to have higher levels of attachment anxiety and avoidance than participants in a control sample (Illing, Tasca, Balfour, \& Bissada, 2010). Consistent with Magai's (1999) suggestion that individuals' internal working models influence their interpersonal transactions, individuals with binge-eating disorder appear to be susceptible to experiencing interpersonal difficulties. Relative to women without eating disorders, those with binge-eating disorder were more likely to report being bothered by having no one to turn to when they had a problem, by taking care of a family member, by an event that had occurred in the past, and by difficulties with a romantic partner; and experienced poorer social and role functioning (Johnson et al., 2001).

Attachment insecurity and interpersonal difficulties have been associated with 
treatment outcomes for patients with binge-eating disorder. As indicated above, individuals who were higher in attachment anxiety benefited more from group psychodynamic interpersonal psychotherapy, which was focused on interpersonal exploration, whereas those lower in attachment anxiety benefitted more from group cognitive-behavioural therapy, which was focused on specific skill deficits that perpetuate binge eating (Tasca, Ritchie et al., 2006). Moreover, Horowitz, Rosenberg, and Bartholomew (1993) found that interpersonal problems related to hostile dominance were difficult to treat in brief dynamic psychotherapy, and that individuals with avoidant attachment styles tended to be higher in hostile dominance. These findings, in conjunction with research indicating that lower group cohesion at pretreatment and higher interpersonal difficulties at pre- and midtreatment predict nonresponse in individuals with binge-eating disorder (Hilbert et al., 2007), indicate that improvements in participants' relationships with others and with the therapy group may be necessary for them to achieve reductions in target symptoms.

Research has indicated that attachment style and interpersonal problems can change during psychotherapy. Tasca, Balfour, Ritchie, and Bissada (2007a) reported that for women receiving either group psychodynamic interpersonal psychotherapy or group cognitive-behavioural therapy for binge-eating disorder, attachment anxiety and avoidance decreased significantly and that for participants who received group psychodynamic interpersonal psychotherapy, reductions in attachment anxiety were associated with decreases in depressive symptoms (Tasca et al., 2007a). Attachment security significantly increased in insecurely attached clients with interpersonal 
difficulties who received time-limited dynamic psychotherapy and in patients who received transference-focused therapy for borderline personality disorder (Levy et al., 2006; Travis, Binder Bliwise, \& Horne-Moyer, 2001). Similarly, Lawson, Barnes, Madkins, and Francios-Lamonte (2006) reported significant decreases in the prevalence of insecure attachment classifications in men who attended an integrated cognitivebehavioural/ psychodynamic group treatment, and participants who became securely attached reported lower levels of posttreatment anxiety and depression than those who remained insecurely attached. Insecurely attached college students who attended an attachment-focused therapy group reported decreased agreement with dysfunctional relationship statements, decreased angry reactions, increased self-esteem, and increased control over their anger (Kilmann, Urbaniak, \& Parnell, 2006). Further, Horowitz, Rosenberg, Baer, Ureño, and Villaseñor (1988) found that interpersonal problems such as nonassertiveness were subject to change during brief dynamic psychotherapy.

Research has also indicated that attachment avoidance predicts attrition. In Tasca and colleagues' (2006) study, participants higher in attachment avoidance were more likely to drop out of group cognitive-behavioural therapy. Further, Tasca, Taylor, Ritchie, and Balfour (2004) reported that in women with anorexia nervosa binge purge type who were higher in attachment avoidance were more likely to drop out of day hospital treatment. However, despite research on the relationship between interpersonal problems, attachment, and eating disorders, no known study has examined whether attachment to the therapy group is associated with treatment outcomes or dropout for patients with eating disorders. 


\section{Attachment and Group Processes}

Researchers have studied the role of attachment in several group contexts including fraternities and sororities, task-oriented groups, peer groups, and psychotherapy groups.

Group attachment. Smith and colleagues (1999) indicated that individuals' emotions, thoughts, and interpersonal behaviours are affected by the social groups to which they belong, and that individuals can develop attachments to groups. Group attachments are one's mental representations of groups, are based on early experiences with the family and other social groups, and influence one's expectations about new groups (Markin \& Maramosh, 2010). Individuals may experience groups as threatening if they have experienced group discrimination, racism, harassment by peers, isolation from popular groups, an unresponsive family, or other forms of group hatred (Markin \& Maramosh, 2010).

Smith and colleagues (1999) proposed that from the perspective of attachment theory, individuals who are higher in attachment anxiety towards the group are likely to view themselves as unworthy group members and to be concerned about being accepted by the group. Conversely, individuals who are lower in attachment anxiety towards the group may be less concerned about obtaining the group's approval and may believe that the group is accepting of them (Smith et al., 1999). Individuals who are higher in attachment avoidance towards the group may believe that closeness to the group is unnecessary and may act independent or aloof to avoid closeness and interdependence with groups. On the other hand, those lower in attachment avoidance towards the group 
are more likely to hold positive views of closeness and interdependence with groups and may attempt to increase and maintain this closeness (Smith et al.). Individuals with more secure attachment orientations towards the group are low on both attachment anxiety and avoidance towards the group. These individuals may believe that they are worthy as group members, view groups as valuable, and expect groups to be accepting of them (Smith et al.). Smith and colleagues viewed attachment anxiety and avoidance to the group as continuous dimensions. They suggested that while general orientations towards groups may shape expectations about new or unknown groups, current experiences in a given group are likely to shape feelings and interactions with that group. Hence, attachment to the group may be prone to change in a therapy group and especially in group psychodynamic interpersonal psychotherapy, which is focused on relational processes within the group (Tasca, Mikail, \& Hewitt, 2005).

To measure attachment to the group, Smith and colleagues (1999) developed the Social Group Attachment Scale (see Appendix B) using items from Collins and Read's (1990) and Bartholomew and Horowitz's (1991) measures of interpersonal attachment. These items were modified to refer to experiences with social groups rather than romantic partners (Smith et al., 1999). In a principle components analysis using varimax rotation, two factors emerged. One factor emerged to measure attachment anxiety towards the group (group attachment anxiety; e.g. "I often worry that my group will not always want me as a member"), and a second factor emerged to measure attachment avoidance towards the group (group attachment avoidance; e.g. "I find it difficult to allow myself to depend on my group"). These group attachment factors were related to but distinct from 
measures of individual attachment anxiety and avoidance. Correlations were moderate and significant between group attachment anxiety and a measure of individual attachment anxiety $(r=.46)$, and between group attachment avoidance and a measure of individual attachment avoidance ( $r=.33$; Smith et al.). In 18-year-old men in the Israeli defense forces, group attachment anxiety and avoidance were each uniquely negatively associated with individuals' evaluations of their instrumental functioning and group attachment avoidance was uniquely negatively associated with individuals' evaluations of their socioemotional functioning (Smith et al.). In individuals who attended university counseling centres, group attachment anxiety and avoidance towards the therapy group were associated with depression (Holtz, 2004). Further, the relationship between group attachment avoidance and depression remained significant after controlling for group cohesiveness and group collective identity (Holtz, 2004). While the Social Group Attachment Scale has evidenced reliability and validity in samples of undergraduate students and clients attending university psychotherapy groups (Holtz, 2004; Smith et al.), no known research has examined the reliability or validity of this measure in a clinical sample, such as women with binge-eating disorder.

Attachment and group processes in task-oriented and peer groups. Research has indicated that individual attachment anxiety and avoidance and group attachment anxiety and avoidance are related to negative perceptions of the self and others in group contexts. In Israeli undergraduate students, individual attachment anxiety was associated with lower self-efficacy in group interactions, higher threat appraisal of groups, more negative appraisals of the self in group interactions, and higher levels of negative 
emotions towards task-oriented groups (Rom \& Mikulincer, 2003). Individual attachment avoidance was associated with negative appraisals of group members (Rom \& Mikulincer, 2003). Further, undergraduate students who scored higher in group attachment anxiety tended to perceive themselves as less worthy group members, and group attachment anxiety and avoidance were associated with negative perceptions of one's group (Smith et al., 1999). In Israeli adults who were closely raised with peers, ratings of peer groups as caring were associated with lower group attachment anxiety, and participants who experienced their childhood peer groups as exclusive reported higher levels of group attachment anxiety (Weiss \& Shilkret, 2010). Further, those who did not rate their peer groups or their parents as caring had particularly high levels of group attachment anxiety and avoidance (Weiss \& Shilkret, 2010).

Attachment insecurity and negative experiences with groups may influence individuals' group-related goals. While individual attachment anxiety was associated with goals related to security and love, individual attachment avoidance was associated with goals related to self-reliance (Rom \& Mikuliner, 2003). These goals may influence individuals' functioning in groups. For example in 18 -year-old men in the Israeli defense forces, individual and group attachment anxiety and avoidance were associated with impaired instrumental functioning. These results indicate that during task-oriented group activities, individuals higher in individual attachment anxiety were more focused on maintaining positive emotions in the group than on completing group tasks (Rom \& Mikulincer, 2003). Individuals higher in individual attachment avoidance may have been unable to suppress negative emotions during tasks and may have discounted the 
interdependence necessary to complete such tasks because they experienced group interactions as so distressing (Rom \& Mikulincer, 2003). These findings are consistent with research indicating that individuals higher in group attachment avoidance do not value cooperating with the group to meet the group's needs (Smith et al.).

Given that group attachment anxiety and avoidance appear to be associated with poor instrumental functioning in groups focused on task completion, reductions in group attachment anxiety and avoidance may be required for individuals to accomplish group tasks. This possibility has implications for group contexts in addition to task-oriented groups. For example, decreases in and abstinence from binge eating are central tasks of group therapy treatments for binge-eating disorder. Hence, reductions in group attachment anxiety and avoidance may be required for women receiving group psychodynamic interpersonal psychotherapy to experience reductions in the symptoms of binge-eating disorder. This possibility is consistent with findings that reductions in attachment anxiety predict reductions in depressive symptoms for women receiving group psychodynamic interpersonal psychotherapy for binge-eating disorder (Tasca et al., 2007a), and that group attachment anxiety and avoidance are associated with negative perceptions of group-related factors and impaired group functioning (Rom \& Mikulincer, 2003).

Research has also indicated that group attachment avoidance may predict group dropout, defined as a patient unilaterally withdrawing from group therapy. Smith and colleagues (1999) reported that in undergraduate students, group attachment anxiety and avoidance were positively associated with plans to leave sororities and fraternities. Given 
this finding and research indicating that individual attachment avoidance is associated with dropout (Tasca, Ritchie et al., 2006; Tasca et al., 2004), group attachment avoidance earlier in treatment may predict attrition in women receiving group psychodynamic interpersonal psychotherapy for binge-eating disorder.

Attachment and group processes in psychotherapy groups. Attachment has been associated with group processes in therapy groups. In college students and intake clients at a university mental health clinic, individuals higher in individual attachment avoidance were less comfortable with vulnerability in a group context (Maramosh, et al., 2009). In counselling and teacher education students, participants with secure individual attachment styles reported higher levels of group intimacy during a first counselling session than those with avoidant individual attachment styles (Schechtman \& Rybko, 2004). Securely attached participants were also higher in self-disclosure and productive group behaviour than participants with anxious and avoidant individual attachment styles, and counsellors rated those with anxious individual attachment styles as having higher levels of intimacy than those with avoidant individual attachment styles (Schechtman \& Rybko, 2004). Additionally, higher individual attachment anxiety and lower individual attachment avoidance were positively associated with perceptions of growth in group therapy alliance for women with binge-eating disorder who received group psychodynamic interpersonal psychotherapy, but not for those who received group cognitive-behavioural therapy (Tasca et al., 2007b). Tasca and colleagues' (2007b) findings indicate that during group psychodynamic interpersonal psychotherapy, group members' attachment-based defensive strategies may become primed and affect their 
experiences of the group. These experiences may in turn affect treatment outcomes.

Research has indicated that women with binge-eating disorder who are higher in individual attachment anxiety may be particularly sensitive to change in group processes. As indicated above, treatment modality (i.e. group cognitive-behavioural therapy vs. group psychodynamic interpersonal psychotherapy) moderated the relationship between change in individual attachment anxiety and number of days binged in women with binge-eating disorder (Tasca, Ritchie et al., 2006), and between pretreatment attachment anxiety and growth in therapeutic alliance. Also, growth in group therapy alliance was associated with improvement in number of days binged for participants who were higher in pretreatment attachment anxiety, but not for those who were lower in pretreatment attachment anxiety (Tasca et al., 2012). Additionally, growth in engagement with the therapy group partially mediated the relationship between attachment anxiety and reductions in number of days binged (Tasca, Ritchie, et al., 2006). Given these findings and others indicating that individuals higher in individual attachment anxiety tend to perceive groups as more threatening and to experience elevated levels of negative affect towards their group (Rom \& Mikulincer, 2003), participants higher in individual attachment anxiety may be especially responsive to changes in group attachment insecurity. Research in this area will contribute to current psychotherapy research, as no study has examined change in group attachment.

\section{The Present Study}

To date, little research has examined change in group attachment in women receiving group treatment for binge-eating disorder, nor is there any research on group 
attachment as a predictor of treatment outcomes in psychotherapy (Markin \& Maramosh, 2010). Research in this area would follow from Holtz's (2004) suggestions that therapists' awareness of individuals' group attachment styles may facilitate the treatment of interpersonal issues, that measuring group attachment over several time points will enhance current knowledge of change in group attachment, and that group attachment may be related to treatment outcomes.

The first objective of this study was to examine the psychometric properties of the Social Group Attachment Scale in a clinical sample of women with binge-eating disorder. A second objective was to examine whether group attachment avoidance predicts dropout from group psychodynamic interpersonal psychotherapy. A third objective was to examine whether group attachment anxiety and avoidance decrease during treatment, and whether these changes are linear or non-linear in nature. A fourth objective was to examine whether these decreases are associated with decreases in number of days binged and depressive symptoms at post-treatment. Finally, I examined whether pretreatment individual attachment anxiety moderates the relationship between change in group attachment anxiety and avoidance during treatment and reductions in days binged and depressive symptoms up to 12 months posttreatment. Thus, I hypothesized:

1. The Social Group Attachment Scale subscales will demonstrate good convergent validity. Specifically, early group attachment anxiety will be positively correlated with pretreatment measures of individual attachment anxiety and with early group cohesion, and negatively correlated with pre-treatment self-esteem. Early group attachment avoidance will be positively correlated with pretreatment measures of 
individual attachment avoidance, and negatively correlated with pretreatment selfesteem and early group cohesion.

2. Group attachment avoidance at week 4 of group psychodynamic interpersonal psychotherapy will be positively associated with dropping out of group therapy for women with binge-eating disorder, controlling for pretreatment individual attachment avoidance.

3. Group attachment anxiety and avoidance will decrease significantly throughout group treatment for binge-eating disorder.

4. Decreases in group attachment anxiety and avoidance during treatment will predict reduced days binged and reduced depressive symptoms at posttreatment, 6 months posttreatment, and 12 months posttreatment in women receiving group psychodynamic interpersonal psychotherapy for binge-eating disorder.

5. Individual attachment anxiety will moderate the relationships between changes in group attachment anxiety and avoidance and changes in treatment outcomes. Specifically, the positive relationship between group attachment anxiety and avoidance and reductions in days binged and depressive symptoms will be stronger for those higher in pretreatment individual attachment anxiety.

\section{Method}

\section{Participants}

Participants were 87 women who met DSM-IV-TR criteria for binge-eating disorder (APA, 2000). Their data were collected for a previous study on the effectiveness of group psychodynamic interpersonal psychotherapy for women with binge-eating 
disorder (Tasca et al., 2012). Participants were assigned to homogeneous groups based on whether they were higher or lower in individual attachment anxiety (described below; Tasca et al.). Table 1 presents participants' demographic information for each study condition. At telephone screening, $34.5 \%$ of participants $(n=30)$ were taking antidepressant medications, which they had been taking for a median of 24 months $(M=$ $41.61, S D=48.63$ ). No participant began group psychodynamic interpersonal psychotherapy within 16 weeks of beginning to take antidepressant medications, suggesting that the benefits of antidepressant medications occurred prior to completion of pretreatment measures and to starting treatment (Gelenberg \& Chesen, 2000).

Six female therapists (one Master's level advanced practice nurse, three $\mathrm{Ph} . \mathrm{D}$. psychologists, and two psychiatrists) who had at least two years of postgraduate experience in conducting group psychotherapy led the therapy groups.

Table 1

Pretreatment Demographics by Condition

\begin{tabular}{lcc}
\hline & \multicolumn{2}{c}{ Condition } \\
\cline { 2 - 3 } Demographic & Higher & Lower \\
\hline Mean Age (SD) & $43.28(12.41)$ & $45.54(10.65)$ \\
Mean BMI (SD) & $38.87(7.07)$ & $38.41(7.26)$ \\
Mean Chronicity of Eating Disorder in Years (SD) & $14.83(18.76)$ & $21.50(25.37)$ \\
Co-Morbid Affective Disorder (\%) & $47.7 \%$ & $27.9 \%$ \\
Co-morbid Anxiety Disorder (\%) & $40.9 \%$ & $25.6 \%$ \\
Employment Status & & \\
Employed full-time (\%) & $72.7 \%$ & $67.5 \%$ \\
Employed part-time (\%) & $11.4 \%$ & $17.5 \%$ \\
Ethnicity & & \\
African (\%) & $0.0 \%$ & $2.4 \%$ \\
Arab (\%) & $0.0 \%$ & $7.3 \%$ \\
Caucasian (\%) & $95.6 \%$ & $85.4 \%$ \\
South Asian (\%) & $2.2 \%$ & $0.0 \%$ \\
Other (\%) & $2.2 \%$ & $4.9 \%$ \\
\hline
\end{tabular}




\begin{tabular}{|c|c|c|}
\hline \multirow[b]{2}{*}{ Demographic } & \multicolumn{2}{|c|}{ Condition } \\
\hline & Higher & Lower \\
\hline \multicolumn{3}{|l|}{ Family Income ${ }^{a}$} \\
\hline$\$ 10,000-\$ 19,999$ & $2.4 \%$ & $4.9 \%$ \\
\hline$\$ 20,000-\$ 29,999$ & $0.0 \%$ & $7.3 \%$ \\
\hline$\$ 30,000-\$ 39,999$ & $9.5 \%$ & $7.3 \%$ \\
\hline$\$ 40,000-\$ 49,999$ & $19.0 \%$ & $14.6 \%$ \\
\hline$\$ 50,000-\$ 59,999$ & $7.1 \%$ & $14.6 \%$ \\
\hline$\$ 60,000-\$ 69,999$ & $4.8 \%$ & $12.2 \%$ \\
\hline$\$ 70,000-\$ 79,999$ & $16.7 \%$ & $12.2 \%$ \\
\hline$\$ 80,000$ and above & $40.5 \%$ & $26.8 \%$ \\
\hline \multicolumn{3}{|l|}{ Highest Education Obtained } \\
\hline Completed Graduate Training ( $\%)$ & $2.3 \%$ & $17.1 \%$ \\
\hline Some Graduate Training (\%) & $2.3 \%$ & $7.3 \%$ \\
\hline Completed Undergraduate or College Training (\%) & $54.5 \%$ & $46.3 \%$ \\
\hline Some Undergraduate or College Training (\%) & $15.9 \%$ & $14.6 \%$ \\
\hline Completed CEGEP (\%) & $6.8 \%$ & $0.0 \%$ \\
\hline Some CEGEP (\%) & $2.3 \%$ & $0.0 \%$ \\
\hline Completed High School (\%) & $15.9 \%$ & $9.8 \%$ \\
\hline Some High School $(\%)$ & $0.0 \%$ & $4.9 \%$ \\
\hline \multicolumn{3}{|l|}{ Language } \\
\hline English (\%) & $82.2 \%$ & $87.5 \%$ \\
\hline French $(\%)$ & $8.9 \%$ & $7.5 \%$ \\
\hline Bilingual (\%) & $8.9 \%$ & $5.0 \%$ \\
\hline \multicolumn{3}{|l|}{ Living Situation } \\
\hline Alone (\%) & $35.6 \%$ & $36.6 \%$ \\
\hline Conjugal $(\%)$ & $44.4 \%$ & $34.1 \%$ \\
\hline Dorm/ Shared Apartment (\%) & $6.7 \%$ & $4.9 \%$ \\
\hline With Parents/ Relatives (\%) & $2.2 \%$ & $9.8 \%$ \\
\hline Other $(\%)$ & $11.1 \%$ & $14.6 \%$ \\
\hline \multicolumn{3}{|l|}{ Marital Status } \\
\hline Married/Common Law (\%) & $48.9 \%$ & $36.6 \%$ \\
\hline Separated/Divorced (\%) & $11.1 \%$ & $34.1 \%$ \\
\hline Single (\%) & $37.8 \%$ & $24.4 \%$ \\
\hline Widowed (\%) & $2.2 \%$ & $4.9 \%$ \\
\hline \multicolumn{3}{|c|}{$\begin{array}{l}\text { Note. Lower }=\text { lower attachment anxiety condition }(n=41) \text {, Higher }=\text { higher attachment } \\
\text { anxiety condition }(n=46) . \mathrm{BMI}=\text { body mass index }\left(\mathrm{kg} / \mathrm{m}^{2}\right) ; \text { CEGEP }=\text { Collège } \\
\text { d'enseignement général et professionnel. } \\
{ }^{\mathrm{a}} \$ 1 \text { Canadian }=\$ 0.98 \text { US. }\end{array}$} \\
\hline
\end{tabular}

\section{Measures}

Assessment of binge eating. Binge eating was assessed with the Eating Disorder Examination (Fairburn \& Cooper, 1993). This semi-structured interview contains items 
that assess for number of days binged in the past 28 days, and for the presence of bingeeating disorder (Fairburn \& Cooper, 1993). The interview discriminated between the eating disorders (Cooper, Cooper, \& Fairburn, 1989) and had a mean inter rater reliability of .97 (Rizvi, Peterson, Crow, \& Agras, 2000). In the current study, a research coordinator who was unaware of participants' study conditions re-assessed $10 \%$ of recorded Eating Disorder Examinations to assess agreement on number of days binged in the past 28 days (Tasca et al., 2012). The intraclass correlation coefficient was then obtained from a two-way random effects model (Shrout \& Fleiss, 1979). The intraclass correlation coefficient of .98 indicated high agreement for number of days binged in the past 28 days (Tasca et al.).

Diagnosis of binge-eating disorder, affective disorders, and anxiety disorders. The Structured Clinical Interview for DSM-IV Axis I Disorders (SCID; First et al., 2007) was used to assess for Axis I DSM-IV disorders that are frequently diagnosed in adults (First et al.). Research has indicated that the SCID is valid and reliable. In outpatients who attended a community mental health centre, diagnoses based on the SCID were more accurate than diagnoses made by psychiatrists during routine care (Basco et al., 2000). Mean test-retest reliabilities were .35 to .61 for affective disorders, .44 to .78 for anxiety disorders, and .64 for eating disorders (Zanarini et al., 2000). For the sample in the current study, interrater reliability as assessed with Cohen's kappa indicated good agreement between independent raters for current mood disorders, $k=.82$, and for current anxiety disorders, $k=.83$ (Tasca, et al., 2011). All SCIDS were audio-recorded.

Depressive symptoms. To assess depressive symptoms, the Beck Depression 
Inventory-II (Beck, Steer, \& Brown, 1996) was used. The Beck Depression Inventory-II contains 21 items with response options ranging from 0 to 3 and with total scores ranging from 0 to 63 . Higher scores reflect greater depressive symptoms. This scale has shown criterion validity, as depressive scores were higher in a clinical sample $(M=22.45[S D=$ 12.75]) than a normative sample $(M=12.56[S D=9.93])$, and as total scores on the Beck Depression Inventory-II were positively associated with having a mood disorder in psychiatric outpatients (Beck, Steer, \& Brown, 1996). In this study sample, Cronbach's alpha was .91 for the Beck Depression Inventory-II. The mean inter item correlation was also used to assess internal consistency because unlike Cronbach's alpha, it is not influenced by the number of scale items (Clark \& Watson, 1995). Clark and Watson (1995) recommended mean interitem correlations between .15 and .50 . In this study, the mean interitem correlation for the Beck Depression Inventory-II was .35 (see Appendix C for proration decisions).

Group attachment. As indicated above, the Social Group Attachment Scale (Smith et al., 1999) was used to measure group attachment. The Social Group Attachment Scale contains 25 items with response options ranging from 1 (Strongly Disagree) to 7 (Strongly Agree). However, Smith and colleagues (1999) and Holtz (2004) found that items $5,6,7,8$, and 20 had loadings below .50 . Also, Smith and colleagues reported that item 15 cross-loaded on two factors at .50 and .57 . Thus, consistent with previous research (Rom \& Mikulincer, 2003), only 19 items were used in the current study. The Social Group Attachment Scale anxiety subscale contains 10 items and the Social Group Attachment Scale avoidance subscale contains nine items. 
The Social Group Attachment Scale anxiety and avoidance subscales have shown convergent validity in undergraduate students (Smith et al.) and individuals attending university counselling centres (Holtz, 2004). In undergraduate students, both subscales were positively associated with negative affect and with plans to leave social groups (Smith et al.). Additionally, both subscales were significantly negatively correlated with self-esteem, group identification, positive feelings towards social groups, affective extremity, number of and satisfaction with social supports, individuals' perceptions of the value of their social groups, and individuals' perceptions of others' beliefs about their social groups (Holtz, 2004; Smith et al.). The anxiety subscale was significantly positively associated with group cohesiveness and with the tendency to not express disagreement so as to avoid group conflict, and was significantly negatively associated with individuals' perceptions of their worth as group members and with the number of activities and amount of time spent with social groups (Holtz, 2004; Smith et al.). The avoidance subscale was significantly negatively associated with participants' perceptions of the importance of group membership to their identities, with their perceptions of the value of their therapy groups, with their perceptions of others' valuations of their groups, with group cohesiveness, with the extent to which individuals identified with their groups, and with the tendency to accommodate the group's needs as a means of avoiding conflict (Holtz, 2004; Smith et al.).

Test-retest reliability ranged from .80 to .90 for group attachment anxiety and from .73 to .87 for group attachment avoidance, and estimated theta reliabilities (Armor, 1974 , as cited in Smith et al.) ranged from .86 to .91 for group attachment anxiety and 
from .75 to .84 for group attachment avoidance (Smith et al.). In the present study, Cronbach's alpha was .80 and the mean interitem correlation was .29 for group attachment anxiety, and Cronbach's alpha was .78 and the mean interitem correlation was .28 for group attachment avoidance.

Individual attachment. To assess individual attachment anxiety and avoidance, the Attachment Styles Questionnaire (Feeney, Noller, \& Hanrahan, 1994) was used. The Attachment Styles Questionnaire is a self-report measure with 40 items. Response options range from 1 (totally disagree) to 6 (totally agree). The questionnaire contains five subscales. The Confidence in Relationships (Confidence) subscale contains eight items, and assesses secure attachment and the extent to which one holds positive attitudes towards the self and others (Feeney et al.). The Need for Approval subscale and Preoccupation with Relationships subscales both measure individual attachment anxiety. The Need for Approval subscale contains seven items and assesses one's need for others' confirmation and acceptance. The Preoccupation with Relationships subscale contains eight items and assesses the tendency to turn to others to fulfill one's needs for dependence (Feeney et al.). The Discomfort with Closeness and Relationships as Secondary subscales measure individual attachment avoidance. The Discomfort with Closeness subscale contains 10 items that assess difficulty with becoming close with, trusting, and depending on others. The Relationships as Secondary subscale contains seven items and assesses the extent to which individuals emphasize achievement as a means of protecting themselves from being hurt and vulnerable in relationships (Feeney et al.). 
Brennan, Clark, and Shaver (1998) factor analyzed 60 self-report attachment scales on two independent, higher order factors of attachment anxiety and avoidance in 1,086 undergraduate students. The Need for Approval and Preoccupation subscales loaded on the individual attachment anxiety factor at .62 and .86 , respectively, and the Discomfort with Closeness and Relationships as Secondary subscales loaded on the individual attachment avoidance factor at .86 and .61 , respectively (Brennan et al.). Tenweek test-retest reliabilities were .74 for Confidence, .78 for Need for Approval, .72 for Preoccupation with Relationships, .74 for Discomfort with Closeness, and .67 for Relationships as Secondary (Feeney et al.). Table 2 presents measures of internal consistency for the Attachment Styles Questionnaire from the current study.

Table 2

Measures of Internal Consistency for the Attachment Styles Questionnaire

\begin{tabular}{lcc}
\hline Attachment Styles Questionnaire Subscale & Cronbach's Alpha & $\begin{array}{c}\text { Mean Interitem } \\
\text { Correlation }\end{array}$ \\
\hline Confidence & .84 & .40 \\
Need for Approval & .80 & .36 \\
Preoccupation with Relationships & .85 & .28 \\
Discomfort with Closeness & .87 & .43 \\
Relationships as Secondary & .66 & .22 \\
\hline
\end{tabular}

Assignment of participants to individual attachment anxiety conditions.

Participants who had a score equal to or above 3.59 on the Need for Approval subscale were assigned to the higher individual attachment anxiety condition, and those who had a score below 3.59 were assigned to the lower individual attachment anxiety condition. The cut-off score of 3.59 was based on the finding that the interaction between Need for Approval scores and treatment type (group psychodynamic interpersonal psychotherapy vs. group cognitive-behavioural therapy) predicted reductions in number of days binged 
in the past 7 days between pre- and posttreatment, and that the point of intersection of the regression lines for the two treatment types was 3.59 on the Need for Approval subscale (Tasca, Ritchie et al., 2006). From this result, it was ascertained that a score equal to or above 3.59 represented a higher level of individual attachment anxiety, and that a score below 3.59 represented lower level of lower individual attachment anxiety (Tasca et al., 2012).

Group engagement. The Group Climate Questionnaire (MacKenzie, 1983) contains 12 items with response options ranging from 0 (Not at all) to 6 (Extremely), and has subscales measuring engagement, conflict, and avoidance. The Engaged subscale contains five items that measure the extent to which members contribute to a positive group climate (MacKenzie, 1983) and has shown good evidence for convergent validity. In individuals who attended personal growth groups, the Engaged subscale was significantly positively correlated with group cohesion, with perceptions of group leaders' and clinicians' empathy, with clients' perceptions of mutual attachment between group members and the clinician, with clients' perceptions of in-session action as efficacious and pertinent, and with clients' perceptions of concordance between the clinician's and group members' anticipated treatment outcomes (Johnson, Burlingame, Olsen, \& Gleave, 2005). In this study, Cronbach's alpha was .75 and the mean interitem correlation was .38 for the Engaged subscale of the Group Climate Questionnaire.

Self-esteem. To measure self-esteem, the Rosenberg Self-Esteem Scale (Rosenberg, 1979) was used. This scale contains 10 items with response options ranging from 1 (Strongly Disagree) to 4 (Strongly Agree). Higher scores indicate higher self- 
esteem, and total scores range from 10 to 40 . This scale has good evidence for construct validity. It was negatively correlated with emotional and family functioning in 18 - and 19-year old students (Bagley, Bolitho, \& Bertrand, 1997). The mean Rosenberg SelfEsteem Scale score was $31.46(S D=4.80)$ for a sample of college students (Reynolds, $1988)$, and $27.05(S D=5.75)$ for a sample of individuals with binge-eating disorder (Wilfley et al., 2002). In undergraduate students, 4-year test-retest reliability was .69 (Robins, Hendin, \& Trzesniewski, 2001). In this study, Cronbach's alpha was .83 and the mean interitem correlation was .37 for the Rosenberg Self-Esteem Scale.

Treatment completion vs. dropout. Individuals were categorized as having dropped out of treatment if they did not attend group psychodynamic interpersonal psychotherapy after the $12^{\text {th }}$ session, if they attended fewer than half of the 16 treatment sessions, and if they unilaterally terminated treatment.

\section{Procedure}

Participants were referred to a binge eating treatment study by the Regional Centre for the Treatment of Eating Disorders at The Ottawa Hospital General Campus, or responded to community newspaper advertisements for the treatment of binge eating. A program evaluator or research coordinator described the nature of the study over the phone, assessed for the presence of binge-eating disorder with the Eating Disorder Examination (Fairburn \& Cooper, 1993), and screened individuals for exclusion criteria. To participate in the study, participants had to have a BMI equal to or above 27 , speak English, and agree to abstain from new treatments while they received group psychodynamic interpersonal psychotherapy. Exclusion criteria were: current or past 
compensatory behaviors such as self-induced vomiting, a diagnosis of bipolar disorder or a psychotic disorder, drug or alcohol abuse in the past 6 months, taking medications that may affect weight during treatment, pregnancy or plans to become pregnant in the next 12 months, and enrollment or plans to enroll in a weight loss program.

A total of 230 individuals contacted the program about the study, and 81 individuals met exclusion criteria. A further 29 individuals declined an in-person assessment, and 120 attended an in-person assessment. During these assessments, participants received the audio-recorded SCID administered by a research coordinator, a program evaluator, or a doctoral student. Upon completion of the SCID, a further five individuals met study exclusion criteria and 13 declined treatment. Of the 102 individuals who began treatment, 52 were assigned to the lower individual attachment anxiety condition and 50 were assigned to the higher individual attachment anxiety condition. For the current study, data were available for 41 individuals in the lower condition and for 46 individuals who were in the higher condition (see Figure 1).

A research coordinator, program evaluator, or doctoral student in clinical psychology then conducted an audio-recorded patient version of the SCID (First et al., 2007 ) in person with each participant to confirm binge-eating disorder diagnosis and to assess for the presence of affective and anxiety disorders. Participants completed pretreatment psychological self-report measures, including the Beck Depression Inventory-II, the Attachment Styles Questionnaire, and the Rosenberg Self-Esteem Scale. Participants received one pre-group preparation session and then attended 16 weeks of group psychodynamic interpersonal psychotherapy. They completed the Social Group 


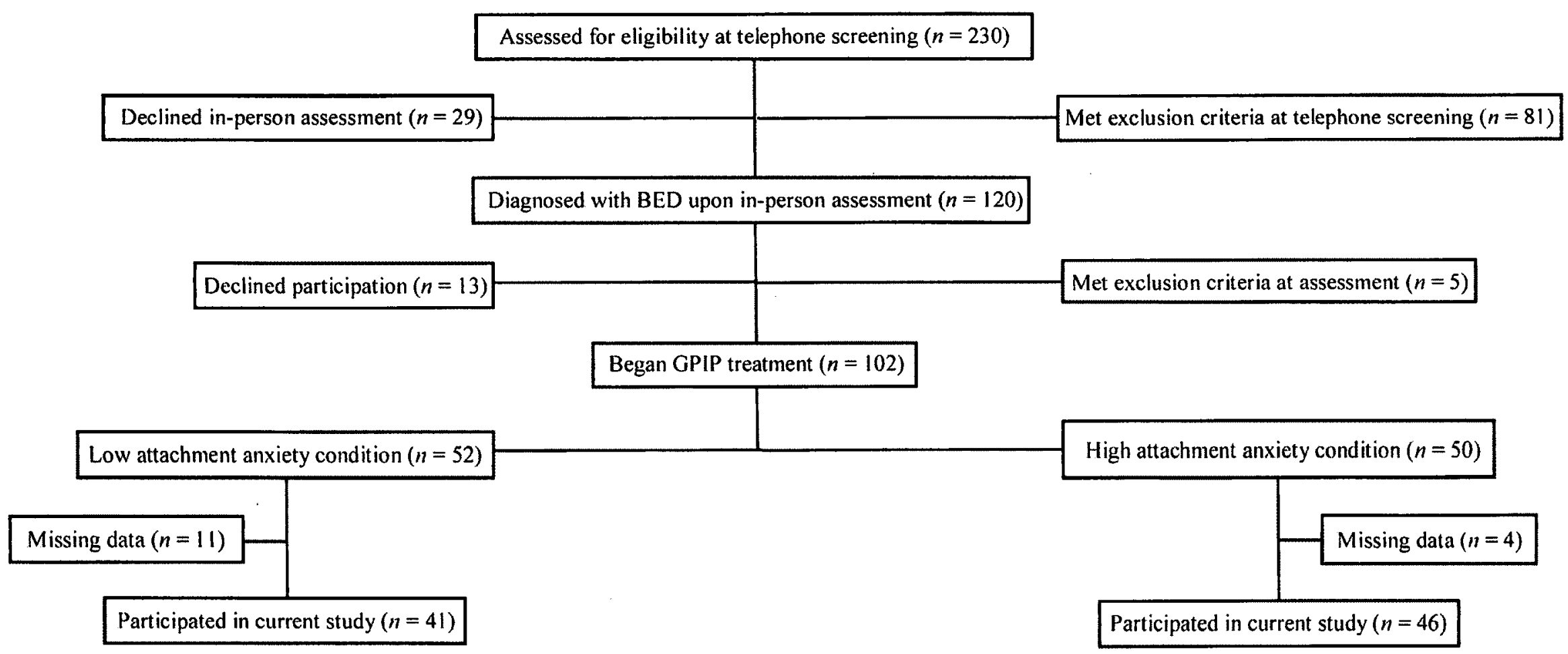

Figure 1. Participant flow chart.

Note. $\mathrm{BED}=$ binge-eating disorder. GPIP = group psychodynamic interpersonal psychotherapy. 
Attachment Scale at weeks 4, 8, 12, and 16 of treatment and the Group Climate Questionnaire at each week of treatment.

There were 12 therapy groups with each group consisting of five to 10 participants. There were six therapists who were unaware of participants' study conditions. Because each therapist led one group in the higher individual attachment anxiety condition and one group in the lower attachment anxiety condition, therapist effects were controlled for. All therapists attended a 2-day workshop on how to provide group psychodynamic interpersonal psychotherapy, as well as weekly supervision sessions for manual adherence and quality assurance. To assess therapist adherence to the manuals, the Tape Rating Instrument for Psychotherapy of Eating Disorders (TRIPED; Olmsted, Isaacs, Bemis, \& Garner, 1988) was used (Tasca et al., 2012). Research indicates that scores of 3 and above reflect minimally acceptable adherence (Tasca, Ritchie et al., 2006); in this study, the mean TRIPED score was $M=3.88(S D=.55)$ and no therapist had a mean adherence score $<3$ (Tasca et al.). A senior psychologist with 20 years of experience in group therapy, supervision, and eating disorders treatment supervised the six therapists.

Participants completed the Beck Depression Inventory-II, the Attachment Styles Questionnaire, and the Rosenberg Self-Esteem Scale, and received the Eating Disorder Examination interview at posttreatment and at 6 months posttreatment. At 12 months posttreatment, a program evaluator or research coordinator phoned participants and assessed for number of days binged in the past 7 and 28 days with the Eating Disorder Examination and mailed participants the questionnaires. All therapy sessions were video recorded and all participants provided informed consent. The Ottawa Hospital Research 
Institute's ethics board approved the study.

\section{Group Psychodynamic Interpersonal Psychotherapy}

- Therapists conduct group psychodynamic interpersonal psychotherapy using Tasca and colleagues' (2005) group psychodynamic interpersonal psychotherapy manual. Group psychodynamic interpersonal psychotherapy is a 16-week group psychotherapy. According to the group psychodynamic interpersonal psychotherapy model, individuals' unmet attachment needs result in fears of rejection, which in turn lead to negative affect such as anger, alexithymia (numbed affect), and hostility (Tasca et al.). To protect one's self-esteem and self-concept from such negative affect, individuals may develop a number of coping or defensive strategies. These strategies are often evident in individuals' Cyclical Relationship Patterns (Strupp \& Binder, 1984). Cyclical Relationship Patterns are interpersonal interaction patterns in which an individual may typically engage. Components of Cyclical Relationship Patterns include Acts of Self (one's behaviours, thoughts, and feelings in an interaction), Acts of Others (others' behaviors towards the self), Expectations of Others (assumptions about others' thoughts or feelings toward the self), and Introject (acts of self toward the self or the internalization of interaction patterns into a self concept). Cyclical Relationship Patterns may result in maladaptive interpersonal contexts (e.g., conflict, low social support, avoidance) that exacerbate negative affect. These patterns may involve relating to others in ways that alleviate or avoid negative affect, and as such may give rise to symptoms such as binge eating as a means of coping (Tasca et al.). Such symptoms provide temporary relief from negative affect and do not allow the individual to adaptively deal with interpersonal distress and affective dysregulation (Tasca et al.). Therefore, group 
psychodynamic interpersonal psychotherapy addresses and modifies individuals' Cyclical Relationship Patterns as a means of reducing negative affect and increasing adaptive coping as a means of reducing urges to binge eat.

An awareness of an individual's Cyclical Relationship Pattern is advantageous because it provides the therapist with a framework from which to understand the individual's interpersonal behaviours, affective experiences, and symptoms (Tasca et al., 2005). Further, knowledge of such a pattern provides the therapist with insight into the motives underlying individuals' behaviours and facilitates affective communication (Tasca et al.). This knowledge also serves as an effective tool for developing interventions and, when made explicit to the individual, enhances that individual's level of self-awareness and thereby expands his or her ability to develop more adaptive interpersonal patterns (Tasca et al.). For these reasons, during a pre-group preparation session, a psychologist who was not one of the six therapists evaluated participants' Cyclical Relationship Patterns and how these patterns influenced binge-eating disorder symptoms. The psychologist provided each group therapist with information about each participant's Cyclical Relationship Patterns prior to the first session of group psychodynamic interpersonal psychotherapy.

The first phase of group psychodynamic interpersonal psychotherapy treatment was focused on identifying participants' Cyclical Relationship Patterns and on increasing group cohesion (Tasca et al., 2005). The second phase was focused on promoting change in Cyclical Relationship Patterns through encouragement of more adaptive group interactions and on generalizing these interactions to relationships outside of the group. During this phase, therapists identified a participant as an Emotional Leader who could 
model reflective functioning, important emotional progress, and interpersonal changes for the group (Beck, Dugo, Eng, \& Lewis, 1986). During the third phase, the focus was on consolidating the changes in Cyclical Relationship Patterns that participants made during treatment and on individuals' reactions to the approaching termination of treatment (Tasca et al.). Throughout treatment, binge-eating disorder symptoms were discussed within the context of participants' Cyclical Relationship Patterns.

\section{Results}

\section{Data Screening Procedures}

I assessed all variables in the study for accuracy of data entry and missingness. I then evaluated the fit between the variables' distributions and the assumptions of multivariate normality.

\section{Consideration of missing data.}

Hypothesis 1. Table 3 presents the numbers of cases with available and missing data on each variable in the study. Many variables were missing data for at least $5 \%$ of cases, indicating potential problems concerning the generalizability of the study's results (Tabachnick \& Fidell, 2007); that is to say, cases with complete data may have been unrepresentative of all women with binge-eating disorder (Schafer \& Graham, 2002). To evaluate this possibility, I assessed the two assumptions required for data to be missing completely at random (MCAR): (a) that missingness on a variable is unrelated to other variables in the dataset, and (b) that missingness on a variable is unrelated to that variable (Schafer \& Graham, 2002). Little's MCAR test was not significant, $\chi^{2}(1642)=1570.27$, $p=.896$, indicating that missingness on a variable was unrelated to a case's score on another variable and that the first MCAR assumption was met (Schafer \& Graham, 
2002). While it was impossible to test the second MCAR assumption, Schafer and Graham (2002) suggested that in social science research it is the exception for one's value on a response variable to be related to missingness on that variable. Further, participants were assured that their responses were confidential, and attachment avoidance (the only variable in the current study that, to my knowledge, has been found to predict attrition; Tasca, Ritchie, et al., 2006) did not predict dropout (discussed below). Therefore, it appeared unlikely that a missingness pattern due to social desirability or attrition, respectively, was related to a case's score on that variable. Hence, data appeared to be MCAR. Multiple imputation was deemed appropriate for estimating missing data for the Hypothesis 1 variables because multiple imputation assumes that data are missing at random or completely at random and because of problems associated with casewise deletion (e.g. reductions in power, failure to make full use of potentially predictive information in the dataset; Schafer \& Graham, 2002). Appendix D provides a description of multiple imputation.

Hypotheses 2 to 5. Multilevel modeling (discussed below) allows for missingness to be related to other predictors in the model, but requires that missingness be unrelated to the outcome variable (Gallop \& Tasca, 2009). To test this requirement I implemented pattern mixture models for all significant models (see Models 1 and 2, Appendix E), as these models are appropriate for clinical studies in which dropout may be related to the outcomes assessed (Schafer \& Graham, 2002). Of the 102 participants who commenced group psychodynamic interpersonal psychotherapy, $18(17.6 \%)$ dropped out and up to 58 (56.86\%) did not return 12 months posttreatment questionnaires. Hence, dropout was a prominent missing data pattern in the current study. Therefore, I assessed the significance 
Table 3

Number of Cases Missing Data on the Variables Studies

\begin{tabular}{|c|c|c|}
\hline Variable & Available Data (\%) & Missing Data (\%) \\
\hline Treatment Completion Status & $102(100.00 \%)$ & $0(0 \%)$ \\
\hline \multicolumn{3}{|l|}{ Demographic Characteristics } \\
\hline Age & $101(99.02 \%)$ & $1(.98 \%)$ \\
\hline Education & $100(98.04 \%)$ & $2(1.96 \%)$ \\
\hline Employment & $100(98.04 \%)$ & $2(1.96 \%)$ \\
\hline Ethnicity & $101(99.02 \%)$ & $1(.98 \%)$ \\
\hline Income & $97(95.10 \%)$ & $5(4.90 \%)$ \\
\hline Language & $100(98.04 \%)$ & $2(1.96 \%)$ \\
\hline Living arrangements & $101(99.02 \%)$ & $1(.98 \%)$ \\
\hline Marital status & $101(99.02 \%)$ & $1(.98 \%)$ \\
\hline \multicolumn{3}{|l|}{ Group Process Measures } \\
\hline Group attachment anxiety slope & $85(83.33 \%)$ & $16(16.66 \%)$ \\
\hline Group attachment avoidance slope & $85(83.33 \%)$ & $16(16.66 \%)$ \\
\hline Week 4 group attachment anxiety & $87(85.29 \%)$ & $15(14.71 \%)$ \\
\hline Week 4 group attachment avoidance & $87(85.29 \%)$ & $15(14.71 \%)$ \\
\hline Week 4 group engagement & $78(76.47 \%)$ & $24(23.53 \%)$ \\
\hline \multicolumn{3}{|l|}{ Individual Attachment Measures } \\
\hline \multicolumn{3}{|l|}{ Confidence } \\
\hline Pretreatment & $102(100.00 \%)$ & $0(0.00 \%)$ \\
\hline Posttreatment & $82(80.39 \%)$ & $20(19.61 \%)$ \\
\hline 6 months posttreatment & $61(59.80 \%)$ & $41(40.20 \%)$ \\
\hline 12 months posttreatment & $44(43.14 \%)$ & $58(56.86 \%)$ \\
\hline \multicolumn{3}{|l|}{ Need for Approval } \\
\hline Pretreatment & $102(100.00 \%)$ & $0(0.00 \%)$ \\
\hline Posttreatment & $82(80.39 \%)$ & $20(19.61 \%)$ \\
\hline 6 months posttreatment & $62(60.78 \%)$ & $40(39.22 \%)$ \\
\hline 12 months posttreatment & $44(43.14 \%)$ & $58(56.86 \%)$ \\
\hline \multicolumn{3}{|l|}{ Preoccupation with Relationships } \\
\hline Pretreatment & $102(100.00 \%)$ & $0(0.00 \%)$ \\
\hline Posttreatment & $82(80.39 \%)$ & $20(19.61 \%)$ \\
\hline 6 months posttreatment & $62(60.78 \%)$ & $40(39.22 \%)$ \\
\hline 12 months posttreatment & $44(43.14 \%)$ & $58(56.86 \%)$ \\
\hline \multicolumn{3}{|l|}{ Discomfort with Closeness } \\
\hline Pretreatment & $102(100.00 \%)$ & $0(0.00 \%)$ \\
\hline Posttreatment & $82(80.39 \%)$ & $20(19.61 \%)$ \\
\hline 6 months posttreatment & $62(60.78 \%)$ & $40(39.22 \%)$ \\
\hline 12 months posttreatment & $44(43.14 \%)$ & $58(56.86 \%)$ \\
\hline \multicolumn{3}{|l|}{ Relationships as Secondary } \\
\hline Pretreatment & $101(99.02 \%)$ & $1(.98 \%)$ \\
\hline Posttreatment & $82(80.39 \%)$ & $20(19.61 \%)$ \\
\hline 6 months posttreatment & $63(61.76 \%)$ & $39(38.24 \%)$ \\
\hline 12 months posttreatment & $45(44.12 \%)$ & $57(55.88 \%)$ \\
\hline
\end{tabular}




\begin{tabular}{lcc}
\hline Variable & Available Data (\%) & Missing Data (\%) \\
\hline Days Binged & & \\
Pretreatment & $102(100.00 \%)$ & $0(0.00 \%)$ \\
Posttreatment & $70(68.63 \%)$ & $32(31.37 \%)$ \\
6 months posttreatment & $57(55.88 \%)^{\mathrm{a}}$ & $45(44.12 \%)$ \\
12 months posttreatment & $49(48.04 \%)$ & $53(51.96 \%)$ \\
Depressive Symptoms & & \\
Pretreatment & $100(98.04 \%)$ & $2(1.96 \%)$ \\
Posttreatment & $81(79.41 \%)$ & $21(20.59 \%)$ \\
6 months posttreatment & $63(61.76 \%)$ & $39(38.24 \%$ \\
12 months posttreatment & $44(43.14 \%)$ & $58(56.86 \%)$ \\
Pretreatment Rosenberg Self-Esteem & $100(98.04 \%)$ & $2(1.96 \%)$ \\
\hline
\end{tabular}

${ }^{a}$ Data were available for 57 cases $(55.88 \%)$ for number of days binged in the past seven days at 6 months posttreatment, and 58 cases $(56.86 \%)$ for number of days binged in the past 28 days at 6 months posttreatment.

of dropout as a level-2 predictor in the multilevel models for which the parameters of interest were significant ${ }^{1}$. Dropout was not a significant predictor of treatment outcomes in these models.

\section{Consideration of normality and univariate outliers. All variables were} assessed for skewness, kurtosis, and univariate outliers. Variables were considered to be significantly non-normally distributed if dividing skewness or kurtosis statistics by their standard errors yielded absolute values greater than 3.29 (Tabachnick \& Fidell, 2007). Cases with standardized scores with absolute values greater than 3.29 were considered to be univariate outliers (Tabachnick \& Fidell, 2007). Table 4 presents skewness and kurtosis statistics as well as the highest and lowest standardized score on each variable.

For Preoccupation with Relationships, there was a univariate outlier at

\footnotetext{
${ }^{1}$ Typically, the coefficient of interest in pattern mixture models is the missing pattern $\mathrm{x}$ level-2 variable interaction (Gallop \& Tasca, 2009; see Model 1, Appendix E), as this coefficient indicates whether the effects of a variable of interest differ as a function of missing data patterns. However, this interaction term could only be computed for the 87 individuals who had enough data on the Social Group Attachment Scale to generate a slope representing change in group attachment. To examine whether dropout was associated with change in treatment outcomes in the sample of 102 individuals, the significance of $\beta_{12}$ in Model 2 (Appendix E) was assessed. No dropout or dropout $\mathrm{x}$ group attachment slope coefficient was significant.
} 
posttreatment. However, the score was not substantially lower than the cut-off of 3.29. For this reason and to avoid introducing bias in cases' slopes due to adjusting their scores at particular time points, the case's score was left unadjusted. This variable was significantly leptokurtic at 12 months posttreatment. However, all other time points for this variable were normally distributed, and kurtosis was not substantially different from the 3.29-cut-off. For these reasons, the original distribution was retained.

For days binged in the past 7 days, the distributions were significantly positively skewed for posttreatment and 6 months posttreatment. For days binged in the past 28 days, variables were skewed for posttreatment, 6 months posttreatment, and 12 months posttreatment. However, because the variables were not significantly skewed for all time points and because skewness was not severe, the original data were retained.

The depressive symptoms variable was significantly positively skewed for posttreatment and 6 months posttreatment. However, because the variable was not significantly skewed for all time points and because skewness was not severe, the original data were retained. There was one univariate outlier for each of these time points. However, because adjusting case's scores would influence their slopes and because the outlying scores were not substantially higher than the cut-off of 3.29 , scores were not adjusted.

Consideration of linearity and homoscedasticity. Inspection of scatterplots suggested that the relationships between most variables appeared linear. In the event of nonlinearity, the relationships appeared to be nonexistent rather than curvilinear, so no transformation appeared necessary.

There appeared to be three potentially heteroscedastic relationships. First, the 
Table 4

Normality Statistics and Outliers for Each Variable in the Study

\begin{tabular}{|c|c|c|c|c|c|c|}
\hline Variable & Skewness $(S E)$ & $Z_{\text {skewness }}$ & Kurtosis (SE) & Zurtosis & Lowest $z$ & Highest $z$ \\
\hline \multicolumn{7}{|l|}{ Group Attachment Slopes } \\
\hline Anxiety & $-0.04(0.26)$ & -0.15 & $-0.65(0.52)$ & -1.25 & -2.16 & 1.95 \\
\hline Avoidance & $-0.22(0.26)$ & -0.85 & $-0.15(0.52)$ & -0.29 & -2.22 & 2.21 \\
\hline \multicolumn{7}{|l|}{ Week 4} \\
\hline Group attachment anxiety & $0.12(0.26)$ & 0.46 & $-0.78(0.51)$ & -1.53 & -1.70 & 2.60 \\
\hline Group attachment avoidance & $0.11(0.26)$ & 0.42 & $-0.21(0.51)$ & -0.41 & -2.18 & 2.87 \\
\hline Group engagement & $-0.40(0.27)$ & 1.48 & $0.03(0.54)$ & 0.06 & -2.40 & 2.08 \\
\hline \multicolumn{7}{|l|}{ Individual Attachment Measures } \\
\hline \multicolumn{7}{|l|}{ Confidence } \\
\hline Pretreatment $^{\mathrm{a}}$ & $0.08(0.24)$ & 0.33 & $-0.33(0.74)$ & 0.45 & -2.42 & 2.30 \\
\hline Posttreatment & $-.06(0.27)$ & -0.22 & $-0.33(0.53)$ & -0.62 & -2.06 & 2.14 \\
\hline 6 months posttreatment & $-0.25(0.31)$ & -0.81 & $-0.19(0.60)$ & -0.32 & -2.43 & 2.08 \\
\hline 12 months posttreatment & $-0.37(0.36)$ & -1.03 & $0.33(0.70)$ & 0.47 & -2.92 & 1.72 \\
\hline \multicolumn{7}{|l|}{ Need for Approval } \\
\hline Pretreatment & $-0.21(0.24)$ & -0.88 & $-0.61(0.47)$ & -1.30 & -2.51 & 1.92 \\
\hline Posttreatment & $-0.24(0.27)$ & -0.89 & $-0.60(0.53)$ & -1.13 & -2.51 & 2.05 \\
\hline 6 months posttreatment & $-0.41(0.30)$ & -1.37 & $-0.29(0.60)$ & -0.48 & -2.49 & 1.68 \\
\hline 12 months posttreatment & $-0.82(0.36)$ & -2.28 & $0.10(0.70)$ & 0.14 & -2.60 & 1.44 \\
\hline \multicolumn{7}{|l|}{ Preoccupation $^{b}$} \\
\hline Pretreatment & $-0.42(0.24)$ & -1.75 & $0.56(0.47)$ & 1.19 & -2.72 & 2.09 \\
\hline Posttreatment & $-0.59(.27)$ & -2.19 & $1.22(0.53)$ & 2.30 & -3.33 & 2.69 \\
\hline 6 months posttreatment & $-0.16(0.30)$ & -0.53 & $-0.33(0.60)$ & -0.55 & -2.36 & 2.21 \\
\hline 12 months posttreatment & $-1.08(0.36)$ & -3.00 & $2.31(0.70)$ & $\mathbf{3 . 3 0}$ & -2.98 & 1.81 \\
\hline \multicolumn{7}{|l|}{ Discomfort with Closeness } \\
\hline Pretreatment & $-0.38(0.24)$ & -1.58 & $0.17(0.47)$ & 0.36 & -3.13 & 1.92 \\
\hline Posttreatment & $-0.44(0.27)$ & -1.63 & $0.42(0.53)$ & 0.79 & -2.70 & 2.35 \\
\hline 6 months posttreatment & $-0.37(0.30)$ & -1.23 & $0.46(0.60)$ & 0.77 & -3.17 & 1.86 \\
\hline 12 months posttreatment & $-0.61(0.36)$ & -1.69 & $0.29(0.70)$ & 0.41 & -2.51 & 1.73 \\
\hline \multicolumn{7}{|l|}{ Relationships as Secondary } \\
\hline Pretreatment & $0.19(0.24)$ & 0.79 & $0.16(0.48)$ & 0.33 & -2.24 & 2.89 \\
\hline Posttreatment & $0.21(0.27)$ & 0.78 & $-0.29(0.53)$ & -0.01 & -2.04 & 2.36 \\
\hline 6 months posttreatment & $-0.07(0.30)$ & -0.23 & $-0.20(0.60)$ & -0.33 & -2.36 & 2.23 \\
\hline 12 months posttreatment & $0.07(0.35)$ & -.20 & $-0.55(0.70)$ & -0.79 & -1.88 & 2.19 \\
\hline \multicolumn{7}{|l|}{ Days Binged (7 Days) } \\
\hline Pretreatment & $-.38(0.24)$ & -1.58 & $-0.32(0.47)$ & -0.68 & -2.37 & 1.86 \\
\hline Posttreatment & $1.11(0.29)$ & 3.83 & $0.39(0.57)$ & 0.68 & -0.92 & 2.45 \\
\hline 6 months posttreatment & $1.25(0.32)$ & 3.91 & $-.03(0.62)$ & -0.05 & -0.68 & 2.11 \\
\hline 12 months posttreatment & $0.07(0.35)$ & 0.20 & $-0.55(0.70)$ & -0.79 & -0.68 & 2.81 \\
\hline \multicolumn{7}{|l|}{ Days Binged (28 Days) } \\
\hline Pretreatment & $0.60(0.24)$ & 2.50 & $-0.48(0.47)$ & -1.02 & -1.77 & 2.02 \\
\hline Posttreatment & $1.29(0.29)$ & 4.45 & $1.10(0.57)$ & 1.93 & -0.98 & 2.93 \\
\hline 6 months posttreatment & $1.38(0.31)$ & 4.45 & $0.55(0.62)$ & 0.89 & -0.76 & 2.40 \\
\hline \multicolumn{7}{|l|}{ Depressive Symptoms } \\
\hline Pretreatment & $0.25(0.24)$ & 1.04 & $-0.59(0.48)$ & -1.23 & -1.73 & 2.53 \\
\hline Posttreatment & $1.03(0.27)$ & 3.81 & $0.76(0.53)$ & 1.43 & -1.25 & 3.36 \\
\hline 6 months posttreatment & $1.02(0.30)$ & 3.40 & $1.28(0.60)$ & 2.13 & -1.22 & 3.52 \\
\hline 12 months posttreatment & $0.81(0.36)$ & 2.25 & $0.70(0.70)$ & 1.00 & -1.27 & 3.15 \\
\hline Pretreatment Self-Esteem & $0.26(0.24)$ & 1.08 & $-0.96(0.48)$ & -2.00 & -1.73 & 2.13 \\
\hline
\end{tabular}


${ }^{\text {a }}$ Pretreatment values are presented for the 102 participants who commenced treatment rather than only for the 87 participants with complete data, as the former were used to examine Hypothesis 1. Pretreatment diagnostic statistics for the 87 participants differed minimally from those for the 102 participants.

${ }^{\mathrm{b}}$ Preoccupation $=$ Preoccupation with Relationships .

Note. Potential outliers and problems with normality appear in boldface.

relationship between week 4 group attachment anxiety and pretreatment self-esteem appeared somewhat heteroscedastic such that there appeared to be slightly more variance at high rather than low levels of the standardized predicted values. Square root transformation of the self-esteem variable appeared to improve homoscedasticity and after transformation, self-esteem remained normally distributed and without univariate outliers. Because results did not change with transformation, the original data were retained so as to maintain interpretability.

Second, the relationship between week 4 group attachment anxiety and pretreatment Preoccupation with Relationships also appeared slightly heteroscedastic, as there was more variance at high than low standardized predicted values. The relationship appeared more homoscedastic after squaring week 4 group attachment, and the variable remained normally distributed. However, the original distribution was retained as results did not change with the transformation.

Third, the relationship between group attachment avoidance and pretreatment Discomfort with Closeness appeared slightly heteroscedastic such that the variance appeared to be higher at higher levels of standardized predicted values. This relationship improved after I squared the Discomfort with Closeness variable, which remained normally distributed with no univariate outliers after transformation. However because results did not change with transformation, the original variable was retained. 
Consideration of multivariate outliers. I used Mahalanobis distances to assess for multivariate outliers. For analyses with two variables of interest (e.g. bivariate correlations between variables for Hypothesis 1 ), I used a cut-off of $\chi^{2}(2)=13.82, p=$ .001 ; for analyses with three variables of interest (e.g. in which pretreatment scores, group attachment anxiety slopes, and group attachment avoidance slopes were in the model for Hypothesis 4), I used a cut-off of $\chi^{2}(3)=16.27, p=.001$ (Tabachnick \& Fidell, 2007). Based on these criteria, there were no multivariate outliers.

Consideration of multicollinearity. To assess for multicollinearity between the level-2 predictors of interest ${ }^{2}$, I assessed correlations between variables and tolerance values. Group attachment anxiety and group attachment avoidance slopes were correlated at $r=.58(n=85, p<.001)$. Correlations between these slopes and pretreatment variables did not exceed .12. All tolerance values were equal to or above .64 . Therefore, multicollinearity was not a problem (Cohen et al. 2003).

Assumptions of multilevel modeling. After the final models were determined, the six assumptions of multilevel modeling were assessed and determined to be met (see Appendix F).

\section{Comparison of Attachment Anxiety Conditions}

To evaluate the extent to which participants in the higher individual attachment anxiety condition differed from those in the lower individual attachment anxiety condition on pretreatment measures of individual attachment, I performed independent samples $t$ tests. As indicated in Table 5, relative to participants in the lower attachment

\footnotetext{
${ }^{2}$ Because bivariate correlations were of interest for Hypothesis 1 and because a time variable was the only level-1 predictor in the multilevel models (discussed below), multicollinearity was only pertinent for the level-2 predictors that were together in a model (i.e. group attachment anxiety slopes, group attachment avoidance slopes, and pretreatment scores).
} 
anxiety condition, those in the higher condition reported significantly lower levels of Confidence and significantly higher levels of Need for Approval, Preoccupation with Relationships, Discomfort with Closeness, and Relationships as Secondary. Therefore relative to participants in higher individual attachment anxiety condition, those in the lower individual attachment anxiety condition appeared to be more securely attached overall (see Discussion section for further consideration of this issue).

Table 5

Comparisons of Higher and Lower Attachment Anxiety Conditions on Attachment

\begin{tabular}{lcccccc}
\hline & \multicolumn{7}{c}{ Attachment Anxiety Condition } \\
\cline { 2 - 5 } Attachment Styles Questionnaire & \multicolumn{2}{c}{ Higher } & \multicolumn{2}{c}{ Lower } & & \\
\cline { 2 - 6 } Subscale & $M$ & $S D$ & $M$ & $S D$ & $t$ & $d$ \\
\hline Confidence & 3.32 & 0.71 & 4.16 & 0.76 & $-5.31^{* *}$ & 1.14 \\
Need for Approval & 4.78 & 0.45 & 3.29 & 0.55 & $13.72^{* *}$ & 2.97 \\
Preoccupation with Relationships & 4.21 & 0.71 & 3.49 & 0.77 & $4.53^{* *}$ & 0.98 \\
Discomfort with Closeness & 4.55 & 0.68 & 3.71 & 0.71 & $5.62^{* *}$ & 1.21 \\
Relationships as Secondary & 2.98 & 0.76 & 2.49 & 0.61 & $3.30^{*}$ & 0.71 \\
\hline
\end{tabular}
${ }^{*} p=.001{ }^{* *} \mathrm{p}<.001$.

\section{Hypothesis Test Results}

Convergent Validity of the Social Group Attachment Scale. The first hypothesis of this study was that the Social Group Attachment Scale would show evidence of convergent validity. Specifically, I expected that the group attachment anxiety subscale would be positively correlated with measures of individual attachment anxiety and group engagement, and negatively correlated with self-esteem. I also expected that the group attachment avoidance subscale would be positively correlated with measures of individual attachment avoidance, and negatively correlated with selfesteem and group engagement. As indicated in Table 6, results of most tests provided support for Hypothesis 1. 
Table 6

Correlations (and p Values) Used to Assess the Convergent Validity of the Social Group Attachment Scale

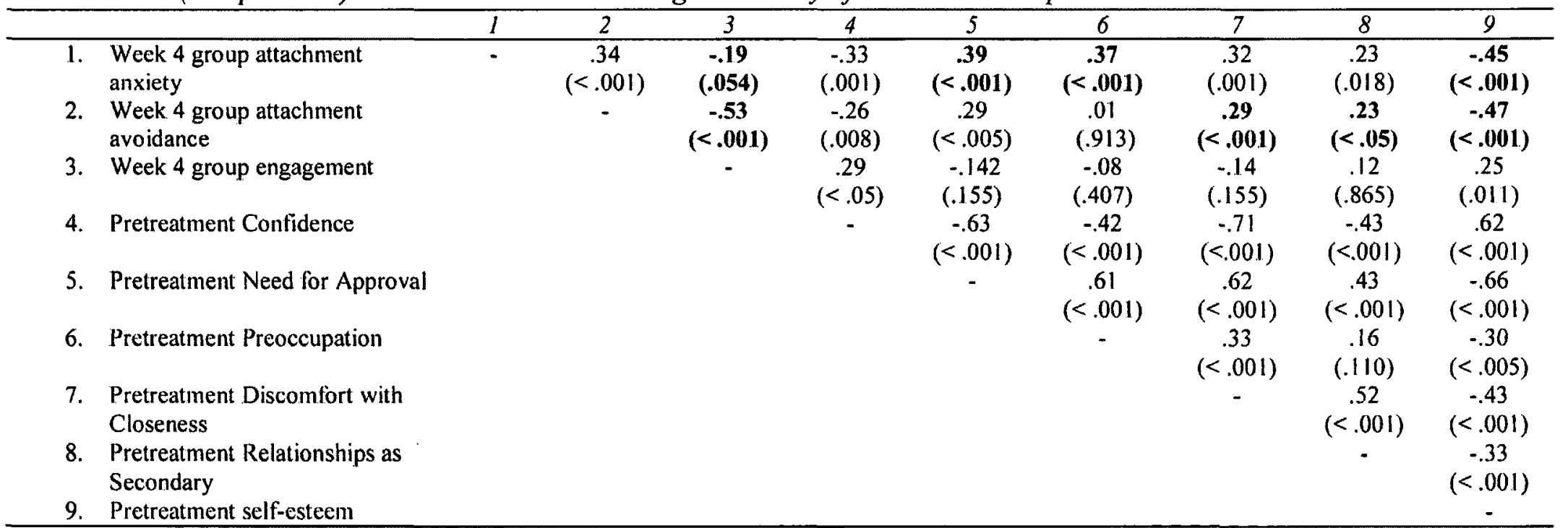

Note. $N=102$. Multiple imputation was used to obtain these results. These correlations differed minimally from those based on only those with complete data. Values that address Hypothesis 1 appear in boldface. Preoccupation = Preoccupation with Relationships.

Week 4 group attachment anxiety was significantly positively correlated with pretreatment Need for Approval and pretreatment Preoccupation with Relationships, and significantly negatively correlated with pretreatment self-esteem. Effect sizes for these relationships were medium to large (Cohen, 1992). Week 4 group attachment anxiety was not significantly associated with week 4 group engagement, although the effect was marginally significant and small to medium (Cohen, 1992).

Week 4 group attachment avoidance was significantly positively related to pretreatment Discomfort with Closeness and pretreatment Relationships as Secondary, with small to medium effect sizes (Cohen, 1992). Week 4 group attachment avoidance 
was also significantly negatively related to pretreatment self-esteem and group engagement. These effect sizes were medium to large and large, respectively. Additionally, week 4 group engagement was not significantly associated with pretreatment measures of individual attachment anxiety and avoidance, suggesting that the Social Group Attachment Scale provided incremental validity over and above measures of individual attachment. To further assess this possibility, I conducted a hierarchical multiple regression analysis in which measures of individual attachment anxiety and avoidance were entered in a first step, and group attachment anxiety and avoidance were entered in the second step. Table 7 shows results of this analysis. At step 1, pretreatment Need for Approval, pretreatment Discomfort with Closeness, and pretreatment Relationships as Secondary significantly predicted Week 4 such that participants with lower scores on Need for Approval and Discomfort with closeness and with higher scores on Relationships as Secondary reported higher levels of group engagement. However, the effect size for this relationship was negligible (Cohen, 1992). At step 2, week 4 group attachment anxiety did not significantly predict week 4 group engagement. However, week 4 group attachment avoidance was significantly negatively associated with week 4 group engagement, with a large effect size. Therefore, group attachment avoidance predicted incremental variance in week 4 group engagement over and above pretreatment measures of individual attachment, while group attachment anxiety did not.

In sum, results supported the convergent validity of the Social Group Attachment Scale. 
Table 7

Hierarchical Multiple Regression Analysis Predicting Week 4 Group Engagement from Pretreatment Individual Attachment and Week 4 Group Attachment

\begin{tabular}{|c|c|c|c|c|c|c|c|}
\hline & $B$ & $S E$ & $\beta$ & $t$ & $p$ & $95 \% \mathrm{Cl}$ & $s r^{2}$ \\
\hline \multicolumn{8}{|l|}{ Step 1} \\
\hline Pretreatment Need for Approval & -.15 & .06 & .165 & -2.62 & .009 & {$[-.26,-.04]$} & .01 \\
\hline Pretreatment Preoccupation & .07 & .05 & .07 & 1.39 & .165 & {$[-.03, .17]$} & .00 \\
\hline Pretreatment Discomfort with Closeness & -.13 & .05 & -.14 & -2.45 & .015 & {$[-.23,-.03]$} & .01 \\
\hline Pretreatment Relationships as Secondary & .14 & .05 & .14 & 2.92 & .004 & {$[.05, .24]$} & .01 \\
\hline \multicolumn{8}{|l|}{ Step 2} \\
\hline Pretreatment Need for Approval & .01 & .05 & .01 & .23 & .818 & {$[-.09, .11]$} & .00 \\
\hline Pretreatinent Preoccupation & -.05 & .05 & -.05 & -1.16 & .245 & {$[-.14, .04]$} & .00 \\
\hline Pretreatment Discomfort with Closeness & -.05 & .04 & -.06 & -1.18 & .239 & {$[-.14, .04]$} & .00 \\
\hline Pretreatment Relationships as Secondary & .18 & .04 & .17 & 4.22 & $<.001$ & {$[.09, .26]$} & .02 \\
\hline Week 4 group attachment anxiety & -.01 & .03 & -.01 & -.28 & .781 & {$[-.07, .05]$} & .00 \\
\hline Week 4 group attachment avoidance & -.45 & .03 & -.56 & -14.28 & $<.001$ & {$[-.52,-.39]$} & .24 \\
\hline
\end{tabular}

Note. $\mathrm{SE}=$ standard error of $B ; \mathrm{Cl}=$ confidence interval; Preoccupation = Preoccupation with Relationships.

Group Attachment Avoidance as a Predictor of Dropout. This study's second hypothesis was that group attachment

avoidance would be positively associated with dropping out of group therapy for women with binge-eating disorder, controlling for individual attachment avoidance. To test this hypothesis, I used multilevel modeling (described in Appendix F). Table 8 presents the multilevel models used to test Hypotheses 2, 3, 4, and 5. Because the outcome for Hypothesis 2 was binary (i.e. treatment dropout vs. treatment completion) I used a model with a Bernoulli distribution (Raudenbush \& Bryk, 2002). This model is similar to logistic regression models in that the probability of the outcome is logarithmically transformed to improve issues with nonnormality and nonlinearity (Raudenbush \& Bryk, 2002). I used Model 3 (Appendix E) to test Hypothesis 2, and Appendix G provides a rationale for centering decisions used in this model. To assess effect size I assessed the odds ratio, the change in odds of a participant completing 
treatment with a 1 -unit increase in the predictor variable (Tabachnick \& Fidell, 2007). As indicated in Table 9, results did not support Hypothesis 2. Controlling for pretreatment individual attachment avoidance, week 4 group attachment avoidance did not significantly predict dropout. The model that included week 4 group attachment avoidance at level 1 did not improve model fit, $\chi^{2}(4)=1.97, p>.500$. However, given that only eight $(9.30 \%)$ of the 86 individuals with available data on the Social Group Attachment Scale dropped out of treatment and that the odds ratio of 1.30 represented a small to medium effect size (where $1.17=$ small, $1.66=$ medium, and $2.55=$ large; Allen \& Le, 2008), I conducted an independent samples $t$ test with all 102 participants in the dataset. Even using data from all 102 participants there were no significant differences between those who completed and dropped out from treatment, $t(99)=1.32, p=.189$, and the effect size of $d=.34$ remained small (Cohen, 1992).

Change in Group Attachment Anxiety and Avoidance. This study's third hypothesis was that group attachment anxiety and avoidance would decrease significantly during therapy. I used multilevel modeling to test this hypothesis (see Model 6, Appendix E). To assess effect size I examined pseudo $-R^{2}$, the proportion of total within-person variance from a completely unconditional model $\left(\sigma^{2}\right)$ accounted for by adding time to the model in which $\sigma^{2}$ is the within person variance associated with time in the model: i.e., pseudo- $R^{2}=\left(\sigma_{u}^{2}-\sigma^{2}\right) / \sigma_{u}^{2}$ (Raudenbush \& Bryk, 2002).

Table10 presents results of these analyses. Group attachment anxiety decreased significantly during treatment, controlling for week 4 group attachment anxiety. Further, adding the logarithmic time variable to the model significantly improved model fit, $\chi^{2}(3)$ $=11.07, p=.011$. 
Table 8

Multilevel Models Used to test Hypotheses 2, 3, 4, and 5

\begin{tabular}{|c|c|}
\hline Hypothesis & Analysis \\
\hline $\begin{array}{l}\text { 2. Group attachment avoidance is positively } \\
\text { associated with dropping out of group psychodynamic } \\
\text { interpersonal psychotherapy, controlling for individual } \\
\text { attachment avoidance. }\end{array}$ & 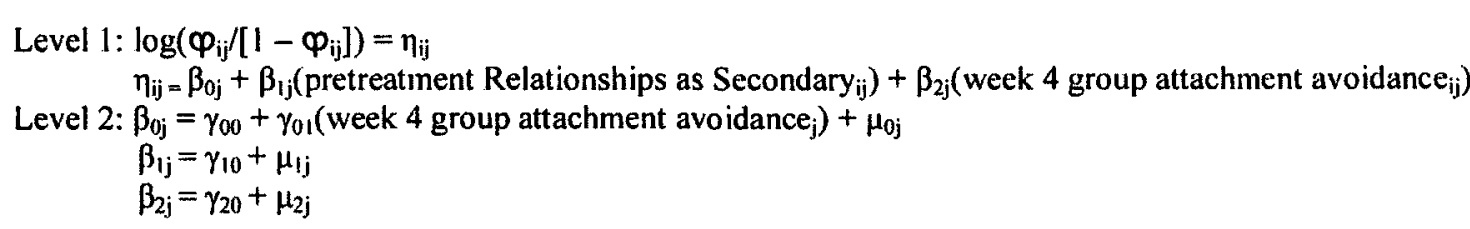 \\
\hline & Where $\varphi_{\mathrm{ij}}$ represents the predicted probability that a participant completed treatment. \\
\hline $\begin{array}{l}\text { 3. Group attachment anxiety and avoidance decrease } \\
\text { significantly during group psychodynamic } \\
\text { interpersonal psychotherapy. }\end{array}$ & $\begin{array}{l}\text { Multilevel modeling: } \\
\text { Level 1: } Y_{1 \mathrm{i}}=\pi_{0 \mathrm{i}}+\pi_{1 \mathrm{i}}\left(\text { logtime }_{\mathrm{ti}}\right)+\mathrm{e}_{\mathrm{ti}} \\
\text { Level 2: } \pi_{0 \mathrm{i}}=\beta_{00}+\beta_{01}\left(\text { Week } 4 \text { group attachment anxiety or avoidance } \mathrm{i}_{\mathrm{i}}\right)+\mathrm{r}_{0 \mathrm{i}} \\
\qquad \pi_{1 \mathrm{ij}}=\beta_{10}+\beta_{11}\left(\text { Week } 4 \text { group attachment anxiety or avoidance }{ }_{\mathrm{i}}\right)+r_{1 \mathrm{i}} \\
\text { Where } Y_{\mathrm{ti}} \text { represents a participant's group attachment anxiety or avoidance score at a given time. }\end{array}$ \\
\hline $\begin{array}{l}\text { 4. Decreases in group attachment anxiety and } \\
\text { avoidance during group psychodynamic interpersonal } \\
\text { therapy predict decreases in number of days binged } \\
\text { and depressive symptoms. }\end{array}$ & 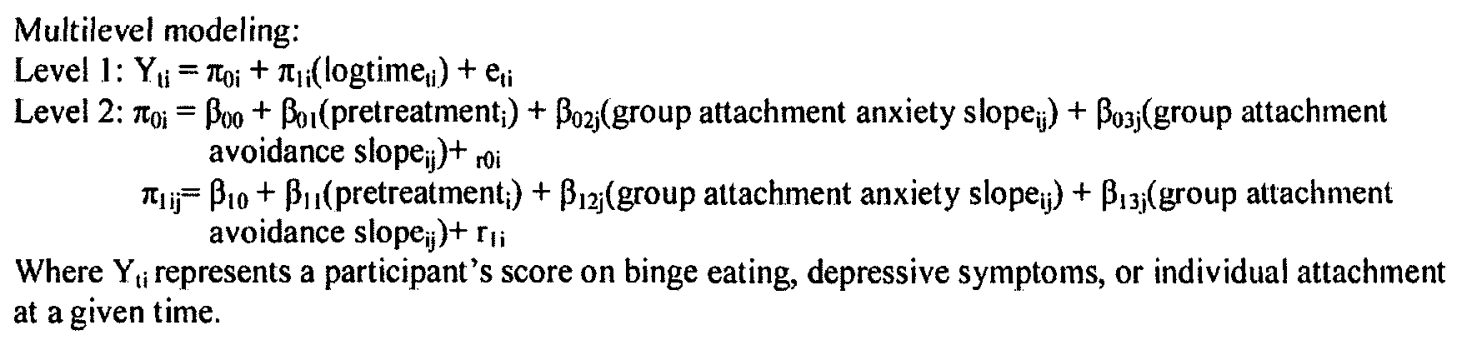 \\
\hline $\begin{array}{l}\text { 5. Individual attachment anxiety moderates the } \\
\text { relationships between changes in group attachment } \\
\text { anxiety and avoidance and changes in treatment } \\
\text { outcomes. }\end{array}$ & 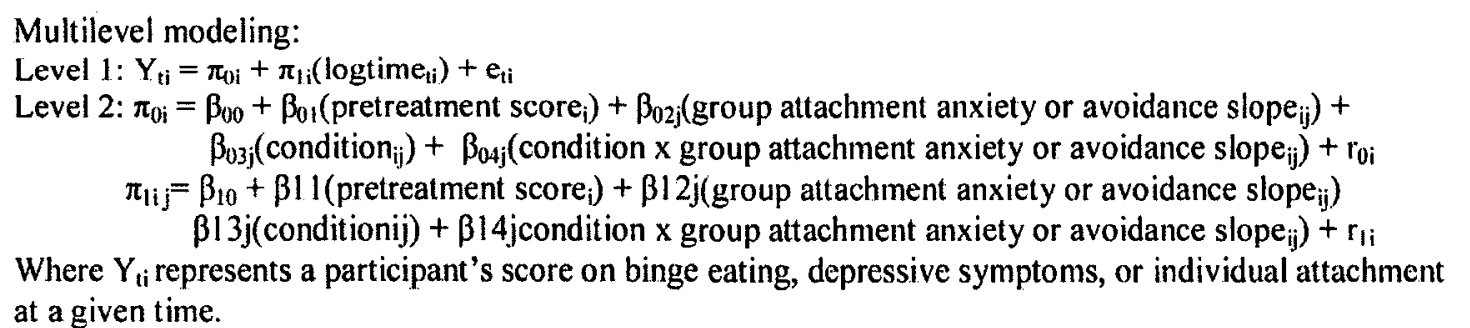 \\
\hline
\end{tabular}


Table 9

Results of Model Predicting Treatment Dropout from Week 4 Group Attachment Avoidance and Pretreatment Individual Attachment Avoidance

\begin{tabular}{lccccc}
\hline Predictors & $\gamma(S E)$ & $t$ & $p$ & $O R$ & $95 \% \mathrm{CI}$ \\
\hline Level I $^{\text {Pretreatment Relationships as Secondary }}{ }^{\mathrm{a}}$ & $-.16(.55)$ & -.29 & .780 & .85 & {$[.26,2.85]$} \\
Week 4 group attachment avoidance $^{\mathrm{b}}$ & $\mathbf{. 2 6}(\mathbf{4 8 )}$ & $\mathbf{. 5 5}$ & $\mathbf{. 5 9 1}$ & $\mathbf{1 . 3 0}$ & {$[\mathbf{. 4 6}, \mathbf{3 . 7 1}]$} \\
Level 2 $^{\text {Week 4 group attachment avoidance }}$ & & & & & \\
\end{tabular}

Note. $N=86 . S E=$ standard error. $O R=$ odds ratio. $\mathrm{CI}=$ confidence interval for $\mathrm{OR}$.

Values that specifically address Hypothesis 2 appear in boldface. Deviance statistic for the model without level-1 week 4 group attachment avoidance $=210.97$. Deviance for the model with level-1 week 4 group attachment avoidance $=210.55$.

${ }^{a}$ Pretreatment Relationships as Secondary was grand-mean centered.

${ }^{b}$ Level-1 week 4 group attachment avoidance was group-mean centered.

${ }^{c}$ Level-2 week 4 group attachment avoidance was grand-mean centered.

Group attachment avoidance also decreased significantly during treatment, controlling for week 4 group attachment avoidance. The model that included the logtime variable at level-1 fit the data significantly better than the model that did not include this variable, $\chi^{2}(3)=20.06, p<.001$. Therefore, consistent with this study's third hypothesis, both group attachment anxiety and avoidance decreased significantly during treatment. Specifically, participants tended to experience substantial decreases in group attachment insecurity between weeks 4 and 8 of treatment, and such changes were less substantial between weeks 8 and 16. After the final model was determined, the six assumptions of multilevel modeling were assessed and determined to be met (see Appendix F).

Change in Group Attachment as a Predictor of Treatment Outcomes. For Hypothesis 4, I expected that reductions in group attachment anxiety and avoidance would predict reductions in number of days binged in the past 7 and 28 days and in depressive symptoms at posttreatment, 6 months posttreatment, and 12 months posttreatment. To assess this hypothesis, I saved participants' ordinary least squares 
Table 10

Fixed and Random Effects Estimates for Models of Change in Group Attachment Anxiety and Avoidance During Treatment

\begin{tabular}{|c|c|c|c|c|c|c|c|c|}
\hline & \multicolumn{3}{|c|}{ Fixed Effects } & \multicolumn{3}{|c|}{ Random Effects } & \multicolumn{2}{|c|}{ Deviance } \\
\hline Outcome & $\beta(S E)$ & $t$ & $p$ & $\sigma_{b}^{2}$ & $\sigma_{1}^{2}$ & $R^{2}$ & Base & Logtime \\
\hline Group attachment anxiety & $-.48(.14)$ & -3.36 & .001 & .38 & .33 & .13 & 738.85 & 727.78 \\
\hline Group attachment avoidance & $-.45(.16)$ & -2.49 & .006 & .35 & .29 & .17 & 732.27 & 712.27 \\
\hline
\end{tabular}

Note. $N=87 . S E=$ standard error. $\sigma_{\mathrm{b}}^{2}=$ level-1 variance component from a null model (i.e. with no predictors; $d f=3$ ). $\sigma_{1}^{2}=$ level-1 variance component from a conditional model (i.e. in which a logtime variable was added to the model; $d f=6$ ).

group attachment anxiety and avoidance slopes from Model 6 (Appendix E). I then entered these slopes as a level-2 (person-level) variable in a model that predicted change in treatment outcomes (see Model 7, Appendix E).

As indicated in Table 11, participants experienced significant reductions in all outcome variables. For each variable, adding logtime to the model significantly improved model fit, indicating that participants experienced substantial changes in binge eating and depressive symptoms during treatment and that such changes were maintained at 12 months posttreatment. Statistics representing improvement in model fit are as follows: $\chi^{2}(3)=95.94, p<.001$ for days binged $(7$ days $) ; \chi^{2}(3)=114.18, p<.001$ for days binged $(28$ days); and $\chi^{2}(3)=56.62, p<.001$ for depressive symptoms. However as indicated in Table 12, change in group attachment anxiety and avoidance did not predict change in number of days binged or depressive symptoms.

To further explore the influence of change in group attachment, I examined whether change in group attachment anxiety and avoidance predicted change in individual attachment anxiety and avoidance from pre-treatment to 12 months posttreatment. Once again, all measures of individual attachment anxiety and avoidance significantly decreased (see Table 11), and adding logtime to the 
Table 11

Fixed and Random Effects Estimates for Models of Change in Treatment Outcomes Between Pretreatment and 12 Months Posttreatment

\begin{tabular}{|c|c|c|c|c|c|c|c|c|}
\hline \multirow[b]{2}{*}{ Outcomes } & \multicolumn{3}{|c|}{ Fixed Effects } & \multicolumn{3}{|c|}{ Random Effects } & \multicolumn{2}{|c|}{ Deviance } \\
\hline & $\beta(S E)$ & $t$ & $p$ & $\sigma_{b}^{2}$ & $\sigma_{1}^{2}$ & $R^{2}$ & Base & Logtime \\
\hline \multicolumn{9}{|l|}{ Individual Attachment } \\
\hline Need for Approval & $-.99(.14)$ & -7.19 & $<.001$ & .27 & .19 & .30 & 575.99 & 533.32 \\
\hline $\begin{array}{l}\text { Preoccupation with } \\
\text { Relationships }\end{array}$ & $-.34(.12)$ & -2.84 & .006 & .20 & .17 & .15 & $478.98 \mathrm{~S}$ & 469.68 \\
\hline Discomfort with Closeness & $-.73(.13)$ & -5.79 & $<.001$ & .22 & .13 & .41 & 514.65 & 474.13 \\
\hline Relationships as Secondary & $-.73(.14)$ & -5.40 & $<.001$ & .24 & .18 & .25 & 534.46 & 507.04 \\
\hline \multicolumn{9}{|l|}{ Days Binged } \\
\hline 7 days & $-4.34(.42)$ & -10.44 & $<.001$ & 3.82 & 2.31 & .40 & 1239.38 & 1143.44 \\
\hline 28 days & $-18.7(1.44)$ & -13.04 & $<.001$ & 56.06 & 31.20 & .44 & 2010.86 & 1896.68 \\
\hline Depressive Symptoms & $-15.54(2.03)$ & -7.66 & $<.001$ & 54.58 & 33.59 & .38 & 1932.24 & 1875.62 \\
\hline
\end{tabular}

Note. For most variables, results are based on the $N=85$ cases with available data on the Social Group Attachment Scale, as these participants' data were then used to determine whether change in group attachment predicted change in treatment outcomes. The exception is the depressive symptoms variable, for which 84 cases had available data. $S E=$ standard error. $\sigma_{b}^{2}=$ level-1 variance component from a null model (i.e. with no predictors; $d f=3$ ). $\sigma_{1}^{2}=$ level-1 variance component from a conditional model (i.e. in which a logtime variable was added to the model; $d f=6$ ).

model significantly improved model fit: $\chi^{2}(3)=42.67, p<.001$ for Need for Approval; $\chi^{2}(3)=27.42, p<.001$ for Preoccupation with Relationships; $\chi^{2}(3)=40.52, p<.001$ for Discomfort with Closeness; and $\chi^{2}(3)=9.30, p=.025$ for Relationships as Secondary.

Reductions in group attachment avoidance predicted reductions in three measures of individual attachment (see Table 12).

First, reductions in group attachment avoidance during group therapy predicted reductions in Need for Approval up to 12 months 
Table 12

Fixed and Random Effects for Models Predicting Pretreatment to 12 Months Posttreatment Change in Treatment Outcomes from Change in Group Attachment

\begin{tabular}{|c|c|c|c|c|c|c|c|c|c|}
\hline \multirow[b]{3}{*}{ Outcomes } & \multicolumn{6}{|c|}{ Fixed Effects } & \multicolumn{3}{|c|}{ Random Effects } \\
\hline & \multicolumn{3}{|c|}{ Group Attachment Anxiety } & \multicolumn{3}{|c|}{ Group Attachment Avoidance } & \multirow[b]{2}{*}{$\tau_{1}^{2}$} & \multirow[b]{2}{*}{$\tau_{s}^{2}$} & \multirow[b]{2}{*}{$R^{2}$} \\
\hline & $\beta_{\mathrm{anx}}(S E)$ & $t_{\mathrm{anx}}$ & $p_{\text {anx }}$ & $\beta_{\text {avoid }}(S E)$ & $t_{\text {nvoid }}$ & $p_{\text {avoid }}$ & & & \\
\hline \multicolumn{10}{|l|}{ Individual attachment } \\
\hline Need for Approval & $0.03(0.10)$ & 0.34 & .733 & $0.27(0.11)$ & 2.52 & .014 & 1.18 & 0.97 & .18 \\
\hline Preoccupation with Relationships & $0.04(0.08)$ & 0.43 & .666 & $0.20(0.10)$ & 2.08 & .040 & 1.08 & 0.96 & .11 \\
\hline Discomfort with Closeness & $-0.08(0.10)$ & -0.78 & .440 & $0.17(0.08)$ & 2.05 & .044 & 0.96 & 0.92 & .04 \\
\hline Relationships as Secondary & $-0.03(0.09)$ & -0.37 & .712 & $0.10(0.09)$ & 1.12 & .266 & 0.78 & 0.74 & .05 \\
\hline \multicolumn{10}{|l|}{ Days Binged } \\
\hline 7 days & $-0.01(0.35)$ & -0.02 & .981 & $-0.32033)$ & -0.99 & .325 & 9.55 & 9.47 & .01 \\
\hline 28 days & $-0.57(1.14)$ & -0.50 & .620 & $-0.11(1.13)$ & -0.10 & .921 & 115.27 & 115.34 & .00 \\
\hline Depressive Symptoms & $-1.36(1.57)$ & -0.86 & .391 & $0.93(1.48)$ & 0.63 & .533 & 246.04 & 243.46 & .01 \\
\hline
\end{tabular}

Note. Results are based on the $N=85$ cases with available data on the Social Group Attachment Scale, with the exception being the depressive symptoms variable for which 84 cases had available data. $\beta_{\mathrm{anx}}=$ relationship between change in group attachment anxiety and change in treatment outcomes. $\beta_{\text {avoid }}=$ relationship between change in attachment avoidance and change in treatment outcomes. $S E$ $=$ standard error. $\tau^{2}{ }_{\mathrm{t}}=$ level-2 variance component from model with logtime at level 1 and pretreatment scores at level $2(d f=8) . \tau^{2}{ }_{\mathrm{s}}=$ level-2 variance component from a model to which group attachment anxiety and avoidance slopes were added $(d f=12)$.

posttreatment, and adding the group attachment slopes significantly improved model fit, $\chi^{2}[4]=13.57, p=.009$. Second, decreases in group attachment avoidance during treatment predicted decreases in Preoccupation with Relationships up to 12 months posttreatment, however adding the group attachment slopes did not improve model fit, $\chi^{2}[4]=8.17, p=.085$. Third, reductions in group attachment avoidance during group therapy were associated with reductions in Discomfort with Closeness up to 12 months posttreatment, but adding the group attachment slopes to the model did not improve the model fit, $\chi^{2}[4]=5.90, p=.205$. Therefore, while reductions in group attachment avoidance significantly predicted reductions in individual attachment insecurity, the models that included change in 
group attachment avoidance as a predictor of either Preoccupation with Relationships or Discomfort with Closeness were not significantly more likely to fit the overall data than the models that did not include group attachment avoidance slopes (Raudenbush \& Bryk, 2002).

In sum, results did not support Hypothesis 4 as reductions in group attachment during therapy did not predict reductions in number of days binged or depressive symptoms up to 12 months posttreatment. However, decreases in group attachment avoidance during therapy predicted decreases in measures of individual attachment anxiety and avoidance up to 12 months posttreatment.

Moderating Effects of Individual Attachment Anxiety. This study's fifth hypothesis was that individual attachment anxiety condition would moderate the relationships between change in group attachment and change in treatment outcomes such that these relationships would be particularly strong for those higher in individual attachment anxiety (see Model 8). Table 11 presents results of the models examining the condition $\mathrm{x}$ group attachment anxiety change interaction. Attachment anxiety condition did not moderate the relationship between change group attachment anxiety and change in any treatment outcome. Further, adding attachment anxiety condition to the model did not significantly improve model fit for any outcome: $\chi^{2}(2)=1.91, p>.500$ for days binged $(7$ days $) ; \chi^{2}(2)=0.60, p>.500$ for days binged $(28$ days $) ; \chi^{2}(2)=0.34, p>.500$ for depressive symptoms; $\chi^{2}(2)=1.19, p>.500$ for Need for Approval; $\chi^{2}(2)=0.38, p>$ .500 for Preoccupation with Relationships; $\chi^{2}(2)=3.93, p>.500$ for Discomfort with Closeness; and $\chi^{2}(2)=3.50, p=.172$ for Relationships as Secondary.

As indicated in Table 13, condition also did not moderate the relationship 
between change in group attachment avoidance and change in any treatment outcome, and adding the interaction term to the model did not improve model fit: $\chi^{2}(2)=0.30, p>.500$ for days binged $(7$ days $) ; \chi^{2}(2)=0.12, p>.500$ for days binged $(28$ days $) ; \chi^{2}(2)=1.10, p$ $>.500$ for depressive symptoms; $\chi^{2}(2)=0.08, p>.500$ for Need for Approval; $\chi^{2}(2)=5.52, p=.062$ for Preoccupation with

Relationships; $\chi^{2}(2)=2.30, p=.317$ for Discomfort with Closeness; and $\chi^{2}(2)=1.12, p>.500$ for Relationships as Secondary.

Table 13

Fixed and Random Effects for Models Evaluating the Moderating Effect of Attachment Anxiety Condition on the Relationship Between Change in Group Attachment Anxiety and Change in Treatment Outcomes

\begin{tabular}{|c|c|c|c|c|c|c|c|c|}
\hline \multirow[b]{2}{*}{ Outcomes } & \multicolumn{3}{|c|}{ Fixed Effects } & \multicolumn{3}{|c|}{ Random Effects } & \multicolumn{2}{|c|}{ Deviance } \\
\hline & $\beta(S E)$ & $t$ & $p$ & $\tau_{\mathrm{c}}^{2}$ & $\tau_{i}^{2}$ & $R^{2}$ & No Interaction & Interaction \\
\hline \multicolumn{9}{|l|}{ Individual Attachment } \\
\hline Need for Approval & $-0.23(0.19)$ & -1.25 & .214 & 1.08 & 1.05 & .03 & 316.21 & 315.53 \\
\hline Preoccupation with Relationships & $-0.21(0.18)$ & -1.18 & .241 & 1.02 & 1.00 & .02 & 295.33 & 294.95 \\
\hline Discomfort with Closeness & $-0.22(0.15)$ & -1.45 & .151 & 0.93 & 0.90 & .03 & 225.73 & 221.80 \\
\hline Relationships as Secondary & $-0.32(0.17)$ & -1.85 & .068 & 0.78 & 0.74 & .05 & 277.73 & 274.23 \\
\hline \multicolumn{9}{|l|}{ Days Binged } \\
\hline 7 days & $0.07(0.59)$ & 0.111 & .912 & 9.40 & 9.38 & .00 & 1049.29 & 1048.85 \\
\hline 28 days & $1.78(2.10)$ & 0.86 & .400 & 112.45 & 109.79 & .02 & 1793.01 & 1791.50 \\
\hline Depressive Symptoms & $2.01(2.37)$ & 0.85 & .400 & 244.30 & 241.72 & .01 & 1672.89 & 1672.21 \\
\hline
\end{tabular}

Note. Results are based on the $N=85$ cases with available data on the Social Group Attachment Scale, with the exception being the depressive symptoms variable for which 84 cases had available data. $S E=$ standard error. $\tau_{\mathrm{c}}^{2}=$ level-2 variance component from model with logtime at level 1 and pretreatment scores, group attachment anxiety slopes, and condition at level $2(d f=12) . \tau_{i}^{2}=l e v e l-2$ variance component from a model to which the condition $\mathrm{x}$ group attachment anxiety slope was added $(d f=14)$.

Therefore, results did not support Hypothesis 5. That is, the relationship between change in group attachment and change in treatment outcomes did not differ as a function of whether participants were in the higher or lower in attachment anxiety condition. 
Table 14

Fixed and Random Effects for Models Evaluating the Moderating Effect of Individual Attachment Anxiety Condition on the Relationship Between Change in Group Attachment Avoidance and Change in Treatment Outcomes

\begin{tabular}{|c|c|c|c|c|c|c|c|c|}
\hline \multirow[b]{2}{*}{ Outcomes } & \multicolumn{3}{|c|}{ Fixed Effects } & \multicolumn{3}{|c|}{ Random Effects } & \multicolumn{2}{|c|}{ Deviance } \\
\hline & $\beta(S E)$ & $t$ & $p$ & $\tau_{\mathrm{c}}^{2}$ & $\tau_{i}^{2}$ & $R^{2}$ & No Interaction & Interaction \\
\hline \multicolumn{9}{|l|}{ Individual Attachment } \\
\hline Need for Approval & $0.05(0.21)$ & 0.21 & .833 & 0.97 & 0.97 & .00 & 307.81 & 307.73 \\
\hline Preoccupation with Relationships & $-0.32(0.20)$ & -1.66 & .101 & 0.96 & 0.89 & .07 & 291.24 & 285.72 \\
\hline Discomfort with Closeness & $-0.11(0.15)$ & -0.75 & .454 & 0.88 & 0.88 & .00 & 221.25 & 218.95 \\
\hline Relationships as Secondary & $-0.16(0.18)$ & -0.91 & .366 & 0.75 & 0.74 & .01 & 275.58 & 274.47 \\
\hline \multicolumn{9}{|l|}{ Days Binged } \\
\hline 7 days & $-0.29(0.55)$ & -0.52 & .604 & 9.26 & 9.25 & .00 & 1050.41 & 1050.11 \\
\hline 28 days & $0.38(1.80)$ & 0.21 & .833 & 113.42 & 113.35 & .00 & 1793.83 & 1793.71 \\
\hline Depressive Symptoms & $2.93(2.25)$ & 1.20 & .197 & 243.82 & 240.03 & .02 & 1673.11 & 1672.01 \\
\hline
\end{tabular}

Note. Results are based on the $N=85$ cases with available data on the Social Group Attachment Scale, with the exception being the depressive symptoms variable for which 84 cases had available data. $S E=$ standard error. $\tau^{2}=$ level -2 variance component from model with logtime at level 1 and pretreatment scores, group attachment avoidance slopes, and condition at level $2(d f=12) . \tau^{2}{ }_{i}=$ level-2 variance component from a model to which the condition $x$ group attachment avoidance slope was added $(d f=14)$.

\section{Discussion}

This study had five objectives. The first objective was to assess the convergent validity of the Social Group Attachment Scale in women attending group psychodynamic interpersonal psychotherapy for binge-eating disorder. The second objective was to examine whether individuals higher in group attachment avoidance are more likely to drop out of group therapy, controlling for individual attachment avoidance. The third objective was to assess whether group attachment anxiety and avoidance can change 
during therapy. The fourth objective was to determine whether changes in group attachment anxiety and avoidance during therapy predict changes in treatment outcomes during therapy, and whether participants are able to maintain such changes after therapy. The fifth was to examine whether individual attachment anxiety moderates the relationship between change in group attachment and change in treatment outcomes.

\section{Convergent Validity of the Social Group Attachment Scale}

Group attachment anxiety. Consistent with Smith and colleagues' (1999) research, week 4 group attachment anxiety was significantly positively and moderately correlated with pretreatment Need for Approval and Preoccupation with Relationships, indicating that while group attachment anxiety is related to individual attachment anxiety, the two constructs are distinct. That is, the extent to which women with binge-eating disorder fear rejection and become preoccupied in dyadic relationships (Feeney \& Noller, 1996) is moderately generalizable to the development of an anxious attachment to a group. These positive correlations also indicate that individuals may apply their typical interpersonal patterns to their therapy groups. This possibility is consistent with Mikulincer and Shaver's (2007) suggestion those with more insecure attachment styles are likely to experience greater difficulty in perceiving their groups as sensitive and accessible (Mikulincer \& Shaver, 2007). These correlations also imply that individuals' interpersonal patterns are activated during therapy, a notion underlying group psychodynamic interpersonal psychotherapy. That is, since a central aim of this therapy is to address and modify patients' Cyclical Relationship Patterns (Tasca, Mikail, \& Hewitt, 2005), it is important that the interpersonal patterns that patients bring to the therapy group are those that impact their interpersonal relationships outside of the group. This 
idea is consistent with Yalom's (1994) conceptualization of groups as social microcosoms, in which an individual's interactions in a group are believed to parallel those outside of the group.

However, group attachment anxiety was not significantly positively correlated with group cohesion. This finding is inconsistent with Holtz's (2004) result that group attachment anxiety and group cohesion were positively correlated in individuals who attended a university counseling centre. While the magnitude of the correlations was the same in both studies $(r=.19)$, the relationship was positive in Holtz and colleagues' (2004) study and negative in the current study. This discrepancy may be an artifact of the differences in measures used in other studies. Holtz (2004) used the Cohesiveness Questionnaire, which assesses the extent to which group members are attracted to and feel a sense of belongingness to their groups (Schutz, 1966). In the current study, I used the Engaged subscale of the Group Climate Questionnaire, which assesses the extent to which members appraise their group climates as positive (MacKenzie, 1983). Individuals higher in group attachment anxiety may feel attracted to their groups (supporting Holtz's [2004] finding), yet their tendency to feel concerned about rejection may detract from their ability to experience their groups' climate as positive (supporting the current study's finding). Relatedly, the mixed findings in the literature concerning the relationship between group attachment anxiety and group cohesion may also be explained by Holtz's (2004) suggestion that individuals higher in group attachment anxiety may feel ambivalent towards their groups. That is, while they may view their groups positively, they may also resent their perceived or potential rejection by their groups (Holtz, 2004).

Consistent with Holtz's (2004) and Smith and colleagues' (1999) findings, week 4 
group attachment anxiety was significantly negatively correlated with pretreatment selfesteem. This finding indicates that those with more positive evaluations of themselves may be less preoccupied with whether their groups will accept them, and that those with more negative self-evaluations may be more preoccupied with being accepted by their groups.

Group attachment avoidance. Group attachment avoidance was significantly negatively and moderately related to measures of individual attachment avoidance, indicating that those who avoid intimacy and express discomfort with closeness (Hazan \& Shaver, 1987) in dyadic relationships are likely to exhibit this tendency in a therapy context as well. This finding is consistent with Maramosh and colleagues' (2009) and Smith and colleagues' (1999) findings indicating that group and individual attachment avoidance are related but separate constructs.

Week 4 group attachment avoidance was significantly negatively related to week 4 group cohesion even after accounting for week 4 group attachment anxiety. That is, individuals who were more uncomfortable with interdependence with the therapy group rated the group's engaged climates less positively. This finding is consistent with previous research indicating that relative to individuals lower in group attachment avoidance, those higher in group attachment avoidance view groups as less valuable, rate group cohesion as lower, and place less emphasis on accommodating the group's needs (Holtz, 2004; Smith et al., 1999). This finding also expands on Mallinckrodt, Gantt, and Coble's (1995) finding that attachment avoidance towards the therapist is negatively related to the therapeutic alliance in individual therapy. Alternatively, a high level of group cohesion may imply interdependence among group members, which may 
exacerbate discomfort with closeness and threaten a sense of autonomy in individuals higher in group attachment avoidance (Mikulincer \& Shaver, 2007).

Week 4 group attachment avoidance was significantly negatively related to selfesteem. This relationship, in conjunction with the significant negative relationship between group attachment anxiety and self-esteem, provides further support for Holtz's (2004) proposition that individuals who feel less secure in social groups have more negative self-worth. These findings provide support for the convergent validity of the Social Group Attachment Scale.

\section{Group Attachment Avoidance as a Predictor of Dropout}

This study's second hypothesis was that week 4 group attachment avoidance would predict dropout from treatment, controlling for pretreatment individual attachment avoidance. Results did not support this hypothesis, as neither week 4 group attachment avoidance nor the pretreatment Relationships as Secondary scale were related to dropout. This finding is inconsistent with previous research. For instance, Smith and colleagues (1999) found that group attachment avoidance was positively associated with plans to leave sororities and fraternities. Additionally, Tasca and colleagues (2004) and Tasca, Ritchie and colleagues (2006) found that pretreatment individual attachment avoidance predicted dropout from group cognitive-behavioural therapy in women with binge-eating disorder, and from day hospital treatment in women with anorexia nervosa binge-purge type. Differences between methodology and social settings may account for this discrepancy. That is, participants in Smith and colleagues' study were assessed on their intent rather than their behaviour, and they did not receive therapy treatment. Further, in Tasca, Ritchie and colleagues' study, the therapeutic context of group cognitive- 
behavioural therapy may not have addressed the potentially distressing interpersonal issues that lead individuals higher in attachment avoidance to reject treatment (Dozier, 1990). Group psychodynamic interpersonal psychotherapy, with its focus on modifying maladaptive interpersonal patterns (Tasca et al., 2005), may have led to reductions in group attachment avoidance and subsequently obviated the urge to drop out of treatment in individuals who were uncomfortable with closeness in a group context. Indeed, individual attachment avoidance did not predict attrition in women with binge-eating disorder who received group psychodynamic interpersonal psychotherapy (Tasca et al., 2006).

Alternatively, group and individual attachment avoidance may have failed to predict dropout due to issues with low power. Although I estimated that power was .81 for detecting a significant relationship between week 4 group attachment avoidance and dropout, only eight of the 86 individuals with available data on all measures dropped out of treatment. That is, of the 18 participants who dropped out of group psychodynamic interpersonal psychotherapy, eight had available data on all measures and $10 \mathrm{did}$ not. This small sample may have prevented the model from adequately fitting the data for individuals who dropped out of treatment. Additionally, the 10 participants who dropped out of treatment and who did not have available data dropped out before Week 4 (when group attachment avoidance was measured). Hence, it is possible that results may not generalize to participants who drop out of therapy early in treatment.

\section{Change in Group Attachment Anxiety and Avoidance}

This study's third hypothesis was that women with binge-eating disorder would experience significant reductions in group attachment anxiety and avoidance. Results 
supported this hypothesis as group attachment anxiety and avoidance both significantly decreased, with medium effect sizes. The finding that group attachment anxiety and avoidance changed is consistent with previous research on change in individual attachment in women with binge-eating disorder (Tasca, Balfour et al., 2007a) and in other populations (e.g. Baldwin \& Fehr, 1995; Kilmann, Laughlin, Carranza, Downer, Major, \& Parnell, 1999; Polansky, Lauterbach, Litzke, Coulter, \& Sommers, 2006). Results of the current study indicate that like individual attachment anxiety and avoidance, group attachment insecurity is subject to change and that individuals can become more securely attached to their therapy groups with the progression of treatment.

Three explanations exist for the specific processes by which change in attachment may occur. While these explanations depict change in attachment differently, they are not mutually exclusive. One possibility is that during therapy, participants were able to identify and subsequently modify their current internal working models of relationships. Later interpersonal experiences and a conscious awareness of one's internal working models (i.e. in psychotherapy) may facilitate change in such models by allowing the individual to re-evaluate his or her beliefs, develop a model of the self as worthy and competent, explore new behaviours, and adjust current relationships (Colin, 1996). In therapy, this process is particularly likely to occur when other group members are empathically attuned to one's emotions, thereby allowing the individual to explore and update his or her internal working model of a supportive environment (McCluskey, 2002). Group psychodynamic interpersonal psychotherapy is focused on identifying and adjusting individuals' tendencies to defensively respond to others and the self in ways that temporarily relieve distress (Tasca et al., 2005). This emphasis may have allowed 
individuals in the current study to address their internal working models of the self and others in a group context, thereby facilitating change.

A second possibility to explain the process of change in attachment is that different cognitive schema of the self and of interpersonal relationships may become activated at different times. According to Baldwin and Fehr (1995), individuals may develop different relational schemas (i.e., different patterns of interpersonal relatedness) for different relational expectations, and these schemas may underlie different attachment patterns. Stability in attachment style may reflect a continually activated schema, and an individual's attachment pattern may be an artifact of the memories, expectations, and self-concept that are activated at a given time (Baldwin \& Fehr, 1995) and potentially in a given relationship. In group psychodynamic interpersonal psychotherapy, one of the therapist's tasks is to establish a safe and cohesive environment so as to facilitate authentic attachments among members (Tasca et al., 2005). Potentially, the decreases in group attachment anxiety and avoidance found in the current study may reflect the successful implementation of a safe therapeutic environment, which may have triggered participants' more adaptive models of relationships.

A third process that may explain changes in attachment is that during therapy, therapists and group members acted as a secure base from which participants could explore different models of relationships. According to Bowlby (1979), the therapist's tasks include acting as a secure base from which the patient can explore him- or herself and his or her affectional bonds, and encouraging the patient to consider how his or her behaviour may result in particular relational patterns. More recently, Harris (2003) suggested that in psychotherapy, therapists should mitigate the influence of previous 
experiences with insensitive attachment figures on the individual's internal working model. In group psychodynamic interpersonal psychotherapy, the therapist fosters a safe group context and connects members to one another by emphasizing patients' shared needs and anxieties (Tasca et al., 2005). Therapists also work to establish norms such as a willingness to self-disclose and self-reflect, interpersonal feedback, and respect for interpersonal boundaries, which foster a sense of attunement to group members' needs and subsequently a safe space in which members may explore and modify maladaptive interpersonal patterns (Tasca et al.). Thus in the current study, therapists and group members may have provided a safe space from which participants could explore their maladaptive interpersonal patterns in a group context, and subsequently adjust these patterns.

\section{Change in Group Attachment as a Predictor of Change in Treatment Outcomes}

This study's fourth hypothesis was that reductions in group attachment anxiety and avoidance during group psychodynamic therapy would predict reductions in binge eating and depressive symptoms. Results did not support this hypothesis. This finding appears inconsistent with research indicating that reductions in individual attachment anxiety predict reductions in depressive symptoms in women with binge-eating disorder (Tasca et al., 2007), and that attachment is associated with treatment outcomes in other populations (e.g. Mosheim et al., 2000; Ogrodniczuk et al., 2002; Schechtman \& Dvir, 2006).

These findings, in conjunction with research indicating a relationship between change in individual attachment anxiety and change in depressive symptoms (Tasca, Balfour et al., 2007a), suggest that it is change in individual's dyadic relationships rather 
than in their group relationships that predict improvements in target symptoms.

Alternatively, the short-term nature of group psychodynamic interpersonal therapy may have precluded the potential impact of improvements in group attachment security on binge eating and depressive symptoms. Bowlby (1979) indicated that the restructuring of clients' internal working models and the corresponding behavioural changes is a gradual process, and that patients who frequently act as caretakers for others or who are compulsively self-reliant may require particularly lengthy treatment before positive changes occur. Hence, participants with more insecure attachments towards their groups may require more than 16 weeks of group psychodynamic interpersonal psychotherapy before improvements in the attachment system are manifested in eating and affective symptoms. It was also possible that the discrepancy between Tasca, Balfour and colleagues' finding and results in the current study may have been due to the fact that while the former were based on pre- to posttreatment change in depressive symptoms, the latter were based on pre- to 12 months posttreatment change. Therefore, I also examined whether change in group attachment during treatment predicted pre- to posttreatment change in binge eating and depressive symptoms. However, results of the current study did not change when these relationships were examined.

To further explore the potential effects of change in group attachment, I examined the influence of change in group attachment anxiety and avoidance on change in individual attachment anxiety and avoidance. Reductions in group attachment anxiety did not predict reductions in individual attachment insecurity. However, reductions in group attachment avoidance during treatment were related to reductions in Need for Approval, Preoccupation with Relationships, and Discomfort with Closeness between pretreatment 
and 12 months posttreatment. This finding indicates that participants were able to generalize improvements in their interpersonal relationships in therapy to their individual relationships outside of their groups. That is, as participants became less avoidant of closeness with their groups, they became more securely attached in their dyadic relationships, and these changes tended to last at least 1 year after treatment. This result is consistent with Feeney and Noller's (1996) suggestion that therapeutic interventions may facilitate the individual's development of secure internal working models through the development of positive relationships in therapy. This finding also adds to research indicating that individuals higher in attachment avoidance are more resistant to and rejecting of treatment. Although previous researchers indicate that it is difficult for those with attachment avoidance to engage in treatment (Dozier, 1990; Schetchman Dvir, 2006), the current results indicate that once they do they are likely to experience dramatic improvements in their individual attachment functioning (Meyer \& Pilkonis, 2001), and that such changes are long-lasting.

The finding that participants were able to generalize changes in group attachment during therapy to their relationships outside of their groups seems particularly important for women with binge-eating disorder, as dismissing attachment has been found to be a dominant attachment category for as many as $47 \%$ of these individuals (Barone \& Guiducci, 2009). Hence, change in avoidance during therapy may assist a substantial proportion of women with binge-eating disorder to experience improvements in their interpersonal relationships. The finding that such improvements were maintained at 12 months posttreatment indicates that group psychodynamic interpersonal psychotherapy has a long-term impact on group members' interpersonal functioning. These results are 
consistent with the suggestion that the development of a new internal working model specific to a given relationship (i.e. specific to relationships with group members) can allow individuals to update more general models of relationships (Collins \& Read, 1994).

In summary, results did not support Hypothesis 4 as reductions in group attachment insecurity did not predict reductions in binge eating and depressive symptoms.

Nevertheless, these results indicated that change in group attachment avoidance is an important aspect of group psychodynamic interpersonal psychotherapy in that those who are able to become more comfortable with closeness to their therapy group tend to become more secure in their interpersonal relationships in the long term.

\section{Moderating Effects of Individual Attachment Anxiety}

This study's fifth hypothesis was that individual attachment anxiety condition would moderate the relationship between change in group attachment insecurity and change in treatment outcomes. Specifically, I expected that participants higher in individual attachment anxiety would experience reductions in group attachment anxiety and avoidance as particularly conducive to obtaining improvements in binge eating and depressive symptoms. Results did not support this hypothesis. Attachment anxiety condition also did not moderate the relationship between change in group attachment and change individual attachment. These findings appear inconsistent with research indicating that higher individual attachment anxiety makes women with binge-eating disorder more sensitive to change in group processes (Tasca, Balfour et al., 2007b; Tasca, Balfour et al., 2006).

The finding that the participants in the higher attachment anxiety condition reported elevated levels of individual attachment anxiety and individual attachment 
avoidance also indicates that those in this condition were fearful (Bartholomew \& Horowitz, 1991). That is, participants in the higher attachment anxiety condition exhibited a strong need for acceptance and a tendency to avoid intimacy (Bartholomew \& Horowitz, 1991), and this combination may have made such individuals particularly vulnerable in therapy and unable to benefit as much from therapy as if they had been higher in individual attachment anxiety and lower in individual attachment avoidance. Further, given that the groups were homogeneously composed of individuals with more insecure attachment patterns, it is possible that such individuals may need to interact with more securely attached group members in order to obtain benefit treatment outcomes.

\section{Limitations}

This study had several limitations. First, since data on group attachment were only available for week 4 of treatment and since measures of individual attachment and selfesteem were not collected during treatment, the convergent validity of the Social Group Attachment Scale was assessed using measures from different time points. However, the finding that group attachment anxiety and avoidance correlated with these variables in expected directions despite the 4-week time gap between measurements further supports the convergent validity of the Social Group Attachment Scale.

Second, as discussed above, the small number of participants who dropped out after week 4 of treatment led to issues of low power to test the hypothesis that week 4 group attachment avoidance would predict dropout, and most participants who left the therapy did so before week 4 . Therefore, the generalizability of the results of this hypothesis remains in question. To address this issue, future research may examine whether pretreatment group attachment avoidance predicts dropout from group 
psychodynamic interpersonal therapy. However such research would examine whether general group attachment orientations would predict dropout rather than attachment to a specific therapy group, as at pretreatment participants would not yet have commenced therapy and subsequently would not be able to rate their experiences of their therapy groups.

Third, the correlational nature of this study's data precludes the ability to make causal inferences. To further explore whether attending group psychodynamic interpersonal psychotherapy causes reductions in group attachment anxiety and avoidance and to rule out the potential for regression to the mean, researchers may implement randomized control trials. Relatedly, to assess whether change in group attachment during therapy causes change in individual attachment and the maintenance of such change at 12 months posttreatment, researchers may employ qualitative methods that help identify particular aspects of therapy that participants felt improved their internal working models of themselves and others.

Fourth, while the decision to use a cut-off of 3.59 to classify participants as either high or low in individual attachment anxiety was based on previous research (Tasca, Ritchie et al., 2006), it is unknown whether participants with scores equal to or above 3.59 on the Need for Approval subscale were actually high in individual attachment anxiety, and whether those with scores below 3.59 were actually low on individual attachment anxiety. The establishment of clinically meaningful cut-offs on the Attachment Styles Questionnaire would support the validity of the criterion used in the current study. Nevertheless, the finding that individuals with a score equal to or above 3.59 were more able to benefit from an interpersonally-oriented therapy and that those 
with a score below 3.59 were more able to benefit from a skills-focused therapy (Tasca, Ritchie et al., 2006) supports the validity of this cut-off. Additionally, research has indicated that, using this criterion, participants considered higher in individual attachment anxiety report elevated levels of individual attachment insecurity and distress (Tasca et al., 2011).

Fifth, participants in the current study were all women who were predominantly Caucasian and English-speaking and who had completed post-secondary education. Future research may examine whether this study's results generalize to men or to individuals from more diverse ethnic, cultural, and socioeconomic backgrounds. For example, the higher prevalence of anxious attachment in Israel and Japan and of avoidant attachment in Western European countries (van IJzendoorn \& Kroonenberg, 1988) suggests that individuals from different regions may respond differentially to change in group attachment.

\section{Clinical Implications and Conclusions}

Overall, this study's results indicate that group attachment is related to but distinct from individual attachment. Additionally, group attachment anxiety and avoidance were negatively related to self-esteem, and group attachment avoidance was negatively related to group cohesion. To enhance self-esteem and group cohesion in individuals higher in group attachment insecurity, therapists may strive to maintain an overt nonjudgmental tone in therapy and encourage patients to capitalize on their strengths. Further, when treating patients who are more avoidant of their therapy groups, therapists may focus on engaging participants in the group while simultaneously allowing them to maintain a sense of independence. The evidence supporting the convergent validity for the Social 
Group Attachment Scale also indicates that clinicians may use this scale to identify group members who are particularly anxious or avoidant towards their therapy groups, and address these issues in treatment.

Results of the current study also indicate that like individual attachment, group attachment is susceptible to change following emotionally significant experiences (Collins \& Read, 1994; Tasca, Balfour et al., 2007a). To facilitate the development of more secure attachment styles in their patients, therapists may exemplify sensitive responsiveness, thereby increasing patients' level of trust and allowing for self-disclosure (Harris, 2003). The establishment of more adaptive models of relationships may then allow the patient to develop more positive ways of relating to others (i.e. group members), who in turn are likely to respond more positively to the patient (Harris, 2003). Changes in attachment to the therapy group predicted changes in group members' interpersonal relationship patterns up to 12 months posttreatment. This finding suggests that increases in group attachment security are important for individuals to obtain improvements in their internal working models of themselves and others. Given the wealth of research pointing towards the importance of attachment security to participants' affective regulation strategies and self-perceptions (e.g. Cassidy, 1994; Rom \& Mikulincer, 2003), reductions in group attachment avoidance appear to be important for enhancing socioemotional functioning in women with binge-eating disorder. Rather than contraindicating short-term group treatment for individuals higher in attachment avoidance as suggested by some (Schechtman \& Dvir, 2006), it may be more appropriate for clinicians to address attachment avoidance in the therapy group to assist such individuals in improving their interpersonal patterns outside of the therapy group. 
Addressing attachment avoidance during initial assessments may also be useful so as to increase patients' level of comfort with a group context and subsequently increase treatment uptake. These suggestions are consistent with Muller's (2010) assertion that it is important to address attachment-related trauma in therapy in more avoidant patients, as patients may perceive the therapist's avoidance of such material to be a replication of previous attachment figures' intolerance of disclosures of unsettling information. Similarly, Dozier (1990) suggested that clinicians' withdrawal of assistance may exacerbate interpersonal difficulties in individuals higher in attachment avoidance. In summary, this research, if replicated, supports the existence of the construct of group attachment, and indicates that attachment to the group can change in an interpersonally oriented group therapy context and that change in group attachment has meaningful longterm implications for the quality of women's relationships with themselves and others. 


\section{References}

Agras, W. S., Telch, C. F., Arnow, B., Eldredge, K., Detzer, M. J., Henderson, J., \& Marnell, M. (1995). Does interpersonal therapy help patients with binge-eating disorder who fail to respond to cognitive-behavioral therapy? Journal of Consulting and Clinical Psychology, 63, 356-360. doi:10.1037/0022-006X.63.3.3 56

Allen, J., \& Le, H. (2008). An additional measure of overall effect size for logistic regression models. Journal of Educational and Behavioral Statistics, 33, 416-444. doi:10.3102/1076 998607306081

American Psychiatric Association. (2000). Diagnostic and statistical manual of mental disorders: Text Revision (4th ed.). Washington, DC: Author.

Ansell, E. B., Grilo, C. M., \& White, M. A. (2012). Examining the interpersonal model of binge eating and loss of control over eating in women. International Journal of Eating Disorders, 45, 43-50. doi:10.1002/eat.20897

Arnow, B., Kenardy, J., \& Agras, S. (1992). Binge eating among the obese: A descriptive study. Journal of Behavioral Medicine, 15, 155-170. doi:10.1007/BF00848323

Bagley, C., Bolitho, F., \& Bertrand, L. (1997). Norms and construct validity of the Rosenberg Self-Esteem Scale in Canadian high school populations: Implications for counselling. Canadian Journal of Counselling, 31, 82-92. Retrieved from cjcrcc.ucalgary.ca/cjc/index.php/rcc/article/download/85/234

Baldwin, M., \& Fehr, B. (1995). On the instability of attachment style ratings. Personal Relationships, 2, 247-261. doi:10.1111/j.1475-6811.1995.tb00090.x

Barone, L., \& Guiducci, V. (2009). Mental representations of attachment in eating 
disorders: A pilot study using the Adult Attachment Interview. Attachment \& Human Development, 11, 405-417. doi:10.1080/14616730902814770

Bartholomew, K., \& Horowitz, L. M. (1991). Attachment styles among young adults: A test of a four-category model. Journal of Personality and Social Psychology, 61, 226-244. doi:10.1037/0022-3514.61.2.226

Basco, M. R., Bostic, J. Q., Davies, D., Rush, A. J., Witte, B., Hendrickse, W., \& Barnett, V. (2000). Methods to improve diagnostic accuracy in a community mental health setting. American Journal of Psychiatry, 157, 1599-1605.doi:10.1176/appi.ajp.15 7.10 .1599

Beck, A.P., Dugo, J.M., Eng, A.M., \& Lewis, C.M. (1986). The search for phases in group development. In L.S. Greenberg and W.M. Pinsof (Eds.), The psychotherapeutic process: A research handbook. New York: Guilford.

Beck, A. T., Steer, R. A., \& Brown, G. K. (1996). BDI-II Manual (2nd ed.). San Antonio, TX: The Psychological Corporation.

Beck, A. T., Steer, R. A., Ball, R., \& Ranieri, W. Comparison of Beck Depression Inventories- IA and -II in psychiatric outpatients. Journal of Personality Assessment, 67, 588-597. doi:10.1207/s15327752jpa6703_13

Bohn, K., \& Fairburn, C. G. (2008). The Clinical Impairment Questionnaire (CIQ 3.0). In C. G. Fairburn (Ed.). Cognitive Behavior Therapy and Eating Disorders. New York, New York: Guilford Press.

Bowlby, J. (1973). Attachment and Loss (Vol. 2). London, England: The Hogarth Press. Bowlby, J. (1979). The making and breaking of affectional bonds. London, England: Tavistock. 
Brennan, K. A., Clark, C. L., \& Shaver, P. R. (1998). Self-report measurement of adult attachment: An integrative overview. In J. A. Simpson \& W. S. Rholes (Eds), Attachment theory and close relationships (pp. 46-76). New York: Guilford Press.

Bretherton, I., \& Munholland, K. A. (1999). Internal working models in attachment relationships: A construct revisited. In J. Cassidy \& P. R. Shaver (Eds.), Handbook of attachment: Theory, research, and clinical applications (pp. 89111). New York, NY: The Guilford Press.

Bulik, C. M., Sullivan, P. F., \& Kendler, K. S. (2002). Medical and psychiatric morbidity in obese women with and without binge eating. International Journal of Eating Disorders, 32, 72-78. doi:10.1002/eat.10072

Cassidy, J. (1994). Emotion regulation: Influences of attachment relationships. In N. A. Fox (Ed.), The development of emotion regulation: Biological and behavioral considerations. Monographs of the Society for Research in Child Development, $59(2-3$, Serial No. 240).

Castonguay, L. G., Eldredge, K. L., \& Agras, W. S. (1995). Binge eating disorder: Current state and future directions. Clinical Psychology Review, 15, 865-890. doi:10.1016/02727358(95)00050-X

Ciano, R., Rocco, P. L., Angarano, A., Biasin, E., \& Balestrieri, M. (2002). Groupanalytic and psychoeducational therapies for binge-eating disorder: An exploratory study on efficacy and persistence effects. Psychotherapy Research, 12, 231-239. doi:10.1080/713664282

Clark, L. A., \& Watson, D. (1995). Constructing validity: Basic issues in objective scale development. Psychological Assessment, 7, 309-319. doi:10.1037/1040-3590.7.3. 
Clinton, J. D. (2004). Sphericity assumption. In M. S. Lewis-Beck, A. Bryman, \& T. F. Liao (Eds.), The Sage encyclopedia of social science research methods (Vol. 3, pp. 1057-1058). Thousand Oaks, CA: Sage Publications.

Cohen, J. (1992). A power primer. Psychological Bulletin, 112, 155-159. doi:10.1037/00 $33-2909.112 .1 .155$

Cohen, J., Cohen, P., West, S. G., \& Aiken, L. S. (2003). Applied multiple regression/ correlation analysis for the behavioral sciences ( $3^{\text {rd }}$ ed.). Mahwah, NJ: Lawrence Earlbaum Associates.

Colin, V. L. (1996). Human attachment. Philadelphia, PA: Temple University Press. Collins, N. L., \& Read, S. J. (1990). Adult attachment, working models, and relationship quality in dating couples. Journal of Personality and Social Psychology, 58, 644663. doi:10.1037/0022-3514.58.4.644

Collins, N. L., \& Read, S. J. (1994). Cognitive representations of attachment: The structure and function of working models. In K. Bartholomew \& D. Perlman (Eds.), Attachment processes in adulthood (pp. 53-90). London: Jessica Kingsley. Cooper, Z., Cooper, P. J., \& Fairburn, C. J. (1989). The validity of the Eating Disorder Examination and its subscales [Abstract]. British Journal of Psychiatry, 154, 807812.

de Zwaan, M., Mitchell, J. E., Crosby, R. D., Mussell, M. R., Raymond, N. C., Specken, S. M., \& Seim, H. C. (2005). Short-term cognitive behavioral treatment does not improve outcome of a comprehensive very-low-calorie-diet program in obese women with binge eating disorder. Behavior Therapy, 36, 89-99. doi:10.1016/S00 
$05-7894(05) 80057-7$

Deaver, C. M., Miltenberger, R. G., Smyth, J., Meidinger, A., \& Crosby, R. (2003). An evaluation of affect and binge eating. Behavior Modification, 27, 578-599. doi:10.1177/0 145445503255571

Eames, V., \& Roth, A. (2000). Patient attachment orientation and the early working alliance- a study of patient and therapist reports of alliance quality and ruptures. Psychotherapy Research, 10, 421-434. doi:10.1093/ptr/10.4.421

Eldredge, K. L., Agras, W. S., Arnow, B., Telch, C. F., Bell, S., Castonguay, L., \& Marnell, M. (1997). The effects of extending cognitive-behavioral therapy for binge eating disorder among initial treatment nonresponders. International Journal of Eating Disorders, 21, 347-352. doi:10.1002/(SIC1)1098-108X(1997)21 $: 4<347:$ AID-EAT7>3.0.CO;2-O

Enders, C. K, \& Tofighi, D. (2007). Centering predictor variables in cross-sectional multilevel models: A new look at an old issue. Psychological Methods, 12, 121138. doi: $10.1037 / 1082-989.12 .2 .121$

Fairburn C. G., \& Beglin S. J. Assessment of eating disorders: Interview or self-report questionnaire? International Journal of Eating Disorders, 16, 363-370. doi:10.10 02/1098-108X(199412)16:4<363::AID-EAT2260160405>3.0.CO;2-\#

Fairburn, C. G., \& Cooper, Z. (1993). The Eating Disorder Examination (12th ed.). In C. G. Fairburn \& G. T. Wilson (Eds.), Binge eating: Nature, assessment, and treatment (pp. 317-360). New York, NY: Guilford Press.

Favaro, A., Ferrara, S., \& Santonastaso, P. (2003). The spectrum of eating disorders in young women: A prevalence study in a general population sample. 
Psychosomatic Medicine, 65, 701-708. doi:10.1097/01.PSY.0000073871.67679.D 8

Feeney, J., \& Noller, P. (1996). Adult attachment. Thousand Oaks, CA: Sage Publications.

Feeney, J. A., Noller, P., \& Hanrahan, M. (1994). Assessing adult attachment. In M. B. Sperling \& W. H. Berman (Eds.), Attachment in adults (pp.128-151). New York: Guilford Press.

First, M. B., Spitzer, R. L., Gibbon, M., \& Williams, J. B. W. (2007). Structured Clinical Interview for DSM-IV Axis I Disorders-Patient Edition (SCID-I/P). New York, NY: New York State Psychiatric Institute, Biometrics Research.

Fonagy, P. (2001). Attachment theory and psychoanalysis. New York, NY: Other Press.

Fuendeling, J. M. (1998). Affect regulation as a stylistic process within adult attachment. Journal of Social and Personal Relationships, 15, 291-322. doi:10.1177/0265407 598153001

Garner, D. M. (2004). Eating Disorder Inventory-3: Professional Manual. Odessa, FL: Psychological Assessment Resources.

Gauvin, L., Steiger, H., \& Brodeur, J. (2009). Eating-disorder symptoms and syndromes in a sample of urban-dwelling Canadian women: Contributions toward a population health perspective. International Journal of Eating Disorders, 42, 158165. doi: $10.1002 /$ eat. 20590

Gelenberg, A. J., \& Chesen, C. L. (2000). How fast are antidepressants? Journal of Clinical Psychiatry, 61, 712-721. Retrieved from http://www.psychiatrist.com/ default2.asp 
Grenon, R., Tasca, G. A., Cwinn, E., Coyle, D., Summer, A., Gick, M., \& Bissada, H. (2010). Depressive symptoms are associated with medication use and lower health-related quality of life in overweight women with binge eating disorder. Women's Health Issues, 20, 435-440. doi:10.1016/j.whi.2010.07.004

Grucza, R. A., Przybeck, T. R., \& Cloninger, C. R. (2007). Prevalence and correlates of binge eating disorder in a community sample. Comprehensive Psychiatry, 48, 124-131. doi:10.1016/j.comppsych.2006.08.002

Guh, D. P., Zhang, W., Bansback, N., Amarsi, Z., Birmingham, C. L., \& Anis, A. H. (2009). The incidence of co-morbidities related to obesity and overweight: A systematic review and meta-analysis. BMC Public Health, 9(88). doi:10.1186/147 $1-2458-9-88$

Harris, T. (2003). Implications of attachment theory for developing a therapeutic alliance and insight in psychoanalytic psychotherapy. In M. Cortina \& M. Marrone (Eds.), Attachment theory and the psychoanalytic process (pp. 62-91). London, England: Whurr Publishers.

Hazan, C., \& Shaver, P. (1987). Romantic love conceptualized as an attachment process. Journal of Personality and Social Psychology, 52, 51 1-524. doi:10.1037/00223514.52 .3 .511

Heatherton, T. E., \& Baumeister, R. F. (1991). Binge eating as escape from selfawareness. Psychological Bulletin, 110, 86-108. doi:10.1037/0033-2909.110.1.86 Hilbert, A., Saelens, B. E., Stein, R. I., Mockus, D. S., Welch, R. R., Matt, G. E., \& Wilfley, D. E. (2007). Pretreatment and process predictors of outcome in interpersonal and cognitive behavioral psychotherapy for binge eating disorder. 
Journal of Consulting and Clinical Psychology, 75, 645-651. doi:10.1037/0022$006 \times .75 .4 .645$

Holtz, A. (2004). Measuring the therapy group attachment in group psychotherapy: $A$ validation of the Social Group Attachment Scale (Doctoral dissertation). Retrieved from http://search.proquest.com.proxy.library.carleton.ca/pqdtft/ index?accountid $=9894$

Horowitz, L. M., Rosebnger, S. E., Baer, B. A., Ureño, G., \& Villaseñor, V. S. (1988). Inventory of Interpersonal Problems: Psychometric properties and clinical applications. Journal of Consulting and Clinical Psychology, 56, 885-892. doi:10. 1037/0022-006X.56.6.885

Horowitz, L. M., Rosenberg, S. E., \& Bartholomew, K. (1993). Interpersonal problems, attachment styles, and outcome in brief dynamic psychotherapy. Journal of Consulting and Clinical Psychology, 61, 549-560. doi:10.1037/0022-006X.61.4.5 49

Hudson, J. I., Hiripi, E., Pope, H. G., \& Kessler, R. C. (2007). The prevalence and correlates of eating disorders in the National Comorbidity Survey Replication. Biological Psychiatry, 61, 348-358. doi:10.1016/j.biopsych.2006.03.040

Illing, V., Tasca, G. A., Balfour, L., \& Bissada, H. (2010). Attachment insecurity predicts eating disorder symptoms and treatment outcomes in a clinical sample of women. Journal of Nervous and Mental Disease, 198, 653-659. doi:10.1097/ NMD.0b013e3181ef34b2

Johnson, J. E., Burlingame, G. M., Olsen, J. A., Davies, R., \& Gleave, R. L. (2005). Group climate, cohesion, alliance, and empathy in group psychotherapy: 
Multilevel structural equation models. Journal of Counseling Psychology, 52, 510-521. doi: $10.1037 / 0022-0167.52 .3 .310$

Johnson, J. G., Spitzer, R. L., \& Williams, B. W. (2001). Health problems, impairment, and illnesses associated with bulimia nervosa and binge eating disorder among primary care and obstetric gynaecology patients. Psychological Medicine, 31, 1455-1466. doi:10.1017\}S0033291701004640

Kenny, D. A., Kashy, D., \& Bolger, N. (1998). Data analysis in social psychology. In D. Gilbert, S. Fiske, and G. Lindzey (Eds.), Handbook of social psychology (4th ed., pp. 233-265). New York: McGraw-Hill.

Kessler, R. C., \& Merikangas, K. R. (2004). The National Comorbidity Survey Replication (NCS-R): Background and aims. International Journal of Methods in Psychiatric Research, 13, 60-68. doi:10.1002/mpr.166

Kilmann, P. R., Laughlin, J. E., Carranza, L. V., Downer, J. T., Major, S., \& Parnell, M. M. (1999). Effects of an attachment-focused group preventative intervention on insecure women. Group Dynamics: Theory, Research, and Practice, 3, 138-147. doi:10.1037/1089-2699.3.2.138

Kilmann, P. R., Urbaniak, G. C., \& Parnell, M. M. (2006). Effects of attachment-focused versus relationship skills-focused group interventions for college students with secure attachment patterns. Attachment \& Human Development, 8, 47-62. doi:10.1080/1461673 0600585219

Kobak, R. (1999). The emotional dynamics of disruptions in attachment relationships: Implications for theory, research, and clinical intervention. In J. Cassidy \& P. R. Shaver (Eds.), Handbook of attachment: Theory, research, and clinical 
applications (pp. 21- 43). New York, NY: The Guilford Press.

Kobak, R. R., \& Sceery, A. (1988). Attachment in late adolescence: Working models, affect regulation, and representations of self and others. Child Development, 59, 135-146. doi:10.2307/1130395

Kreft, I., \& de Leeuw, J. (1998). Introducing multilevel modeling. London, England: Sage Publications.

Kristeller, J. L., \& Hallett, C. B. (1999). An exploratory study of a meditation-based intervention for binge eating disorder. Journal of Health Psychology, 4, 357-363. doi:10.1177/135910539900400305

Lawson, D. M., Barnes, A. D., Madkins, J. P., \& Francio-Lamonte, B. M. (2006). Changes in male partner abuser attachment styles in group treatment. Psychotherapy: Theory, Research, Practice, Training, 43, 232-237. doi:10.1037/ $0033-3204.43 .2 .232$

Levy, K. N., Meehan, K. B., Kelly, K. M., Reynoso, J. S., Weber, M., Clarkin, J. F., \& Kernberg, O. F. (2006). Change in attachment patterns and reflective function in a randomized control trial of transference-focused psychotherapy for borderline personality disorder. Journal of Consulting and Clinical Psychology, 74, 10271040. doi:10.1037/0022-006X.74.6.1027

Lopez, F. G. (1995). Contemporary attachment theory: An introduction with implications for counseling psychology. The Counseling Psychologist, 23, 395-414. doi:10.117 $7 / 0011000095233001$

MacKenzie, K. R. (1983). The clinical application of a Group Climate measure. In R. R. Dies \& K. R. MacKenzie (Eds.), Advances in group psychotherapy: Integrating 
research and practice (pp. 159-170). New York: International Universities Press.

Magai, C. (1999). Affect, imagery, and attachment: Working models of interpersonal affect and the socialization of emotion. In J. Cassidy \& P. R. Shaver (Eds.), Handbook of attachment: Theory, research, and clinical applications (pp. 787802). New York, NY: The Guilford Press.

Maier, M. A., Bernier, A., Pekrun, R., Zimmermann, P., \& Grossman, K. E. (2004). Attachment working models as unconscious structures: An experimental test. International Journal of Behavioral Development, 28, 180-189. doi:10.1080/0165 0250344000398

Mallinckrodt, B. (2000). Attachment, social competencies, social support, and interpersonal process in psychotherapy. Psychotherapy Research, 10, 239-266. doi:10.1093/ptr/10.3.239

Mallinckrodt, B., Gantt, D. L., \& Coble, H. M. (1995). Attachment patterns in the psychotherapy relationship: Development of the Client Attachment to the Therapist Scale. Journal of Counseling Psychology, 42, 307-317. doi:10.1037 10022-0167.42.3.307

Maramosh, C. L., \& Markin, R. D. (2007). Group and personal attachments: Two is better than one when predicting college adjustment. Group Dynamics: Theory, Research, and Practice, 11, 153-164. doi:10.1037/1089-2699.11.3.153153

Maramosh, C. L., Whipple, R., Schettler, M., Pinhas, S., Wolf, J., \& Savit, S. (2009). Adult attachment styles and group psychotherapy attitudes. Group Dynamics: Theory, Research, and Practice, 13, 255-264. doi:10.1037/a0015957 
Markin, R. D., \& Maramosh, C. (2010). Application of adult attachment theory to group member transference and the group therapy process. Psychotherapy Theory, Research, Practice, Training, 47, 111-121. doi:10.1037/a0018840

McCluskey, U. (2002). The dynamics of attachment and systems-centered group psychotherapy. Group Dynamics: Theory, Research, and Practice, 6, 131-142. doi: $10.1037 / / 1089-2699.6 .2 .131$

McIntire, S. A., \& Miller, L. A. (2007). Foundations of Psychological Testing: A Practical Approach ( $2^{\text {nd }}$ ed.). Thousand Oaks, CA: Sage Publications.

Meyer, B., \& Pilkonis, P. A. (2001). Attachment style. Psychotherapy, 38, 466-472. doi:10.1037/0033-3204.38.4.466

Mikulincer, M. (1998). Attachment working models and the sense of trust: An exploration of interaction goals and affect regulation. Journal of Personality and Social Psychology, 74, 1209-1224. doi:10.1037/0022-3514.74.5.1209

Mikulincer, M., \& Shaver, P. R. (2005). Attachment security, compassion, and altruism. Current Directions in Psychological Science, 14, 34-38. doi:10.1111/j.09637214.2005.00330.x

Mikulincer, M., \& Shaver, P. R. (2007). Attachment, group-related processes, and psychotherapy. International Journal of Group Psychotherapy, 57, 233-245. Retrieved from http://www.swetswise.com.proxy.library.carleton.ca/eAccess/ viewToc.do?titleID $=103846 \&$ yevoID $=1969255$

Mosheim, R., Zachhuber, U., Scharf, L., Hofmann, A., Kemmler, G., Danzl, C., . . (2000). Quality of attachment and interpersonal problems as possible predictors of inpatient-therapy outcome. Psychotherapeut, 45, 223-229. doi:10.1007/PL000067 
19

Muller, R. T. (2010). Trauma and the avoidant client: Attachment-based strategies for healing. New York, NY: W. W. Norton \& Company.

Nezlek, J. B. (2008). An introduction to multilevel modeling for social and personality psychology. Social and Personality Psychology Compass, 2, 842-860. doi:10.1111/j.1751 -9004.2007.00059.x

Olmsted, M.P., Isaacs, P., Bemis, K., \& Garner, D.M. (1988). Tape rating instrument for psychotherapy of eating disorders (TRIPED). Unpublished manuscript.

Ogrodniczuk, J. S., Piper, W. E., McCallum, M., Joyce, A. S., \& Rosie, J. S. (2002).

Interpersonal predictors of group therapy outcome for complicated grief. International Journal of Group Psychotherapy, 52, 511-535. doi:10.1521/ijgp.52.4.511.45520

Polansky, M., Lauterbach, W., Litzke, C., Coulter, B., \& Sommers, L. (2006). A qualitative study of an attachment-based parenting group for mothers with drug addictions: On being and having a mother. Journal of Social Work Practice: Psychotherapeutic Approaches in Health, Welfare and the Community, 20, $115-$ 131. doi: $10.1080 / 02650530600776673$

Raudenbush, S. W., \& Bryk, A. S. (2002). Hierarchical Linear Models ( $2^{\text {nd }}$ ed.). Thousand Oaks, CA: Sage Publications.

Reichborn-Kjennerud, T., Bulik, C. M., Sullivan, P. F., Tambs, K., \& Harris, J. R. (2004). Psychiatric and medical symptoms in binge eating in the absence of compensatory behaviors. Obesity Research, 12, 1445-1454. doi:10.1038/oby.2004.181

Renehan, A. G., Tyson, M., Egger, M., Heller, R. F., \& Zwahlen, M. (2009). Body-mass 
index and incidence of cancer: A systematic review and meta-analysis of prospective observational studies. The Lancet, 371, 569-578. doi:10.1016/S0140$6736(08) 60269-\mathrm{X}$

Reynolds, W. M. (1988). Measurement of academic self-concept in college students. Journal of Personality Assessment , 52, 223- 240. Retrieved from http://www.tandf.co.uk/journals/titles/00223891.asp

Rizvi, S. L., Peterson, C. B., Crow, S. J., \& Agras. W. S. (2000). Test-retest reliability of the Eating Disorder Examination. International Journal of Eating Disorders, 28, 311-316. doi: 10.1002/1098-108X(200011)28:3<311 ::AID-EAT8>3.0.CO;2-K

Robins, R. W., Hendin, H. M., \& Trzesniewski, K. H. (2001). Measuring global selfesteem: Construct validation of a single-item measure and the Rosenberg SelfEsteem Scale. Personality and Social Psychology Bulletin, 27, 151-161. doi:10.1177/0146167201272002

Rom, E., \& Mikulincer, M. (2003). Attachment theory and group processes: The association between attachment style and group-related representations, goals, memories, and functioning. Journal of Personality and Social Psychology, 84, 1220-1235. doi:10.1037/0022-3514.84.6.1220

Rosenberg, M. (1979). Conceiving the self. New York: Basic Books.

Schafer, J. L., \& Graham, J. W. (2002). Missing data: Our view of the state of the art. Psychological Methods, 7, 147-177. doi:10.1037//1082-989X.7.2.147

Shechtman, Z., \& Dvir, V. (2006). Attachment style as a predictor of behavior in group counseling with adolescents. Group Dynamics: Theory, Research, and Practice, 10, 29-42. doi:10.1037/1089-2699.10.1.29 
Schechtman, Z., \& Rybko, J. (2004). Attachment styles and observed initial selfdisclosures as explanatory variables of group functioning. Group Dynamics: Theory, Research, and Practice, 8, 207-220. doi:10.1037/1089-2699.8.3.207207

Schutz, W. (1966). The interpersonal underworld. Palo Alto, CA: Science and Behavior Books.

Shrout, P. E., \& Fleiss, J. L. (1979). Intraclass correlations: Uses in assessing rater reliability. Psychological Bulletin, 86, 420-428. doi:10.1037/0033-2909.86.2.420

Slade, A. (1999). Attachment theory and research: Implications for the theory and practice of individual psychotherapy with adults. In J. Cassidy \& P. R. Shaver (Eds.), Handbook of attachment: Theory, research, and clinical applications (pp. 575-594). New York, NY: The Guilford Press.

Smith, E. R., Murphy, J., \& Coats, S. (2010). Attachment to groups: Theory and measurement. Joumal of Personality and Social Psychology, 74, 94-110. doi:10.1037/0022-3514.77.1.94

Steiger, H., Gauvin, L., Jabalpurwala, S., Séguin, J. R., \& Stotland, S. (1999). Hypersensitivity to social interactions in bulimic syndromes: Relationship to binge eating. Journal of Consulting and Clinical Psychology, 67, 765-775. doi:10.1037/0022-006X.67.5.765

Stevens, J. P. (2002). Applied multivariate statistics for the social sciences (4th ed.). Mahwah, NJ: Erlbaum.

Stickney, M. I., Miltenberger, R. G., 7 Wolff, G. (1999). A descriptive analysis of factors contributing to binge eating. Journal of Behavior Therapy and Experimental Psychiatry, 30, 177-189. doi:10.1016/S0005-7916(99)00019-1 
Strupp, H.H. and Binder, J.L. (1984). Psychotherapy in a new key: A guide to timelimited dynamic psychotherapy. New York: Basic.

Tabachnick, B. G., \& Fidell, L. S. (2007). Using Multivariate Statistics ( $5^{\text {th }}$ ed.). Boston, MA: Pearson Education Inc.

Tasca, G., Balfour, L., Ritchie, K., \& Bissada, H. (2007a). Change in attachment anxiety is associated with improved depression among women with binge eating disorder. Psychotherapy: Theory, Research, Practice, Training, 44, 423-433. doi:10.1037/0 033-3204.44.4.423

Tasca, G. A., Balfour, L., Ritchie, K., \& Bissada, H. (2006). Developmental changes in group climate in two types of group therapy for binge-eating disorder: A growth curve analysis. Psychotherapy Research, 16, 499-514. doi:10.1080/10503300600 593359

Tasca, G. A., Balfour, L., Ritchie, K., \& Bissada, H. (2007b). The relationship between attachment scales and group therapy alliance growth differs by treatment type for women with binge eating disorder. Group Dynamics: Theory, Research, and Practice, 11, 1-14. doi:10.1037/1089-2699.11.1.1

Tasca, G. A., \& Gallop, R. (2009). Multilevel modeling of longitudinal data for psychotherapy researchers: I. The basics. Psychotherapy Research, 19, 429-437. doi:10.1080/10503300802641444

Tasca, G. A., Illing, V., Ogrodniczuk, J. S., \& Joyce, A. S. (2009). Assessing and adjusting for dependent observations in group treatment research using multilevel models. Group Dynamics: Theory, Research, and Practice, 13, 151162. doi: $10.1037 / a 0014837$ 
Tasca, G. A., Mikail, S., \& Hewitt, P. (2005). Group psychodynamic interpersonal psychotherapy: A manual for time limited treatment of binge eating disorder. In M. E. Abelian (Ed.), Focus on psychotherapy research (pp. 159-188). Hauppauge, NY: Nova.

Tasca, G. A., Ramsay, T., Corace, K., Illing, V., Bone, M., Bissada, H., \& Balfour, L. (2010). Modeling longitudinal data from a rolling therapy group program with membership turnover: Does group culture affect individual alliance? Group Dynamics: Theory, Research, and Practice, 14, 151-162. doi:10.1037/a0018778

Tasca, G. A., Ritchie, K., Conrad, G., Balfour, L., Gayton, J., Daigle, V., \& Bissada, H. (2006). Attachment scales predict outcome in a randomized controlled trial of two group therapies for binge eating disorder: An aptitude by treatment interaction. Psychotherapy Research, 16, 106-121. doi:10.1080/10503300500090928

Tasca, G. A., Ritchie, K., Demidenko, N., Balfour, L., Krysanski, V., Weekes, K., Barber, A., Keating, L., \& Bissada, H. (2012). Matching women with binge eating disorder to group treatment based on attachment anxiety: Outcomes and moderating effects. Manuscript submitted for publication.

Tasca, G. A., Taylor, D., Bissada, H., Ritchie, K., \& Balfour, L. (2004). Attachment predicts treatment completion in an eating disorders partial hospital program among women with anorexia nervosa. Journal of Personality and Assessment, 83, 201-212. doi:10.1207/s15327752jpa8303_04

Telch, C. F., Agras, W. S., \& Linehan, M. M. (2001). Dialectical behavior therapy for binge eating disorder. Journal of Consulting and Clinical Psychology, 69, 10611065. doi:10.1037//0022-006X.69.6.1061 
Telch, C. F., \& Stice, E. (1998). Psychiatric comorbidity in women with binge eating disorder: Prevalence rates from a non-treatment-seeking sample. Journal of Consulting and Clinical Psychology, 66, 768-776. doi:10.1037/0022-006X.66.5.7 68

Travis, L. A., Binger, J. L., Bliwise, N. G., \& Horne-Moyer, H. L. (2001). Changes in clients attachment styles over the course of time-limited dynamic therapy. Psychotherapy: Theory, Research, Practice, Training, 38, 149-159. doi: 10.1037/0 033-3204.38.2.149

Van Ginkel, J. R., Sijtsma, K., van der Ark, L. A., \& Vermunt, J. K. (2010). Incidence of missing item scores in personality measurement, and simply item-score imputation. Methodology: European Journal of Research Methods for the Behavioral Sciences, 6, 17-30. doi:10.1027/1614-2241/a000003

van IJzendoorn, M. H., \& Kroonenberg, P. M. (1988). Cross-cultural patterns of attachment: A meta-analysis of the strange situation. Child Development, 59, $147-$ 156. doi: $10.2307 / 1130396$

Vocks, S., Tuschen-Caffier, B., Pietrowsky, R., Rustenbach, S. J., Kersting, A., \& Herpertz, S. (2010). Meta-analysis of the effectiveness of psychological and pharmacological treatments for binge eating disorder. International Journal of Eating Disorders, 43, 205-217. doi:10.1002/eat.20696

von Ranson, K. M., Klump, K. L., Iacono, W. G, \& McGue, M. (2005). The Minnesota Eating Behavior Survey: A brief measure of disordered eating attitudes and behaviors. Eating Behaviors, 6, 373-392. doi:10.1016/j.eatbeh.2004.12.002

Wang, Y. C., McPherson, K, Marsh, T., Gortmaker, S. L., \& Brown, M. (2011). Health 
and economic burden of the projected obesity trends in the USA and the UK. The Lancet, 378, 815-825. doi:10.1016/S0140-6736(11)60814-3

Waters, E., Merrick, S., Treboux, D., Crowell, J., \& Albersheim, L. (2000). Attachment security in infancy and early adulthood: A twenty-year longitudinal study. Child Development, 71, 684-689. doi:10.1111/1467-8624.00176

Wei, M., Vogel, D. L., Ku, T., \& Zakalik, R. A. (2005). Adult attachment, affect regulation, negative mood, and interpersonal problems: The mediating roles of emotional reactivity and emotional cutoff. Journal of Counseling Psychology, 52, 14-24. doi:10.1037/0022-0167.52.1.14

Weinfield, N. S., Sroufe, L. A., Egeland, B., \& Carlson, E. A. (1999). The nature of individual differences in infant-caregiver attachment. In J. Cassidy \& P. R. Shaver (Eds.), Handbook of attachment: Theory, research, and clinical applications (pp. 68-88). New York, NY: The Guilford Press.

Weiss, Y., \& Shilkret, R. (2010). The importance of the peer group in the Israeli Kibbutz for adult attachment style. Smith College Studies in Social Work, 80, 2-19. doi:10.1080/0037 7310903504841

Wilfley, D. E., Agras, W. S., Telch, C. E., Rossiter, E. M., Schneider, J. A., Cole, A. G., ... Raeburn, S. D. (1993). Group cognitive-behavioral therapy and group interpersonal psychotherapy for the nonpurging bulimic individual: A controlled comparison. Journal of Consulting and Clinical Psychology, 61, 296-305. doi:10.1037/0022-006X.61.2.296

Wilfley, D. E., Welch, R. R., Stein, R. I., Spurrell, E. B., Cohen, L. R., Saelens, B. E., ... Matt, G. E. (2002). A randomized comparison of group cognitive-behavioral 
therapy and group interpersonal psychotherapy for the treatment of overweight individuals with binge-eating disorder. Archives of General Psychiatry, 59, 713721. Retrieved from www.archgenpsychiatry.com

Withrow, D., \& Alter, D. A. (2011). The economic burden of obesity worldwide: A systematic review of the direct costs of obesity. Obesity Reviews, 12, 131-141. doi:10.1111/j.1467-7 89X.2009.00712.x

Yalom, I. (1994). The theory and practice of group psychotherapy. New York: Basic.

Zanarini, M. C., Skodol, A. E., Bender, D., Dolon, R., Sanislow, C., Schaefer, E., ... Gunderson, J. G. (2000). The collaborative longitudinal personality disorders study: Reliability of axis I and II diagnoses. Journal of Personality Disorders, 14, 291-299. doi:10.1521/pedi.2000.14.4.21 


\author{
Appendix A \\ DSM-IV-TR Diagnostic Criteria for Binge-Eating Disorder
}

A. Recurrent episodes of binge eating, characterized by:

(1) Eating an unusually large amount of food in a discrete period of time, and

(2) A sense of lost control over eating during the episode of binge eating

B. Three of the following criteria occur with episodes of binge eating:

(1) Eating more rapidly than usual

(2) Feeling uncomfortably full from episodes of binge eating

(3) Eating large quantities of food when one does not physically feel hungry

(4) Eating alone due to feelings of embarrassment regarding one's food intake

(5) Feelings of depression, , or disgust with oneself after binge eating episodes

C. Distress over episodes of binge eating

D. Episodes of binge eating occur at least an average of two days per week for six months 


\section{Appendix B}

\section{Measures}

\section{Social Group Attachment Scale}

\section{Instructions:}

We would like you to consider your membership in THIS GROUP. Please respond to the following statements on the basis of how you feel about THIS GROUP and your membership in it. There are no right or wrong answers to any of these statements; we are interested in your own personal reactions and opinions. Please circle a number on the scale that you feel best describes your feelings for each statement.

\section{Strongly}

\section{Disagree}

1. I find it difficult to allow myself to depend on my group.

1

2
3

4

5

6

7

2. I sometimes worry that I will be hurt if I allow myself to become too close to my group.

3. I want to feel completely at one with my group.

3

4

5

4. I find it relatively easy to get close to my group.

5. I do not often worry about my group getting too close to me.

6. It is very important to me to feel independent and self-sufficient.

7. I am nervous when my group gets too close.

8. My desire to feel completely at one sometimes scares my group away.

9. I prefer not to depend on my group or to have my group depend on me. 
Strongly

Strongly

Disagree

Agree

10. I often worry that my group does not really accept me.

12

3

4

7

11. I am comfortable not being close to my group.

1

2

3

4

6

7

12. I often worry my group will not always want me as a member.

$1-2$

45

6

7

13. I am somewhat uncomfortable being close to my group.

123

$4 \quad 5$

6

7

14. My group is never there when I need it.

15. I find it difficult to completely trust my group.

16. I don't worry about being alone or not being accepted by my group.

17. I find my group is reluctant to get as close as I would like.

18. I am not sure that I can always depend on my group to be there when I need it.

19. Often my group wants me to be more open about my thoughts and feelings that I feel comfortable being.

20. I am comfortable having my group depend on me.

21. I sometimes worry that my group doesn't value me as much as I value 1 my group.

22. I am comfortable depending on my group. 
23. I know that my group will be there when I need it.

24. I want to be emotionally close with my group, but I find it difficult to trust my group completely or to depend on my group.

25. I do not often worry about being abandoned by my group.

4

5

6

\section{Telephone Screening Protocol/ Binge Eating Items from Eating Disorders Examination}

\section{Introduction}

"We are doing a research study to see how group therapy is the most helpful for people who binge eat (people who are very concerned about eating large amounts of food in short periods of time and feel out of control). This is actually a follow-up to a previous successfully completed study. Most people who completed the study improved significantly. The type of group therapy being studied is known as Group Psychodynamic-Interpersonal Therapy (GPIP), as it has proven to be helpful for people with binge eating disorder."

"GPIP helps you make a connection between your eating habits and any interpersonal difficulties that you may be experiencing. With this type of therapy, you will have the opportunity to explore your feelings and use the therapeutic and group relationships to address and test out solutions to interpersonal difficulties."

"The group therapy will be run for 16 weeks ( $1 \frac{1}{2}$ hour sessions weekly in the late afternoon), with a preparation session before the actual therapy group begins. This preparation session will help familiarize you with the group therapy that you will receive. You will be assigned to one of the groups based on an interview that you will complete with one of our psychologists.

\section{Points to Cover}

- Must commit for entire treatment (16 sessions).

- Must commit to 4 testing sessions (pre, post, 2 follow ups) for which they will be reimbursed.

- During course of treatment they will be asked to stay later to complete small set of questionnaires (weeks $4,8,12, \& 16$ ) for which they will be reimbursed

- A one hour interview with Research coordinator to screen for appropriateness for the study

- Two 1 hour interviews will be conducted with one of the Psychologists (Pre, Post)

- Interviews will be audiotaped and treatment sessions videotaped for validity and 
reliability purposes

- A small sample of blood will be drawn at 4 time points (pre, post, $6 \mathrm{~m}$ and $1 \mathrm{yr}$.)

- Remind them that there is no cost involved on their part, only time.

- Remind them that participation is voluntary and they may withdraw consent at any time

\section{Procedure}

"First, I will ask you some questions to see if the treatments are appropriate for you. If they are appropriate and you qualify for the study, we will set up an appointment with you to see one of our staff for an assessment. You should keep in mind that if you come to an assessment session, you will be here for about $3 \mathrm{hrs}$. You will meet with one of our staff for an assessment for about $1 \frac{1 / 2}{2}$ hours, and after the assessment you and I will meet for a short interview and I will give you some questionnaires to complete and return." (Repeat this at the end of the screening, if an assessment is scheduled). "Once you have returned the questionnaires, I will call you, and inform you of the group you will be in and set up an appointment for an orientation to the group. Shortly after that, the group will start."

"I am going to ask you some personal questions about yourself and your eating behaviors now. This is necessary so that we can decide if this research study is appropriate for you. You can ask me to stop the interview at any time. However, I need the information in order to decide if the study is appropriate for you. Would you like to continue?"

\section{Patient Information and Screening Form}

Name:

Referral:

Phone \#: $\mathrm{H}$

Address:

Age:

Height:

BMI ( $\geq 27)$
Screening number:

Cell Number:

Referral Source:

Email:

Marital Status:

Weight:

Date of Screen

Exclusion Criteria

Speaks and reads English?

Yes

No

Have you ever been diagnosed with bipolar disorder (manic-depression)? Yes

No

Have you ever been diagnosed with schizophrenia or a psychotic disorder? Yes

No

Have you ever had a drug or alcohol problem?

Yes

No

Current drug or alcohol problem (dry for $6 \mathrm{~m}$ prior to group) Yes

No 
Are you Pregnant?

Yes

No

Planning to be pregnant during the next year

Yes

No

Are you enrolled in a weight loss program?

Yes

No

Planning to be in a weight loss program during the next year

Yes

No

Have you ever purged (vomited, used laxatives or diuretics, etc)?

No

How often: __ Date of last purge:

Have you ever been diagnosed with an eating disorder?

No

Diagnosis: $\quad$ Date of diagnosis:

Antidepressant Medication or other psychiatric Medication

No

Yes

Date Began:

Binge Eating

Have you eaten an amount of food most people would consider unusually large? Yes No

Have you ever felt out of control while eating a large amount of food? Yes

No

Eating in secret $\quad$ Yes

No

Could not stop once started eating $\quad$ Yes

No

Only stopped when felt ill or in pain $\quad$ Yes

No

Not aware of how much eaten until later $\quad$ Yes

No

When you eat a large amount of food and feel out of control (i.e. binge), do you:

Eat much more rapidly than normal?

Yes

No

Eat until uncomfortably full?

Yes

No

Eat large amounts of food even when not hungry? Yes

No

Eat alone because you are embarrassed about amount you are eating? Yes

No

Feel disgusted with yourself, depressed or guilty about overeating? Yes

No

Are you upset or distressed about binge eating?

Yes

No 


\section{Days Binged}

How many days of overeating and loss of control in the past 7 days?

How many days of overeating and loss of control in the past 28 days?

How many days of overeating and loss of control in the past 6 months?

\section{DSM-IV CRITERIA}

(Check all items that apply)

A 1) eating in a discrete time period (2-hour episode) a large amount a large amount of food.

2) loss of control when eating large amount of food

B 1) eating much more rapidly than normal 2) eating until feeling uncomfortably full 3) eating large amounts of food when not feeling physically 4) eating alone because of being embarrassed by how much one is eating 5) feeling disgusted with oneself, depressed, or very guilty after overeating

$\mathrm{C}$ marked distress regarding binge eating

D _ binge eating occurs, on average, at least 2 days a week for 6 months.

$\mathrm{E}$ no compensatory behaviors

\section{DISPOSITION}

Meet Study Criteria

No

Agrees to Participate

No

Given Assessment Appointment

No

Assessment Date and Time
Yes

Yes

Yes 


\section{Beck Depression Inventory}

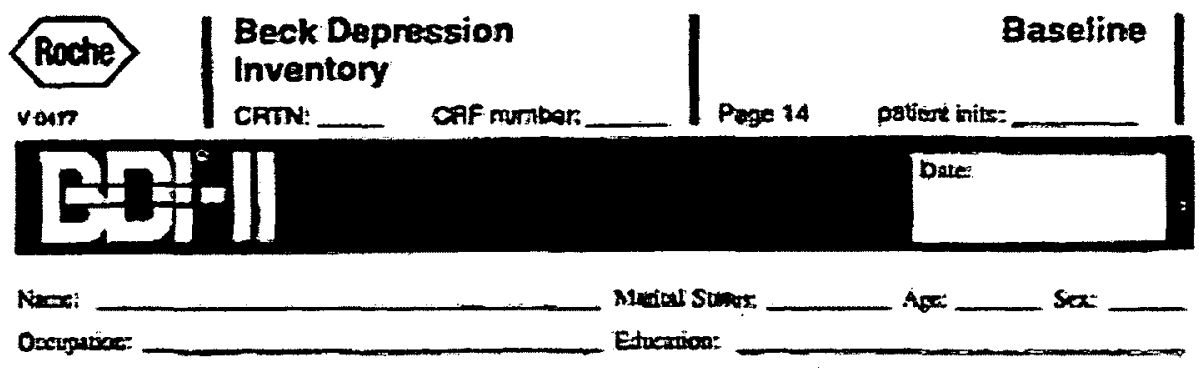

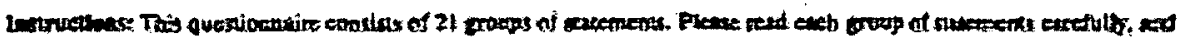

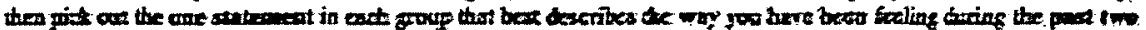

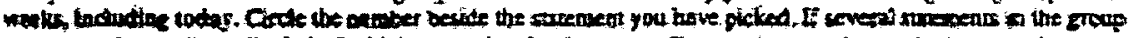

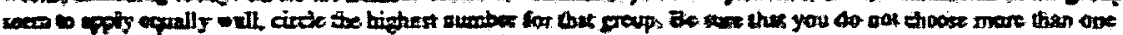

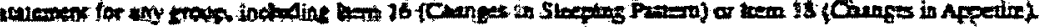

\begin{tabular}{|c|c|c|}
\hline \multicolumn{2}{|c|}{ 1. se:mentents } & 5. Puntemat Factinge \\
\hline 0 & I to war recl cost. & 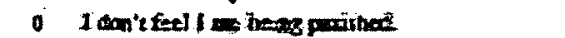 \\
\hline 1 & 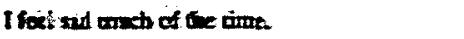 & 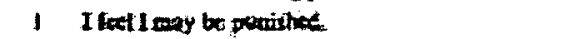 \\
\hline 2 & I an cat all the tint. & J expeca to be pnmix \\
\hline 3 & I an so sud or conlappy tha 3 ean't snad tat. & 3 I feell am being punished \\
\hline \multicolumn{2}{|c|}{ 2. Paximism } & 7, salfown \\
\hline$\bullet$ & 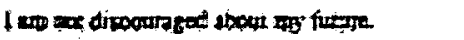 & o I fast the mime aboux myself as ever \\
\hline & 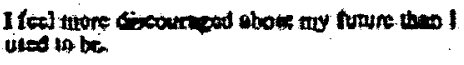 & 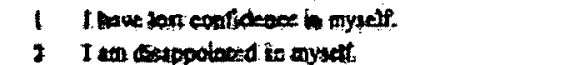 \\
\hline 2 & I do nok expext things wo vock out for we, & 1. I dintle mytall \\
\hline 3 & 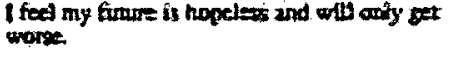 & \multirow{5}{*}{ 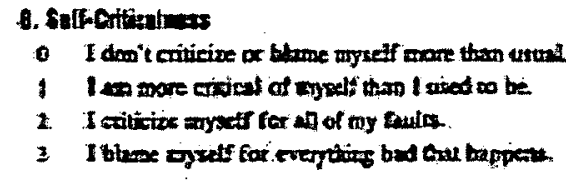 } \\
\hline \multicolumn{2}{|c|}{ 2. Pattane } & \\
\hline 0 & 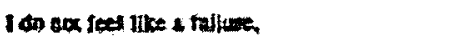 & \\
\hline 1 & 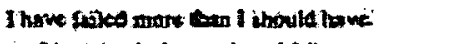 & \\
\hline 2 & 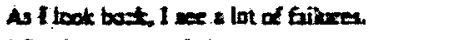 & \\
\hline & 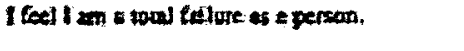 & \multirow{5}{*}{ 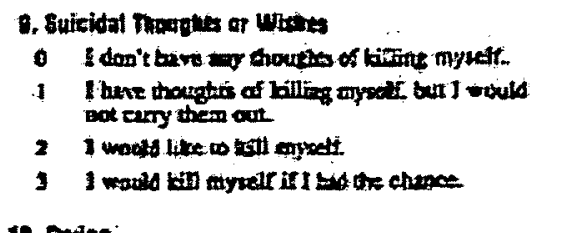 } \\
\hline \multicolumn{2}{|c|}{4 leve of Phasum } & \\
\hline 0 & $\begin{array}{l}\text { I gen as much plearare of cker did fros be } \\
\text { atengs l exgay. }\end{array}$ & \\
\hline $\mathbf{I}$ & 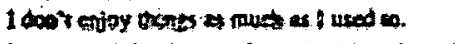 & \\
\hline 2 & 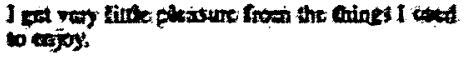 & \\
\hline 3 & 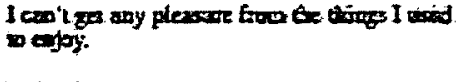 & 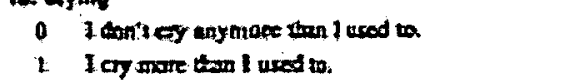 \\
\hline \multicolumn{2}{|c|}{ 8. Goitty redings } & 2 lay oine every lutte thing. \\
\hline a & 1 dan't foes paticularly guilhy. & 9. If \\
\hline 8 & 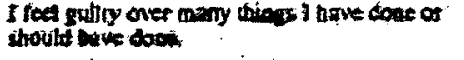 & \\
\hline 2 & 1 fed quirt guilty mest of the two & \\
\hline 3 & If feed guild at of the the & \\
\hline
\end{tabular}




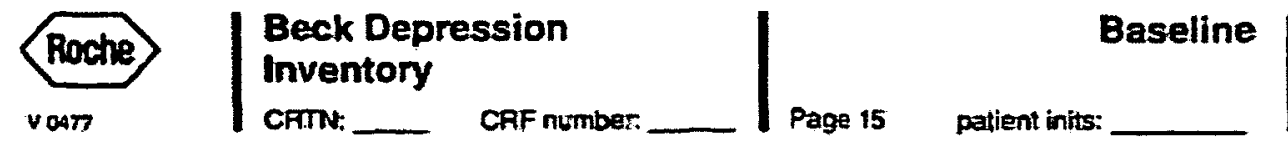
11. Agitution
- I wen no arore reviless of wound up than usual.
1 I fecl more restiess of woond op than usinal
2 I and so resless or aquared that id's hard to stay still.
3 I am eo resiless or agivaled that I have to teen moving or doing somethiog.

\section{Loss of Interest}

- I have not lost interese in other people or activities.

1 I an less interexted in other people or thidz: than before.

2 I have lost woust of wy imerest in other people or things.

3 It's hard to get interested in trothing.

13. tudeetskrenans

- I make decixions about as well as ever.

1 I find it more difficult to make decisiony than ust:u.

3 I have much groser difficulty in moting decisions than I used to.

3 I thave unuble moking any decisions.

\section{Hontesuneas}

- I do oxt fecl 1 am workless.

I I con't consilier ayself as wortbwhile and usefol as I ised to.

2 If fel more worthlets as compared to other people.

3 I feel usterty wouthless.

\section{Lom of Enerit}

- 1 have at nublencrog as ever.

1 I huve less coergy than I used to bave.

2 I don' $\mathrm{C}$ have enajgh enety to do very mach

:3 I doo't bave enough energy to do wyinhing.

\section{Cunpe th steeptan Putem}

- I have noc experieneed any change in my steeging parrom.

iv I rkesp somewhat more thin usal

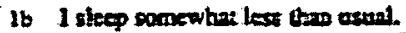

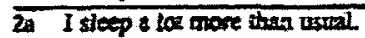

2b I teep a lox kess the und.

30 I lleep acoss of the ary.

36 I wite up 1-2 bouns exily and eas' get beck to sivep

\section{Irtandin}

- 1 an ao morr irrituble then arial.

1 I un more iritable thom asual

21 and more tritabie than antal.

$31 \mathrm{am}$ inciable all the tine

\section{Chagges in Appativ}

- I bave not expexienced any change in eay appraite.

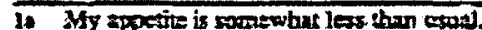

Ib My eppotive is comewhit greater inan usual

20 My eqpecite is much bess thin before.

7) My appetite is puch greater than asual.

3i I bave no wpetite at at

3b I crave food all the time.

19. Consentration Ditfinth

- I cas conocourate as well as ever.

1. I cap'l concentrase as well as oxvit.

2 its bud to bep my mind on arythine for sery loog.

3 I find I can't coocentrate on anything.

\section{Tredinas or fallon}

D I am no more tired or fatigued bun uatal.

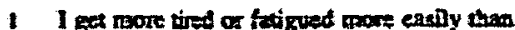
usual.

2 I tra too tired ar fatigned to do a lot of the thing I ased to do

3 I ams too tired of frotigued to da rost of the things I tos da

\section{Los of thereat la sot}

- I buve nok noticed any recent chanet în ray inters in sex.

1 I twi les foreressed in sex thas I used to be

2 I nn mucb less anrerested in cex now.

3 I the los interict in sex ompletely. 
Attachment Styles Questionnaire

\section{Appendix 5.1. Attachment Stgle Questionnaire}

Show how miuch you ggree with each of the following inems by rating them on this sole: 1 - totalfy disagrex; 2 - stronghy disagrec, 3 - slightly disagres; 4 - slightly agrec. 5 - sunongly agree; or 6 - coully agree.

Confidence

Confidence

Confidence

Discomion

Discomion

Rus 5

Ras 5

Ras

R as 5

Ras

N for A

N for A

N for A

R as 5

Nior A

Discamfart

Diseomion

Preoccapation

Confidence

Discourfont

Discomfon

Frecocupation

Discominan

N for $A$

Discomfori

Discomfori

N for $A$
1. Ovarll, 1 an a worthwile person.

2. I an easier io get 10 know than most people.

3. I feel conlident that other people will be there for me when 1 need them.

4. 1 prefer to depend on mysell rather than other people.

5. 1 prefer to heep to myself.

6. To ask for hetp ts to admit that youne a fithure.

7. People's worth should be judged by what they aclueve.

8. Achicving things is more mportant thin building relitionships.

9. Doing your best is more imporiant than geting on with others

10. If you ve got fob to do, you should do it no mauer who gets hutr.

11. I's imponant to me that others like me.

12 It's important to me to awoid doang things that others won't like.

13. I find it had to make decision miess I know what other people think.

14. My relationstuips with others are generally superficial.

15. Sounetimes 1 think 1 am no good at all.

16. I find it hand to trust other people.

17. 1 find is difficult to depend on others.

j8. I find that others are reluciant to get as elose as I would like

19. I find it relaturely easy to gat close to other poople.

20. I find it ensy to trust olhers. (R)

21. I fel comfortable depending on other people (R)

22. I worry that others won't ente about me as much as I care aboui them.

23. I wormy abou people gening too close

24. I worny that I won't measure up to gther people

25. I have mixed feetings about being close to others.

26. While I want to gei close to others, I feel tneasy about it.

27. I wonder why people would want to be involved with me 
Preoccupation

Preoccupation

Preoccupation

Confidence

Preoccupation

Confidence

Discomfort

N tor A

$R$ as $S$

Confidence

Confidence

Preaccapation

Preoccupation
28. It's very importam to me to have a close relationship.

29. I worry a lot about my relationships.

30. I wonder how I would cope without someone to lowe the

31. I feel confideni about relauing to others

32. I often feel left out or alone.

33. I often worry that 1 do not really fit in with other people (R)

34. Other people have their own problems, so I don't bother them with mine.

35. When I talk over my problems with others, 1 generally feel ashamed of toolish.

36. I am too busy with other activities to put moch time into relationships.

37. If something is bothering me, others are generally aware and concerned.

38. I am confident that other people will like and respect me.

39. I get frustrated when others are noi available when I need them.

40. Other people often disappoint me.

Note, hems marked (R) need to be reverse-scored. $R$ as $S$, Relationships as Secondary $N$ For A Need for Approval; Disoomfort, Discomfart wihh Closeness, Preoceupation, Preocarpaton with Relationshtps.

\section{NOTE}

1. The matrix of factor loadings and other relevant information is available from us at the Deparment of Psychology, University of Queensland, Brisbane, Queenstand 4072, Australia.

\section{Group Climate Questionnaire}

Instructions: Read each statement carefully and try to think of the group as a whole. Using the Rating Scale as a guide, circle the number for each statement that best describes the group during today's session. Please mark only ONE answer for each statement.

1. The members liked and cared about each other. 
2. The members tried to understand why they do the things they $\quad \begin{array}{lllllllllll}0 & 0 & 1 & 2 & 3 & 4 & 5 & 6\end{array}$ do, tried to reason it out.

3. The members avoided looking at important issues going on between themselves.

4. The members felt what was happening was important and there $\quad \begin{array}{llllllll}0 & 1 & 2 & 3 & 4 & 5 & 6\end{array}$ was a sense of participation.

5. The members depended on the group leader(s) for direction.

$\begin{array}{lllllll}0 & 1 & 2 & 3 & 4 & 5 & 6\end{array}$

6. There was friction and anger between the members.

$\begin{array}{lllllll}0 & 1 & 2 & 3 & 4 & 5 & 6\end{array}$

7. The members were distant and withdrawn from each other.

$\begin{array}{lllllll}0 & 1 & 2 & 3 & 4 & 5 & 6\end{array}$

8. The members challenged and confronted each other in their efforts to sort things out.

9. The members appeared to do things the way they thought would be acceptable to the group.

10. The members rejected and distrusted each other.

$\begin{array}{lllllll}0 & 1 & 2 & 3 & 4 & 5 & 6\end{array}$

11. The members revealed sensitive personal information or feelings.

$\begin{array}{lllllll}0 & 1 & 2 & 3 & 4 & 5 & 6\end{array}$

12. The members appeared tense and anxious.

$\begin{array}{lllllll}0 & 1 & 2 & 3 & 4 & 5 & 6\end{array}$

\section{Rosenberg Self-Esteem Scale}

DIRECTIONS: Please indicate how much you agree or disagree with the following statements. Circle the appropriate number beside each statement.

$\begin{array}{ccc}\text { Strongly } & \text { Strongly } \\ \text { Disagree } & \text { Agree }\end{array}$

1. I feel that I am a person of worth, at least on an equal plane with others. 
2. I feel that I have a number of good qualities.

3

4

3. All in all, I am inclined to feel that I am a failure.

1

2

3

4

4. I am able to do things as well as most other people.

1

2

3

4

5. I feel that I do not have much to be proud of.

6. I take a positive attitude toward myself.

7. On the whole, I am satisfied with myself.

8. I wish I could have more respect for myself.

9. I certainly feel useless at times.

10. At times, I think I am no good at all. 


\section{Appendix C}

\section{Proration Decisions}

To calculate participants' scores on the Beck Depression Inventory-II, Social Group Attachment Scale subscales, Attachment Styles Questionnaire subscales, and Rosenberg Self-Esteem Scale, I have prorated scores for participants who responded to at least $80 \%$ of items. That is, for participants with $80 \%$ of items on a given scale or subscale, I computed participants' total scores across their observed scores and then rescaled these total scores according to the number of subscale items (van Ginkel, Sijtsma, van der Ark, \& Vermunt, 2010). This procedure is frequently practiced in eating disorders research (e,g, Bohn \& Fairburn, 2008; Garner, 2004; von Ranson, Klump, Iacono, \& McGue, 2005). While van Glinkel and colleagues (2010) indicated that proration ignores differences between item means, the adequate internal consistencies in this study suggest that differences between items on a given scale or subscale are minimal. Van Glinkel and colleagues also stated that proration may bias the error terms of scales and subscales. However, the error terms within individuals' subscale scores are not of central interest in this study. The $80 \%$ criterion is based on amalgamation of the decision rules of several scales. For example, the Clinical Impairment Questionnaire (Bohn \& Fairburn, 2008) requires data for at least $75 \%$ of items for proration, and the Minnesota Eating Behaviors Survey (von Ranson et al.) requires data for least $90 \%$ of items. The only exception is for the Group Climate Questionnaire Engaged subscale, as scoring guidelines for this questionnaire indicate that it is valid unless the entire scale is missing greater than four items (MacKenzie, 1983). However in this study, any participant who had data for one item on the Group Climate Questionnaire Engaged 
subscale had data for the other four items as well. 


\section{Appendix D}

\section{Explication of Multiple Imputation}

Multiple imputation replaces each missing value with a given number $(m)$ of simulated values, thereby producing $m$ alternative versions of the complete data (Schafer \& Graham, 2002). The simulated values are derived as follows: The relationships among variables are estimated from all available data; participants' missing scores are then predicted from their observed scores. To maintain adequate variability in the imputed datasets, random error is then added from a distribution of the missing data. Each version, or dataset, is then analyzed and the estimate of interest is averaged over the analyses (Schafer \& Graham, 2002).

To determine how many imputations to use in the current study, I used Rubin's (1987) equation for calculating the efficiency of estimates based on $m$ imputations. This equation indicates that the efficiency of an estimate is equal to $(1+\lambda / m)^{-1}$, where $\lambda$ represents the rate of missing information. Of the variables used to test the first hypothesis (that group attachment anxiety and avoidance would be correlated with related constructs), the Group Climate Questionnaire Engaged subscale had the highest missingness rate at $23.53 \%$. With five imputations Rubin's (1987) equation yielded an efficiency rate of $(1+.2353 / 5)^{-1}=95.51 \%$, suggesting that additional imputations would minimally reduce error for a given estimate (Schafer $\&$ Graham, 2002). Thus, five imputations were used. 
Appendix E

Multilevel Models

\section{Model 1: Two-Level Pattern Mixture Model Used to Test the Dropout x Group}

\section{Attachment Slope Interaction}

Level 1: $Y_{\mathfrak{t i}}=\pi_{0 \mathrm{i}}+\pi_{\mathrm{li}}\left(\log _{\mathrm{im}} \mathrm{t}_{\mathrm{i}}\right)+\mathrm{e}_{\mathrm{ti}}$

Level 2: $\pi_{0 \mathrm{i}}=\beta_{00}+\beta_{01}\left(\right.$ group attachment slope $\left.\mathrm{e}_{\mathrm{i}}\right)+\beta_{02}\left(\right.$ individual pre-treatment score $\left.\mathrm{i}_{\mathrm{i}}\right)+$

$$
\begin{aligned}
& \beta_{03}\left(\text { dropout }_{i}\right)+\beta_{04}\left(\text { group attachment slope } x \text { dropout }_{i}\right)+r_{0 i} \\
& \left.\pi_{1 \mathrm{i}}=\beta_{10}+\beta_{11} \text { (group attachment slope } \mathrm{i}_{\mathrm{i}}\right)+\beta_{12}\left(\text { individual pretreatment score } \mathrm{i}_{\mathrm{i}}\right)+
\end{aligned}
$$

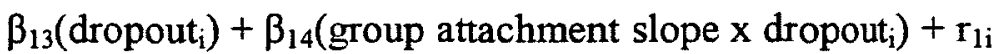

Logtime was uncentered so that the level-1 intercept $\left(\pi_{0 i}\right)$ would represent participants' pretreatment scores. All level-2 variables were grand-mean centered for reasons similar to those used in ordinary least squares regression (i.e. reducing multicollinearity; representing slopes as the average effect rather than as the effect coded zero on variables; Cohen et al., 2003; Enders \& Tofhigi, 2007).

Model 2: Two-Level Model Used to Test the Overall Effect of Dropout on Change in

\section{Treatment Outcomes}

Level 1: $Y_{\mathrm{ti}}=\pi_{0 \mathrm{i}}+\pi_{1 \mathrm{i}}\left(\right.$ logtime $\left._{\mathrm{ti}}\right)+\mathrm{e}_{\mathrm{ti}}$

Level 2: $\pi_{0 \mathrm{i}}=\beta_{00}+\beta_{01}\left(\right.$ individual pre-treatment score $\left.\mathrm{i}_{\mathrm{i}}\right)+\beta_{02}\left(\right.$ dropout $\left._{\mathrm{i}}\right)+\mathrm{r}_{0 \mathrm{i}}$ $\pi_{1 i}=\beta_{10}+\beta_{11}\left((\right.$ individual pre-treatment score $)+\beta_{12}\left(\right.$ dropout $\left._{i}\right)+r_{1 i}$

Logtime was uncentered, and all level-2 variables were grand-mean centered.

\section{Model 3: Two-Level Model Used to Test Hypothesis 2}

Level $1: \log \left(\varphi_{\mathrm{ij}} /\left[1-\varphi_{\mathrm{ij}}\right]\right)=\eta_{\mathrm{ij}}$ $\eta_{\mathrm{ij}=} \beta_{0 \mathrm{j}}+\beta_{1 \mathrm{j}}$ (pretreatment Relationships as Secondary $\left.\mathrm{ij}\right)+\beta_{2 \mathrm{j}}($ week 4 group 
attachment avoidance ${ }_{\mathrm{ij}}$ )

Level 2: $\beta_{0 j}=\gamma_{00}+\gamma_{01}($ week 4 group attachment avoidance $j)+\mu_{0 j}$

$$
\begin{aligned}
& \beta_{1 j}=\gamma_{10}+\mu_{1 j} \\
& \beta_{2 j}=\gamma_{20}+\mu_{2 j}
\end{aligned}
$$

where $\varphi_{\mathrm{ij}}$ represents the predicted probability that a participant will complete treatment.

As discussed in Appendix D, pretreatment Relationships as Secondary was grand-mean centered; week 4 group attachment avoidance at level-1 was group-mean centered; and week 4 group attachment avoidance at level-2 was grand-mean centered.

Model 4: Three-Level Model Used to Calculate Intraclass Correlation Coefficients

\section{for Hypotheses 3, 4, and 5}

Level 1: $\mathrm{Y}_{\mathrm{tij}}=\pi_{0 \mathrm{ij}}+\pi_{1 \mathrm{ij}}\left(\log \mathrm{time}_{\mathrm{tij}}\right)+\mathrm{e}_{\mathrm{tij}}$

Level 2: $\pi_{0 \mathrm{ij}}=\beta_{00 \mathrm{j}}+\beta_{01 j}\left(\right.$ individual initial score $\left.\mathrm{ij}_{\mathrm{ij}}\right)+\mathrm{r}_{0 \mathrm{ij}}$

$$
\pi_{1 \mathrm{ij}}=\beta_{10 \mathrm{j}}+\beta_{11 \mathrm{j}}\left(\text { individual initial score } \mathrm{ij}_{\mathrm{j}}\right)+\mathrm{r}_{1 \mathrm{ij}}
$$

Level 3: $\beta_{00 j}=\gamma_{000}+\gamma_{001}($ group initial score $j)+\gamma_{002}\left(\right.$ condition $\left._{j}\right)+u_{00 j}$

$$
\begin{aligned}
& \beta_{01 j}=\gamma_{010}+u_{01 j} \\
& \beta_{10 j}=\gamma_{100}+\gamma_{101}\left(\text { group initial score }_{j}\right)+\gamma_{102}\left(\text { condition }_{j}\right)+u_{10 j} \\
& \beta_{11 j}=\gamma_{110}+u_{11 j}
\end{aligned}
$$

Logtime was uncentered, individual initial scores were group-mean centered, and group initial scores and condition were grand-mean centered (as suggested by Enders \& Tofighi, 2007 and Tasca et al., 2009).

Model 5: Three-Level Model Used to Calculate Intraclass Correlation Coefficients for Hypotheses 3, 4, and 5

Level 1: $\mathrm{Y}_{\mathrm{tij}}=\pi_{0 \mathrm{ij}}+\pi_{\mathrm{lij}}\left(\log \mathrm{time} \mathrm{tij}_{\mathrm{ij}}\right)+\mathrm{e}_{\mathrm{tij}}$ 
Level 2: $\pi_{0 \mathrm{ij}}=\beta_{00 \mathrm{j}}+\beta_{0 \mathrm{lj}}\left(\right.$ individual initial score $\left._{\mathrm{ij}}\right)+\mathrm{r}_{0 \mathrm{ij}}$

$$
\pi_{1 \mathrm{ij}}=\beta_{10 \mathrm{j}}+\beta_{1 \mathrm{lj}}\left(\text { individual initial } \text { score }_{\mathrm{ij}}\right)+\mathrm{r}_{1 \mathrm{ij}}
$$

Level 3: $\beta_{00 \mathrm{j}}=\gamma_{000}+\gamma_{001}\left(\right.$ group initial score $\left.\mathrm{j}_{\mathrm{j}}\right)+\mathrm{u}_{00 \mathrm{j}}$

$$
\begin{aligned}
& \beta_{01 \mathrm{j}}=\gamma_{010}+u_{01 \mathrm{j}} \\
& \left.\beta_{10 \mathrm{j}}=\gamma_{100}+\gamma_{101} \text { (group initial score }\right)+u_{10 j} \\
& \beta_{11 \mathrm{j}}=\gamma_{110}+u_{11 j}
\end{aligned}
$$

Logtime was uncentered, individual initial scores were group-mean centered, and group initial scores and condition were grand-mean centered (Enders \& Tofighi, 2007; Tasca et al., 2009).

Model 6: Two-Level Model Used to Assess Change in Group Attachment for

\section{Hypothesis 3}

Level 1: $Y_{\mathrm{ti}}=\pi_{0 \mathrm{i}}+\pi_{\mathrm{li}}\left(\right.$ logtime $\left._{\mathrm{ti}}\right)+\mathrm{e}_{\mathrm{ti}}$

Level 2: $\pi_{0 \mathrm{i}}=\beta_{00}++\beta_{01}$ (individual Week 4 group attachment $\left.\mathrm{i}_{\mathrm{i}}\right)+\mathrm{r}_{0 \mathrm{i}}$ $\pi_{1 \mathrm{ij}}=\beta_{10}++\beta_{11}$ (individual Week 4 group attachment $\left.\mathrm{i}_{\mathrm{i}}\right)+\mathrm{r}_{\mathrm{li}}$

Logtime was uncentered and individual Week 4 group attachment scores were grandmean centered.

Model 7: Two-Level Model Used to Assess the Effect of Change in Group Attachment Anxiety and Avoidance on Reductions in Treatment Outcomes for Hypothesis 4

Level 1: $Y_{t i}=\pi_{0 i}+\pi_{1 i}\left(\right.$ logtime $\left._{t i}\right)+e_{t i}$

Level 2: $\pi_{0 \mathrm{i}}=\beta_{00}++\beta_{01}($ pretreatment score $)+\beta_{02 j}\left(\right.$ group attachment anxiety slope $\left.{ }_{i j}\right)+$ $\beta_{03 j}\left(\right.$ group attachment avoidance slope $\left.{ }_{i j}\right) r_{0 i}$ $\pi_{1 \mathrm{ij}}=\beta_{10}++\beta_{11}$ (pretreatment score $)+\beta_{12 \mathrm{j}}\left(\right.$ group attachment anxiety slope $\left.\mathrm{ij}_{\mathrm{ij}}\right)+$ 
$\beta_{13 j}\left(\right.$ group attachment avoidance slope $\left.e_{i j}\right)+r_{1 i}$

Logtime was uncentered and pretreatment scores and group attachment slopes were grand-mean centered.

Model 8: Two-Level Model Used to Assess the Interaction Between Individual Attachment Anxiety and Change in Group Attachment Anxiety and Avoidance in Predicting Reductions in Treatment Outcomes for Hypothesis 5

Level 1: $\mathrm{Y}_{\mathrm{ti}}=\pi_{0 \mathrm{i}}+\pi_{\mathrm{li}}\left(\operatorname{logtime}_{\mathrm{ti}}\right)+\mathrm{e}_{\mathrm{i}}$

Level 2: $\pi_{0 \mathrm{i}}=\beta_{00}++\beta_{01}\left(\right.$ pretreatment score $\left._{\mathrm{i}}\right)+\beta_{02 \mathrm{j}}\left(\right.$ group attachment slope $\left.\mathrm{e}_{\mathrm{ij}}\right)+$ $\beta_{03 \mathrm{j}}\left(\right.$ condition $\left._{\mathrm{ij}}\right)+$

$$
\begin{gathered}
\beta_{04 j}\left(\text { condition x group attachment slope } \mathrm{ij}_{\mathrm{ij}}\right)+\mathrm{r}_{0 \mathrm{i}} \\
\pi_{1 \mathrm{ij}}=\beta_{10}++\beta_{11}\left(\text { pretreatment score }_{\mathrm{i}}\right)+\beta_{12 \mathrm{j}}\left(\text { group attachment slope }_{\mathrm{ij}}\right)
\end{gathered}
$$

$\beta_{13 \mathrm{j}}\left(\right.$ condition $\left._{\mathrm{ij}}\right)+$

$$
\beta_{14 j}\left(\text { condition } x \text { group attachment slope } e_{i j}\right)+r_{1 i}
$$

Logtime was uncentered and pretreatment scores, group attachment slopes, condition, and the condition $\mathrm{x}$ group attachment slope interaction were grand-mean centered. 


\author{
Appendix F \\ Explication of Multilevel Modeling
}

\title{
Rationale for Multilevel Modeling
}

I used multilevel modeling to assess Hypotheses 2, 3, 4, and 5. This technique has several advantages over ordinary least squares techniques. First, it allows for the assessment of individual differences in growth trajectories (Raudenbush \& Bryk, 2002). In the current study, it allowed for assessment of individual differences in change in group attachment for Hypothesis 3 and in treatment outcomes for Hypotheses 4 and 5 .

Second, multilevel modeling addresses issues of dependence in the data. Specifically, when individuals' data are collected in groups, individuals' observations may vary as a function of which groups they belong to thus violating the independence assumption and drastically increasing Type I error (Nezlek, 2001). For example, Hypothesis 2 indicated that week 4 group attachment avoidance would predict dropout, controlling for pretreatment individual attachment avoidance. Because participants' levels of week 4 attachment avoidance may have varied as a function of which of the 12 therapy groups they took part in, their data may not have been independent. Furthermore, with longitudinal data (i.e., repeated-measures observations within an individual) observations in a dataset are often correlated (Nezlek, 2008). In the current study, a given participant's scores on measures of binge eating, depressive symptoms, individual attachment, and group attachment were repeatedly measured and therefore likely dependent on characteristics of that particular individual. Because of these issues with dependence, the data did not contain $N$ independent pieces of information (Tasca et al., 2010). Because ordinary least squares techniques assume that observations are 
independent, they underestimate error and increase Type I error rates when observations are not independent (Nezlek, 2008). Multilevel modeling circumvents issues related to dependence by accounting for the nested nature of grouped and repeated measures data, as it generates a separate prediction equation for each unit of a higher order level (Raudenbush \& Bryk, 2002). That is, in the current study multilevel modeling generated a separate prediction equation for each therapy group for Hypothesis 2, or for each participant for Hypotheses 3 to 5 .

Third, provided that data are missing at random and that participants have data for the intercept and for at least two time points (Gallop \& Tasca, 2009), multilevel modeling estimates parameters when individuals have missing data (Tasca et al., 2010). That is, multilevel modeling computes a matrix of maximum likelihood estimates of regression coefficients and standard errors for complete data given incomplete data and uses these coefficients to estimate scores for each individual (Raudenbush \& Bryk, 2002). Therefore there is no need for imputing missing data or listwise deletion, both of which may introduce biases. In the current study, the multilevel models estimated parameters for all participants who had data for the week 4 group attachment variables (for Hypotheses 2 and 3) or for pretreatment measures on the outcome variables (for Hypothesis 4 and 5), as long as they had data for at least two time points (Gallop \& Tasca, 2020).

Fourth, multilevel models do not assume sphericity, i.e., that error variances for all pairs and linear combinations of repeated measures observations are equivalent across time and treatment (Clinton, 2004; Stevens, 2002). For example in the current study, the error surrounding the relationship between participants' pretreatment and posttreatment scores did not have to be equal to the error surrounding the relationship between 
participants' pretreatment and 6 months posttreatment scores.

\section{Model Considerations}

To control for the relationship between earlier scores and rate of change, I included week 4 group attachment at level 2 for Hypothesis 3, and pretreatment scores at level 2 for Hypotheses 4 and 5 (Tasca \& Gallop, 2009; Tasca et al., 2009). I examined an ordinary least squares regression plot to determine whether a linear or logarithmically transformed time variable best fit the data (Singer \& Willet, 2003). I also examined deviance statistics to assess the extent to which each time variable improved model fit. For the linear time metric I transformed 1, 2, 3 and 4 (representing Week 4, Week 8, Week 12, and Week 16, respectively for Hypothesis 3; and pretreatment, posttreatment, 6 months posttreatment, and 12 months posttreatment, respectively, for Hypotheses 4 and 5) to $0,1,2$, and 3 , so that session 4 was set as the intercept for Hypothesis 3 and so that pretreatment scores were set as the intercepts for Hypotheses 4 and 5. The logarithmically transformed time metric (logtime) transformed $1,2,3$ and 4 to $.00, .30, .48$, and .60 , respectively, so as to model a curvilinear relationship representing more pronounced change earlier in treatment and less pronounced change later in treatment (Tasca et al.). For all models and outcome variables, a logarithmic time variable appeared to fit the data better than the linear time variable. Therefore, I used a logarithmic time variable for all hypothesis tests.

For each model, I assessed parameters of interest (e.g. week 4 group attachment avoidance for Hypothesis 2; logtime for Hypothesis 3; group attachment anxiety and avoidance for Hypothesis 4; group attachment $\mathrm{x}$ condition interaction for Hypothesis 5) for improvement of model fit with the difference in deviance statistics, $D$, using a $\chi^{2}$ 
distribution. The degrees of freedom were equal to the difference between the number of parameters of the nested models that I compared (Raudenbush \& Bryk, 2002).

I used HLM program version 7 with the full maximum likelihood method of estimation, as full maximum likelihood yields unbiased and efficient parameter estimates with larger samples (Raudenbush \& Bryk, 2002).

\section{Assessment of Intraclass Correlation Coefficients}

As indicated above, because data at the individual level were nested within the 12 therapy groups, observations within each group may not have been independent (Nezlek, 2008). Research has indicated that ignoring dependence associated with group membership can result in Type I errors for $10 \%$ of significant findings (Tasca, Illing, Ogrodniczuk, \& Joyce, 2009). To assess for dependence in the data, I calculated the intraclass correlation coefficient $\rho$, from the variance components of a three-level multilevel model in which time (i.e. Week 4, Week 8, Week 12, and Week 16; or pretreatment, posttreatment, 6 months posttreatment, and 12 months posttreatment) was the level-1 unit, individuals were the level- 2 units, and the 12 therapy groups were the level-3 units (Tasca et al.; see Model 4, Appendix D). This model tends to yield reliable parameters despite the small degrees of freedom for groups (Tasca et al.). Variance components represent the variance around the level-1 error and around the level-2 and level-3 random variables for the intercepts and slopes. I entered the between-group variance components for the slopes $\left(\tau_{10 \mathrm{j}}\right)$ of the models with and without attachment anxiety condition (Models 4 and 5, respectively; Appendix D), and the between-person variance component $\left(\tau_{1 i j}\right)$ of the model with attachment anxiety condition into an equation for the intraclass correlation coefficient, $\rho=\tau_{10 j}$ (conditional) $/\left(\tau_{10 j}\left[\right.\right.$ unconditional] $\left.+\tau_{1 \mathrm{ij}}\right)$. 
When $\rho$ is below .05 , the effect of dependence in the data is ignorable (Kenny, Kashy, \& Bolger, 1998) and a two-level model can be used with time as the level-1 unit and individuals as the level-2 units, and with a significance level of .05 (Models 6 and 7, Appendix D). If $\rho$ is equal to or above .05 , one can either: (a) use a three-level model with time as the level-1 unit, individuals as the level-2 units, and groups as the level-3 units (Model 5); or (b) use 2-level models (Models 6 and 7) and adjust the Type 1 error rate based on Kenny and colleagues' (1998) table, which indicates the probability of making a Type 1 error in nested designs when individuals are the unit of analysis. Table F presents the intraclass correlation coefficients for each outcome variable, and the subsequent decision rules. Two-level models were used for all hypotheses and when intraclass correlation coefficients exceeded .05 , the Type I error rate was adjusted accordingly.

\section{Assumptions of Multilevel Modeling}

Multilevel modeling has six assumptions. First, each level-1 residual $\left(r_{i j}\right)$ must be independent and normally distributed, and have a mean of zero and equal variances within each level-2 unit (Raudenbush \& Bryk, 2002). Second, the level-1 predictor variables must be independent of $r_{i j}$. Third, the level-2 error terms, $u_{0 j}$ and $u_{1 j}$, should be multivariate normal and have means of 0 ; variances $\tau_{00}$ and $\tau_{11}$, respectively; and a covariance of $\tau_{01}$. Fourth, the level-2 predictors must be independent of $u_{0 j}$ and $u_{l j}$. Fifth, the level-1error terms must be independent of the level-2 error terms. Sixth, predictors at one level must be independent of the errors at other levels (Raudenbush \& Bryk, 2002). To evaluate these assumptions, I examined the level-1 and level-2 residual files for the models with significant results, and determined these assumptions to be met. 
Table F

Intraclass Correlations and Model Decisions for Multilevel Models

\begin{tabular}{|c|c|c|}
\hline Outcome Variable & $\begin{array}{c}\text { Intraclass Correlation } \\
\text { Coefficient } \\
\end{array}$ & Decision \\
\hline \multicolumn{3}{|l|}{ Group attachment } \\
\hline Anxiety & $<.05$ & 2-level model, $\alpha=.05$ \\
\hline Avoidance & .14 & 2-level mode, $\alpha=.022$ \\
\hline \multicolumn{3}{|l|}{ Individual Attachment } \\
\hline Need for Approval & $<.05$ & 2-level model, $\alpha=.05$ \\
\hline Preoccupation $^{\mathrm{a}}$ & $<.05$ & 2-level model, $\alpha=.05$ \\
\hline Discomfort with Closeness & $<.05$ & 2-level model, $\alpha=.05$ \\
\hline Relationships as Secondary & $<.05$ & 2-level model, $\alpha=.05$ \\
\hline \multicolumn{3}{|l|}{ Days binged } \\
\hline 7 days & .06 & $\begin{array}{c}\text { 2-level model, } \alpha= \\
.033\end{array}$ \\
\hline 28 days & .09 & $\begin{array}{c}\text { 2-level model, } \alpha= \\
.028\end{array}$ \\
\hline Depressive symptoms & $<.05$ & 2-level model, $\alpha=.05$ \\
\hline
\end{tabular}

${ }^{\mathrm{a}}$ Preoccupation $=$ Preoccupation with Relationships. 


\section{Appendix G}

\section{Centering Decisions Concerning Hypothesis 2}

For the Hypothesis 2 model (see Appendix D), I group-mean centered participants' group attachment avoidance scores at level 1. That is, I converted participants' group attachment avoidance scores to deviance scores around the means of their therapy groups (Enders \& Tofighi, 2007). This decision was based on several considerations. First, group-mean centering removes (a) the effect of group membership on the parameter of interest and (b) the correlation between level-1 and level-2 variables, making it more appropriate when a level-1 variable is of substantive interest (Enders \& Tofighi, 2007). Because my interest was in the effect of group attachment avoidance at the individual level (level-1) regardless of group membership, I deemed group-mean centering to be appropriate. Second, group-mean centering can be useful when other group members may influence one's score on a variable (Enders \& Tofighi, 2007). Other group members' behaviour may have influenced participants' relationships with their therapy groups, further implying that group-mean centering would be appropriate. Third, group-mean centering is useful when it is of interest to assess a predictor-outcome relationship at both levels of a hierarchy (Enders \& Tofighi, 2007). Because the relationship between group attachment avoidance scores and treatment dropout may have differed at the individual level versus the group level, I decided to use group-mean centering.

I grand-mean centered participants' Relationships as Secondary (individual attachment avoidance) scores, so that these scores were converted to deviation scores around the grand mean (Enders \& Tofighi, 2007). While grand-mean centering yields 
coefficients that are ambiguous combinations of within- and between-group relationships and introduces dependency between intercepts and slopes (Enders \& Tofighi, 2007), it is ideally suited for studies in which a level-1 variable should be controlled for. Because I was interested in the effect of group attachment avoidance over and above individual attachment avoidance, I decided to grand-mean centre Relationships as Secondary scores. At level 2, I then entered participants' grand-mean centered group attachment avoidance scores, as reintroducing grand-mean centered level-1 variables at level-2 has been found to reduce the deviance of a model, thereby improving model fit $(\mathrm{Kreft} \& \mathrm{de}$ Leeuw, 1998). 